\title{
ZUSES

\section{Potential Sources of Analytical Bias and Error in Selected Trace Element Data-Quality Analyses}

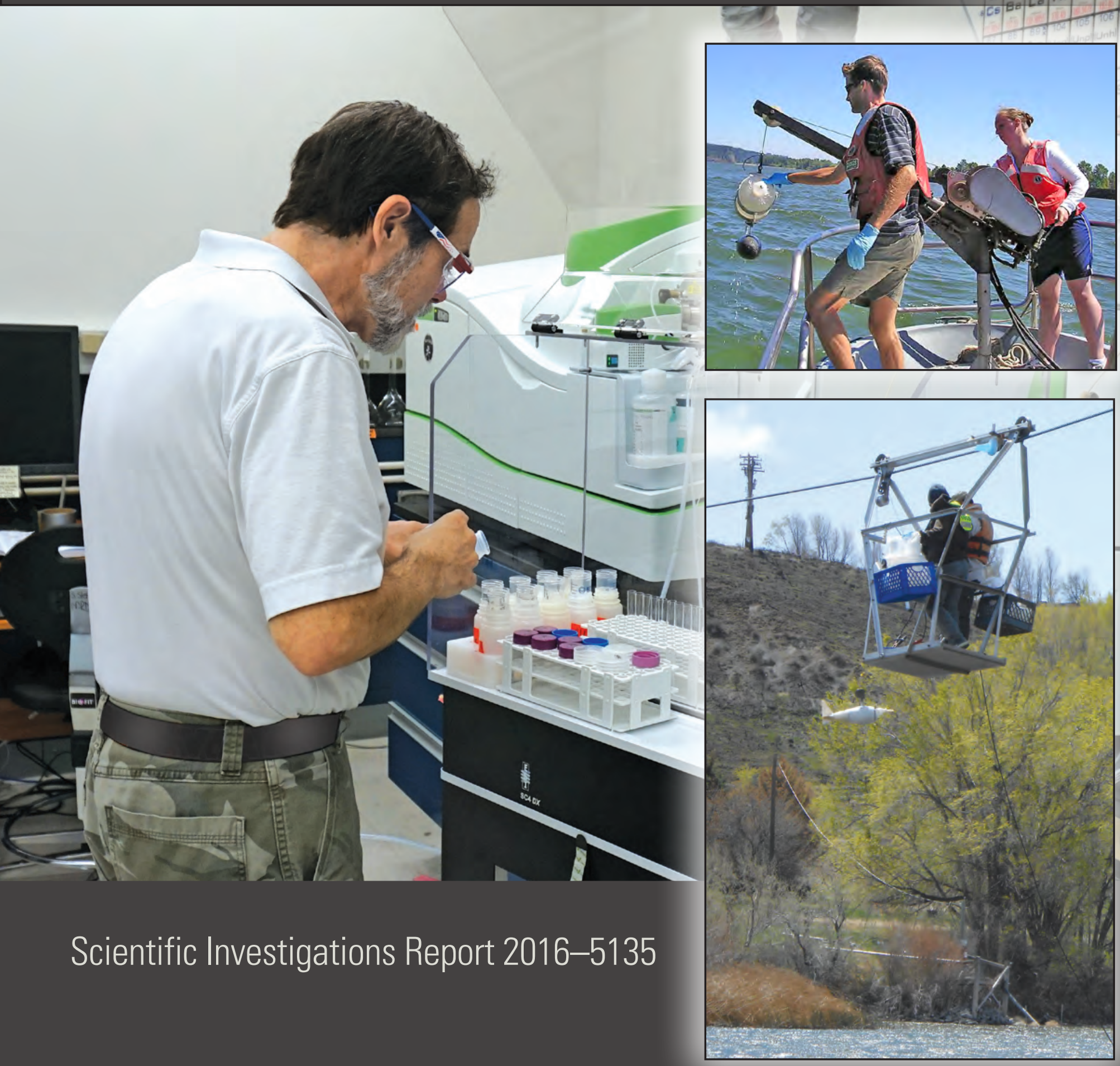

U.S. Department of the Interior

U.S. Geological Survey 
Cover: Chemist analyzing samples on inductively coupled plasma mass spectrometry (ICP-MS) at the National Water Quality Laboratory, Denver, Colorado. Photograph by Sarah Stetson, U.S. Geological Survey, National Water Quality Laboratory, 2016.

Top right inset: USGS scientists collecting water samples from Columbia River at Beaver Army Terminal, near Quincy, Oregon. Photograph by Andrew Arnsberg, U.S. Geological Survey (former USGS), 2005.

Bottom right inset: USGS scientists collecting water samples from Snake River at King Hill, Idaho, from cableway. Photograph by Chris Mebane, U.S. Geological Survey, 2013. 


\section{Potential Sources of Analytical Bias and Error in Selected Trace Element Data-Quality Analyses}

By Angela P. Paul, John R. Garbarino, Lisa D. Olsen, Michael R. Rosen, Christopher A. Mebane, and Tedmund M. Struzeski

Scientific Investigations Report 2016-5135 


\title{
U.S. Department of the Interior SALLY JEWELL, Secretary
}

\section{U.S. Geological Survey Suzette M. Kimball, Director}

\author{
U.S. Geological Survey, Reston, Virginia: 2016
}

For more information on the USGS - the Federal source for science about the Earth, its natural and living resources, natural hazards, and the environment-visit http://www.usgs.gov or call 1-888-ASK-USGS.

For an overview of USGS information products, including maps, imagery, and publications, visit http://store.usgs.gov.

Any use of trade, firm, or product names is for descriptive purposes only and does not imply endorsement by the U.S. Government.

Although this information product, for the most part, is in the public domain, it also may contain copyrighted materials as noted in the text. Permission to reproduce copyrighted items must be secured from the copyright owner.

Suggested citation:

Paul, A.P., Garbarino, J.R., Olsen, L.D., Rosen, M.R., Mebane, C.A., and Struzeski, T.M., 2016, Potential sources of analytical bias and error in selected trace-element data quality analyses: U.S. Geological Survey Scientific Investigations Report 2016-5135, 58 p., http://dx.doi.org/10.3133/sir20165135.

ISSN 2328-0328 (online) 


\section{Contents}

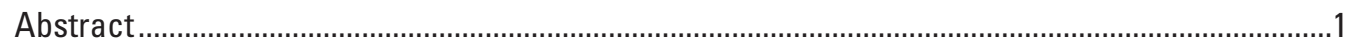

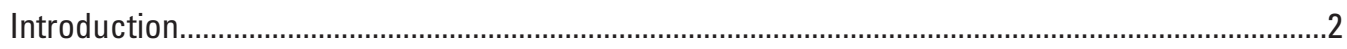

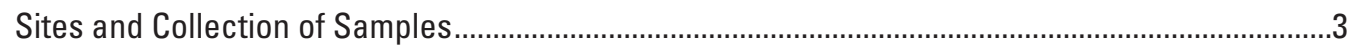

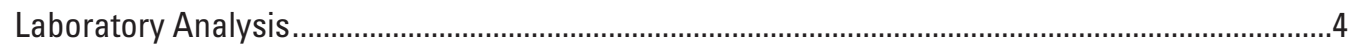

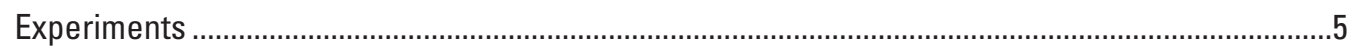

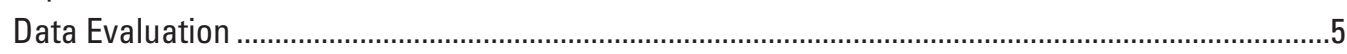

Matrix Matching Filtered and Unfiltered Samples .................................................................

Influence of Instrumentation ................................................................................................

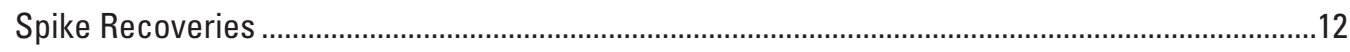

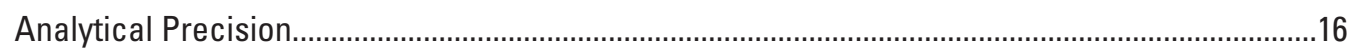

Standard Reference Materials ..................................................................................................

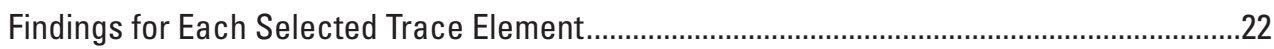

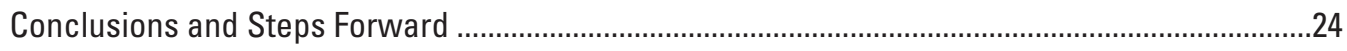

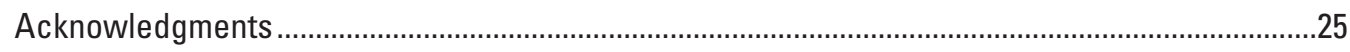

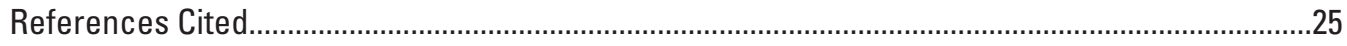

Supplemental Information A. General Chemistries of Surface Water (SW) and

Groundwater (GW) Used to Evaluate the Analyses of Selected Trace Elements in

Various Filtered and Unfiltered Natural Water Matrices by the USGS National

Water Quality Laboratory (NWOL), August-October 2014

Supplemental Information B. Influence of the Addition of Hydrochloric Acid (HCI) To

Filtered Samples To Matrix Match the Filtered Samples To the Matrix of Unfiltered

Samples Treated with $\mathrm{HCl}$ during the In-Bottle Digestion Procedure..

Supplemental Information C. Instrument Variability on Filtered Trace-Element Analyses

Using Inductively Coupled Plasma Mass Spectrometry (ICP-MS), Instruments 6 and 7 ......

Supplemental Information D. Standard Reference Materials (SRMs) from the National Institute of Standards and Technology (NIST) and the National Institute of Advanced Industrial Science and Technology, National Metrology Institute of Japan (NMIJ)..........44

Supplemental Information E. Results for Standard Reference Material (SRM) and Trace Element Spike Recoveries in Filtered and Unfiltered Samples Analyzed on Instruments 6 and 7 . 


\section{Figures}

1. Graphs showing trace element concentrations in filtered samples for evaluating the effects of the addition of hydrochloric $(\mathrm{HCl})$ acid and instrumental variability on filtered sample analytical results.

2. Graphs showing spike recoveries for trace elements in filtered and unfiltered samples with respect to the magnitude of the trace-element spiking concentration relative to the ambient concentration in the sample.

3. Graphs showing percent relative standard deviation (RSD) among analyses for each trace element in ambient filtered samples where concentrations exceeded LT-MDLs for full range of concentrations and for concentrations less than 10 micrograms per liter.

4. Graphs showing percent relative difference (RD) between analyses for each trace element in ambient unfiltered samples where concentrations exceeded LT-MDLs for full range of concentrations and for concentrations less than 80 micrograms per liter

5. Graphs showing percent relative standard deviation (RSD) between analyses for each trace element in spiked filtered samples for full range of concentrations and for concentrations less than 50 micrograms per liter.

6. Graphs showing percent relative difference (RD) between analyses for each trace element in spiked unfiltered samples for full range of concentrations and for concentrations less than 100 micrograms per liter

\section{Tables}

1. Description of sample type, parameter code, analytical method, and long-term method detection limit for each trace element evaluated as part of this study

2. Instruments used to analyze ambient and spiked samples during each of three experiments evaluated as part of this study.

3. Ambient and spiked trace-element concentrations and matrix spike recoveries in paired filtered and unfiltered samples.

4. Instances of trace-element concentrations in ambient and spiked filtered samples exceeding those in associated unfiltered samples when analyzed on different and the same instrumentation

5. Trace-element concentrations in ambient and spiked paired filtered and unfiltered samples as determined during the original and new experiments.

6. Percent matrix spike recoveries for trace elements in filtered and unfiltered sample pairs

7. Assessment of analytical precision of ambient and spiked trace-element concentrations in filtered and unfiltered samples

8. Comparison of trace-element concentrations in digested and undigested standard reference materials. 


\section{Conversion Factors}

Inch/Pound to International System of Units

\begin{tabular}{lcc}
\hline Multiply & By & To obtain \\
\hline & Volume & \\
\hline gallon (gal) & 3.785 & liter (L) \\
\hline & Weight & \\
\hline pounds (lbs) & 0.454 & kilograms (kg ) \\
\hline
\end{tabular}

Temperature in degrees Celsius $\left({ }^{\circ} \mathrm{C}\right)$ may be converted to degrees Fahrenheit $\left({ }^{\circ} \mathrm{F}\right)$ as

$$
{ }^{\circ} \mathrm{F}=\left(1.8 \times{ }^{\circ} \mathrm{C}\right)+32 \text {. }
$$

\section{Supplemental Information}

Specific conductance is given in microsiemens per centimeter at 25 degrees Celsius $(\mu \mathrm{S} / \mathrm{cm}$ at $\left.25^{\circ} \mathrm{C}\right)$.

Concentrations of chemical constituents in water are given in either milligrams per liter (mg/L) or micrograms per liter $(\mu \mathrm{g} / \mathrm{L})$. 


\section{Abbreviations}

$\begin{array}{ll}\text { BOS } & \text { Branch of Quality Systems } \\ \text { Cexp } & \text { expected concentration in spiked sample } \\ \text { CF } & \text { concentration in filtered sample } \\ \text { cICP-MS } & \text { collision/reaction cell inductively coupled plasma mass spectrometry } \\ \text { Cs } & \text { spiked sample trace-element concentration } \\ \text { Cu } & \text { unspiked sample trace-element concentration } \\ \text { CUF } & \text { concentration in unfiltered sample } \\ \text { CV } & \text { certified value } \\ \text { DIS } & \text { dissolved } \\ \text { GW } & \text { groundwater } \\ \text { HCI } & \text { hydrochloric acid } \\ \text { HNO } & \text { nitric acid } \\ \text { ICP-MS } & \text { inductively coupled plasma mass spectrometry } \\ \text { IBSP } & \text { inorganic blind sample program } \\ \text { LIMS } & \text { Laboratory Information Management System } \\ \text { LT-MDL } & \text { long-term method detection limit } \\ \text { NIST } & \text { National Institute of Standards and Technology } \\ \text { NMIJ } & \text { National Metrology Institute of Japan } \\ \text { NWOL } & \text { National Water Quality Laboratory } \\ \text { RD } & \text { relative difference } \\ \text { RSD } & \text { relative standard deviation } \\ \text { SRM } & \text { standard reference material } \\ \text { SRS } & \text { standard reference sample } \\ \text { SW } & \text { surface water } \\ \text { SWAMP } & \text { Surface Water Ambient Monitoring Program } \\ \text { V/v } & \text { volume to volume } \\ \text { WWR } & \text { whole water recoverable } \\ & \end{array}$




\title{
Potential Sources of Analytical Bias and Error in Selected Trace Element Data-Quality Analyses
}

\author{
By Angela P. Paul1, John R. Garbarino², Lisa D. Olsen³, Michael R. Rosen4, Christopher A. Mebane ${ }^{5}$, and \\ Tedmund M. Struzeski ${ }^{6}$
}

\section{Abstract}

Potential sources of analytical bias and error associated with laboratory analyses for selected trace elements where concentrations were greater in filtered samples than in paired unfiltered samples were evaluated by U.S. Geological Survey (USGS) Water Quality Specialists in collaboration with the USGS National Water Quality Laboratory (NWQL) and the Branch of Quality Systems (BQS).

Causes for trace-element concentrations in filtered samples to exceed those in associated unfiltered samples have been attributed to variability in analytical measurements, analytical bias, sample contamination either in the field or laboratory, and (or) sample-matrix chemistry. These issues have not only been attributed to data generated by the USGS NWQL but have been observed in data generated by other laboratories. This study continues the evaluation of potential analytical bias and error resulting from matrix chemistry and instrument variability by evaluating the performance of seven selected trace elements in paired filtered and unfiltered surface-water and groundwater samples collected from 23 sampling sites of varying chemistries from six States, matrix spike recoveries, and standard reference materials.

Filtered and unfiltered samples have been routinely analyzed on separate inductively coupled plasma-mass spectrometry instruments. Unfiltered samples are treated with hydrochloric acid $(\mathrm{HCl})$ during an in-bottle digestion procedure; filtered samples are not routinely treated with $\mathrm{HCl}$ as part of the laboratory analytical procedure. To evaluate the influence of $\mathrm{HCl}$ on different sample matrices, an aliquot of the filtered samples was treated with $\mathrm{HCl}$. The addition of $\mathrm{HCl}$ did little to differentiate the analytical results between filtered samples treated with $\mathrm{HCl}$ from those samples left untreated; however, there was a small, but noticeable, decrease in the number of instances where a particular trace-element concentration was greater in a filtered sample than in the associated unfiltered sample for all trace elements except selenium. Accounting for the small dilution effect (2 percent) from the addition of $\mathrm{HCl}$, as required for the in-bottle digestion procedure for unfiltered samples, may be one step toward decreasing the number of instances where traceelement concentrations are greater in filtered samples than in paired unfiltered samples.

The laboratory analyses of arsenic, cadmium, lead, and zinc did not appear to be influenced by instrument biases. These trace elements showed similar results on both instruments used to analyze filtered and unfiltered samples. The results for aluminum and molybdenum tended to be higher on the instrument designated to analyze unfiltered samples; the results for selenium tended to be lower. The matrices used to prepare calibration standards were different for the two instruments. The instrument designated for the analysis of unfiltered samples was calibrated using standards prepared in a nitric:hydrochloric acid $\left(\mathrm{HNO}_{3}: \mathrm{HCl}\right)$ matrix. The instrument designated for the analysis of filtered samples was calibrated using standards prepared in a matrix acidified only with $\mathrm{HNO}_{3}$. Matrix chemistry may have influenced the responses of aluminum, molybdenum, and selenium on the two instruments. The best analytical practice is to calibrate instruments using calibration standards prepared in matrices that reasonably match those of the samples being analyzed.

\footnotetext{
${ }^{1}$ Water Quality Specialist, USGS, Nevada Water Science Center, Carson City, Nevada.

${ }^{2}$ Chemist (emeritus), USGS, National Water Quality Laboratory, Denver, Colorado.

${ }^{3}$ Water Quality Specialist, USGS, California Water Science Center, Sacramento, California.

${ }^{4}$ Water Quality Specialist, USGS, Water Science Field Team, Carson City, Nevada.

${ }^{5}$ Water Quality Specialist, USGS, Idaho Water Science Center, Boise, Idaho.

${ }^{6}$ Chemist, USGS, Branch of Quality Systems, Denver, Colorado.
} 
Filtered and unfiltered samples were spiked over a range of trace-element concentrations from less than 1 to 58 times ambient concentrations. The greater the magnitude of the trace-element spike concentration relative to the ambient concentration, the greater the likelihood spike recoveries will be within data control guidelines (80-120 percent). Greater variability in spike recoveries occurred when trace elements were spiked at concentrations less than 10 times the ambient concentration. Spike recoveries that were considerably lower than 90 percent often were associated with spiked concentrations substantially lower than what was present in the ambient sample. Because the main purpose of spiking natural water samples with known quantities of a particular analyte is to assess possible matrix effects on analytical results, the results of this study stress the importance of spiking samples at concentrations that are reasonably close to what is expected but sufficiently high to exceed analytical variability. Generally, differences in spike recovery results between paired filtered and unfiltered samples were minimal when samples were analyzed on the same instrument.

Analytical results for trace-element concentrations in ambient filtered and unfiltered samples greater than 10 and $40 \mu \mathrm{g} / \mathrm{L}$, respectively, were within the data-quality objective for precision of \pm 25 percent. Ambient trace-element concentrations in filtered samples greater than the long-term method detection limits but less than $10 \mu \mathrm{g} / \mathrm{L}$ failed to meet the data-quality objective for precision for at least one trace element in about 54 percent of the samples. Similarly, traceelement concentrations in unfiltered samples greater than the long-term method detection limits but less than $40 \mu \mathrm{g} / \mathrm{L}$ failed to meet this data-quality objective for at least one traceelement analysis in about 58 percent of the samples. Although, aluminum and zinc were particularly problematic, limited re-analyses of filtered and unfiltered samples appeared to improve otherwise failed analytical precision.

The evaluation of analytical bias using standard reference materials indicate a slight low bias for results for arsenic, cadmium, selenium, and zinc. Aluminum and molybdenum show signs of high bias. There was no observed bias, as determined using the standard reference materials, during the analysis of lead.

\section{Introduction}

Chemists at the National Water Quality Laboratory (NWQL) have a long history of collaborating with U.S. Geological Survey (USGS) Water-Quality Specialists and Project personnel to improve analytical methods. An objective of many USGS projects is to determine status or identify changes in ambient water chemistry; therefore, the methods used by the NWQL often emphasize attainment of low laboratory reporting limits. In order to continually lower method detection limits for trace elements over time, the NWQL has changed analytical methods and instrumentation as they have improved.

In October 2005, the NWQL began using collision/ reaction cell (cICP-MS) technology instead of the standard mode inductively coupled plasma-mass spectrometry (ICP-MS) for selected trace elements. The cICP-MS method reduces matrix interferences, improves the linearity of response within the working range of concentrations, thereby reducing biases, relative to standard mode ICP-MS. Although instrument detection limits in purified water are not appreciably improved by cICP-MS over standard mode ICP-MS, the practical quantitation limits in natural water samples may be an order of magnitude better using cICP-MS (Thomas, 2002; Garbarino and others, 2006).

Despite the advantages of the cICP-MS approach over previous methods, under some circumstances performance was questionable for some of the trace elements. In particular, Water-Quality Specialists in the Western States and the Inorganic Blind Sample Project (IBSP) of the Branch of Quality Systems (BQS) raised concerns to the NWQL regarding the issue of filtered or "dissolved" (DIS) sample results being greater than unfiltered or "whole water" recoverable (WWR) from the same paired sample. Instances where trace-element concentrations are greater in filtered samples than in associated unfiltered samples is referred to as the " $\mathrm{C}_{\mathrm{F}}>\mathrm{C}_{\mathrm{UF}}$ " issue.

The $\mathrm{C}_{\mathrm{F}}>\mathrm{C}_{\mathrm{UF}}$ issue led to the initiation of project- and NWQL-level supplemental quality-control testing. In 2012, the Idaho Water Science Center submitted four identically processed paired samples (filtered and unfiltered) for analysis of cadmium $(\mathrm{Cd})$, lead $(\mathrm{Pb})$, and zinc ( $\mathrm{Zn})$ by the NWQL. A filtered sample will have a concentration that is approximately less than or equal to the concentration in an associated unfiltered sample. Concentrations of $\mathrm{Cd}$ and $\mathrm{Zn}$ for all four paired samples analyzed by the NWQL were about 10 percent greater in filtered samples than in the associated unfiltered samples. Although the magnitude of bias for any individual paired sample was not extreme, the concern of systematic bias remained.

In 2013, the NWQL conducted a series of investigations into the concerns regarding the trace element $\mathrm{C}_{\mathrm{F}}>\mathrm{C}_{\mathrm{UF}}$ issue. Tasks included examining the frequency of $\mathrm{C}_{\mathrm{F}}>\mathrm{C}_{\mathrm{UF}}$ instances in the NWQL Laboratory Information Management System (LIMS) database and evaluating analytical variability at the NWQL. Potential biases associated with different instruments and analysts were tested using 125 paired filtered and unfiltered samples from various USGS Water Science Centers, 
samples from the BQS IBSP with and without hydrochloric acid $(\mathrm{HCl})$ matrix-matching, and inter-laboratory comparisons. Possible causes for trace-element concentrations in filtered samples exceeding those in associated unfiltered samples were (1) measurement variability; (2) analytical bias; (3) sample contamination (field or laboratory); and (4) samplematrix chemistry. Generally, analytical results were similar for filtered and unfiltered sample pairs analyzed by the NWQL and various TestAmerica Laboratories facilities. The inclusion of trace-element results from TestAmerica Laboratories in this evaluation demonstrated that the instances of $\mathrm{C}_{\mathrm{F}}>\mathrm{C}_{\mathrm{UF}}$ were not unique to the NWQL, as some of the results from the TestAmerica Laboratory were similar (John Garbarino, U.S. Geological Survey, written commun., 2013). This evaluation suggested that analytical variability was greatest at lower concentrations than at higher concentrations and that bias in trace-element analyses would be minimized by analyzing paired filtered and unfiltered samples on the same instrument; however, analysis on the same instrument would likely require matrix matching of filtered and unfiltered samples using $\mathrm{HCl}$ (acid used during the in-bottle digestion procedure for $\mathrm{C}_{\mathrm{UF}}$ analyses) (John Garbarino, U.S. Geological Survey, written commun., 2013).

The issue of filtered sample concentrations being greater than unfiltered sample concentrations is not unique to NWQL. An interlaboratory evaluation conducted using six private commercial and university analytical laboratories based in California found that Se concentrations in filtered and unfiltered surface-water and groundwater samples collected from Orange County, California, were consistently 25 percent higher in filtered samples than in associated unfiltered samples (Nitrogen and Selenium Management Program, 2006). The issue could not be attributed to a particular method of analysis and instrument remedies were not obvious. The recommendation of the interlaboratory evaluation was that total recoverable Se concentrations be determined by adding the measurements of filtered and particulate Se concentrations (Nitrogen and Selenium Management Program, 2006).

The purpose of this investigation is the continued evaluation of potential sources of analytical bias and error in selected trace-element analyses in paired filtered and unfiltered ambient water samples analyzed at the USGS NWQL. Specifically,

1. Does matrix matching filtered samples to unfiltered samples treated with $\mathrm{HCl}$ during the in-bottle digestion procedure influence trace-element concentration results? Does this treatment decrease the instances where trace-element concentrations are greater in filtered samples than in unfiltered samples?
2. What is the effect of analyzing paired filtered and unfiltered samples for trace-element concentrations on the same instrument—as opposed to using different instruments?

3. Do trace-element spike recovery results for filtered and unfiltered natural-water samples analyzed on different or the same instruments show significant bias? 4. Do SRM analyses indicate any notable analytical
biases?

\section{Sites and Collection of Samples}

Identification numbers were provided to the USGS BQS for sites considered for sampling as part of this evaluation (Supplemental Information A). Sites were selected based on previously analyzed samples for which trace-element data were available.

Filtered and unfiltered ambient water samples were collected, in duplicate, from 23 sampling sites in the Western United States. Samples were collected by staff in USGS Water Science Centers in the Western States using standard USGS protocols for the collection of filtered and unfiltered samples for the analyses of trace elements (Wilde and others, 2004, 2014; Wilde, 2005; U.S. Geological Survey, 2006). Samples were collected from 15 surface-water (SW) sites and 8 groundwater $(\mathrm{GW})$ sites of varying chemistries (Supplemental Information A) in the States of California, Idaho, Montana, New Mexico, Nevada, and Oregon.

Four bottles were collected at each site; two filtered and two unfiltered samples (one each for determining ambient concentrations and one each for spiking). Both filtered $(0.45 \mu \mathrm{m})$ and unfiltered samples were preserved in the field using $7.5 \mathrm{~N} \mathrm{HNO}_{3}$ to acidify samples to a $\mathrm{pH}$ less than 2. Upon receipt of samples by the NWQL, filtered samples were analyzed to determine ambient concentrations. These results were used by the BQS to calculate appropriate spiking concentrations for the matrix spikes with the goal being 2 to 10 times the trace-element concentration in filtered samples or 10 times the long-term method detection limit (LT-MDL), whichever was higher. Spikes were directly added to one of the filtered samples and one of the undigested, unfiltered samples.

Two different standard reference materials were analyzed for the same suite of trace elements as the ambient and spiked samples from the USGS Water Science Centers. Standard reference materials (SRM) were acidified commercially available spring water (NIST 1640a) and acidified natural river water from Japan (NMIJ 7202-b). 


\section{Laboratory Analysis}

Prior to the analysis for trace-element concentrations, spiked and unspiked, unfiltered samples were treated with $\mathrm{HCl}$ during the in-bottle digestion procedure by adding $\mathrm{HCl}$ at 2 percent of the sample volume and heating the sample to $65^{\circ} \mathrm{C}$ for 8 hours (modified procedure from Hoffman and others, 1996). After digestion, samples were shaken and filtered to $20-25 \mu \mathrm{m}$. Hoffman and others (1996) found that there was $80-100$ percent recovery of $\mathrm{Cd}, \mathrm{Pb}$, and $\mathrm{Zn}$ in freshwater sediment during the in-bottle digestion procedure. Filtered samples were not subjected to the in-bottle digestion procedure.

The NWQL analyzed each of the ambient, spiked, and SRM samples for the selected suite of trace elements, calculated sample matrix-spike recoveries for the ambient and spiked water samples (eq. 1), and provided a summary of the analytical results to the USGS Water-Quality Specialists. The trace elements selected for analysis were aluminum (Al), arsenic (As), $\mathrm{Cd}, \mathrm{Pb}$, molybdenum (Mo), selenium (Se), and $\mathrm{Zn}$ (table 1). These trace elements were selected on the basis of past results from paired field samples showing instances where concentrations were greater in filtered samples than in unfiltered samples. Sample analysis and reporting of results were tasked to NWQL personnel who routinely process and analyze filtered and unfiltered samples for trace-element analyses at the NWQL.

$$
\text { Spike Recovery }(\%)=\left(\frac{C s-C u}{C e x p}\right) * 100 \%
$$

where

$$
\begin{gathered}
\text { Cs is the measured concentration in the spiked } \\
\text { sample (spike plus ambient), } \\
\mathrm{Cu} \text { is the measured concentration in the unspiked } \\
\text { sample (ambient), and } \\
\text { Cexp is the known concentration of the analyte } \\
\text { added to the spiked sample (spike added). }
\end{gathered}
$$

Analytical methods used to determine trace-element concentrations in filtered and unfiltered ambient and spiked water samples and SRMs followed those outlined in NWQL Laboratory Schedule 2578. Detailed information on these methods can be found in Garbarino and others (2006). Traceelement concentrations were determined using ICP-MS and cICP-MS. Generally, cICP-MS was expected to decrease sample-matrix interferences relative to ICP-MS analyses (Garbarino and others, 2006). Each ICP-MS and cICP-MS was calibrated daily to optimize over the entire mass range of elements evaluated and quality-control samples were analyzed systematically during analyses. Water-Quality Specialists from the USGS Water Science Centers in the Western States and John Garbarino (emeritus, USGS NWQL) reviewed and

\begin{tabular}{|c|c|c|c|c|c|c|}
\hline \multirow{2}{*}{$\begin{array}{l}\text { Trace } \\
\text { element }\end{array}$} & \multirow{2}{*}{$\begin{array}{c}\text { Sample } \\
\text { type }\end{array}$} & \multirow{2}{*}{$\begin{array}{l}\text { Parameter } \\
\text { code }\end{array}$} & \multirow{2}{*}{$\begin{array}{l}\text { Laboratory } \\
\text { code }\end{array}$} & \multicolumn{2}{|c|}{ Analytical method } & \multirow{2}{*}{$\begin{array}{c}\text { LT-MDL } \\
(\mu g / L)\end{array}$} \\
\hline & & & & Method code & Method & \\
\hline \multirow[t]{2}{*}{ Aluminum } & Filtered & 01106 & 1784 & PLM43 & ICP-MS & 2.2 \\
\hline & Unfiltered & 01105 & 2372 & PLM48 & ICP-MS & 3.8 \\
\hline \multirow[t]{2}{*}{ Arsenic } & Filtered & 01000 & 3122 & PLM10 & cICP-MS & 0.1 \\
\hline & Unfiltered & 01002 & 3123 & PLM11 & cICP-MS & 0.28 \\
\hline \multirow[t]{2}{*}{ Cadmium } & Filtered & 01025 & 1788 & PLM43 & ICP-MS & 0.03 \\
\hline & Unfiltered & 01027 & 2376 & PLM47 & ICP-MS & 0.03 \\
\hline \multirow[t]{2}{*}{ Lead } & Filtered & 01060 & 1794 & PLM43 & ICP-MS & 0.04 \\
\hline & Unfiltered & 01062 & 2383 & PLM48 & ICP-MS & 0.04 \\
\hline \multirow[t]{2}{*}{ Molybdenum } & Filtered & 01049 & 1792 & PLM43 & ICP-MS & 0.05 \\
\hline & Unfiltered & 01051 & 2380 & PLM48 & ICP-MS & 0.05 \\
\hline \multirow[t]{2}{*}{ Selenium } & Filtered & 01145 & 3132 & PLM10 & cICP-MS & 0.05 \\
\hline & Unfiltered & 01147 & 3133 & PLM11 & cICP-MS & 0.1 \\
\hline \multirow[t]{2}{*}{ Zinc } & Filtered & 01090 & 3138 & PLM10 & cICP-MS & 2.0 \\
\hline & Unfiltered & 01092 & 3139 & PLM11 & cICP-MS & 2.0 \\
\hline
\end{tabular}
evaluated the analytical laboratory results.

Table 1. Description of sample type, parameter code, analytical method, and long-term method detection limit for each trace element evaluated as part of this study.

[Analytical method: ICP-MS, inductively coupled plasma-mass spectrometry; cICP-MS, collision cell inductively coupled plasma-mass spectrometry. LT-MDL: Long-term method detection limit used to evaluate analytical results provided by the NWQL (http://wwwnwql.cr.usgs.gov/USGS/, accessed April 2014). $\mu \mathrm{g} / \mathrm{L}$, microgram per liter] 


\section{Experiments}

Using samples from the USGS Water Science Centers in the Western States, three experiments were conducted(1) original, (2), new, and (3) matrix match. During the first (original) experiment, the filtered and unfiltered samples were analyzed on different instruments, as has been customary for these analyses. Unfiltered samples were analyzed on instrument 6 and filtered samples were analyzed on instrument 7 (table 2; original). Unfiltered sample results were not adjusted to account for the 2-percent by volume $(\mathrm{v} / \mathrm{v})$ addition of $\mathrm{HCl}$. The rationale the NWQL has provided for analyzing filtered and unfiltered samples on separate instruments is that analyzing paired filtered and unfiltered samples on the same instrument can, over time, potentially have a negative effect on analytical performance for filtered samples due to a long-lasting residual background chloride signal caused by the routine analysis of unfiltered samples with the $\mathrm{HNO}_{3}: \mathrm{HCl}$ matrix from the in-bottle digestion procedure.

To assess possible instrument variability, a second experiment (new) was performed where paired filtered and unfiltered samples were analyzed on the same instrument (instrument 6 , table 2, new). The matrix of the filtered samples was 0.4 percent $\mathrm{HNO}_{3}$; however, instrument 6 was calibrated with a $\mathrm{HNO}_{3}: \mathrm{HCl}$ matrix. Unfiltered sample results were not adjusted for the addition of 2-percent ( $\mathrm{v} / \mathrm{v})$ addition of $\mathrm{HCl}$; however, only filtered sample results were compared during the assessment of instrumental variability. Filtered samples were not treated with $\mathrm{HCl}$.

A third experiment (matrix match) evaluated the influence of "matrix matching" the filtered samples to unfiltered samples treated with $\mathrm{HCl}$ at 2 percent (v/v) during the in-bottle digestion procedure (table 2, matrix match). The ICP-MS used for the analysis of these samples (instrument 6) was calibrated using standards prepared in a $\mathrm{HNO}_{3}: \mathrm{HCl}$ matrix. During the matrix match evaluation, the trace-element concentrations determined for the filtered and unfiltered samples were adjusted for dilution resulting from adding HCl. Filtered and unfiltered matrix-matched samples were analyzed on the same instrumentation (instrument 6).

Table 2. Instruments used to analyze ambient and spiked samples during each of three experiments evaluated as part of this study.

[Aluminum, arsenic, cadmium, lead, molybdenum, selenium, and zinc were considered separately during each experiment]

\begin{tabular}{lcccccc}
\hline \multirow{2}{*}{ Experiment } & \multicolumn{2}{c}{ Filtered samples } & & \multicolumn{2}{c}{ Unfiltered samples } \\
\cline { 2 - 3 } & Ambient & $\begin{array}{c}\text { Matrix } \\
\text { spiked }\end{array}$ & & Ambient & & $\begin{array}{c}\text { Matrix } \\
\text { spiked }\end{array}$ \\
& Instrument 7 & Instrument 7 & & Instrument 6 & Instrument 6 \\
Original & Instrument 6 & Instrument 6 & & Instrument 6 & Instrument 6 \\
Matrix match & Instrument 6 & Instrument 6 & & Instrument 6 & Instrument 6 \\
\hline
\end{tabular}

\section{Data Evaluation}

Using linear regression, the NWQL evaluated the effects of matrix matching filtered samples to unfiltered samples treated with $\mathrm{HCl}$ during the in-bottle digestion procedure. Instrument variability on trace-element concentrations in ambient water samples that were and were not matrix matched with $\mathrm{HCl}$ was examined. Trace-element concentrations in standard reference materials treated with $\mathrm{HCl}$ during the in-bottle digestion procedure were summarized.

Trace-element concentrations in paired filtered and unfiltered samples in ambient (unspiked), spiked, matrix matched, and reference material water samples were compared and evaluated. Four metrics were used to compare method performance across experiments:

1. Frequency of instances of $\mathrm{C}_{\mathrm{F}}>\mathrm{C}_{\mathrm{UF}}$ for each experimental treatment,

2. Average spike recovery for each treatment (spiked samples only),

3. Frequency of instances of spike recovery less than 80 percent or greater than 120 percent (spiked samples only), and

4. Evaluation of high or low analytical bias in certified standard reference materials.

Instances of $\mathrm{C}_{\mathrm{F}}>\mathrm{C}_{\mathrm{UF}}$ for each trace element were tabulated by identifying paired samples for which the concentration (or recovery) in the filtered sample was greater than 110 percent of the concentration (or recovery) in the associated unfiltered sample. Data were excluded from evaluation for unspiked samples for which the concentration was lower than the long-term method detection limit (LT-MDL); instances are noted. Data also were excluded for spiked pairs that had been spiked too low relative to the concentration in the unspiked sample (that is, when the spike concentration was less than 25 percent of the ambient concentration). The criterion for spike recoveries (80-120 percent) was selected because of its use by the California Surface Water Ambient Monitoring Program (SWAMP; Quality Assurance Research Group, 2010); however, other criteria (for example, $90-110$ or $75-125$ percent) could have been applied to yield qualitatively similar results in terms of identifying relative performance between experiments.

The original and new experiments included repeated analyses of filtered and unfiltered samples; therefore, it was possible to evaluate the variability in trace-element concentrations in repeated analyses of unspiked samples and the recoveries in the spiked samples. Variability was calculated as the absolute value ( $a b s$ ) of relative percent difference (for two samples) and 
as the relative percent standard deviation (where more than two analyses were available) and compared to a criterion of 75-125 percent (Quality Assurance Research Group, 2010). In addition, the effect of environmentally relevant spiking was summarized.

Relative Percent Difference $=a b s\left(\frac{C 1-C 2}{\left(\frac{C 1+C 2}{2}\right)}\right) * 100 \%$,

where

$$
\begin{aligned}
& a b s \text { is the absolute value, } \\
& C 1 \text { is the concentration from first analysis, and } \\
& C 2 \text { is the concentration from the second analysis. }
\end{aligned}
$$

Percent Relative Standard Deviation,

$$
=\left(\frac{\operatorname{stdev}(C 1-C 3)}{\operatorname{mean}(C 1-C 3)}\right) * 100 \% \text {, }
$$

where

"mean (C1-C3)" is the mean concentration of three analyses (C1-C3).

"stdev (C1-C3)" is the standard deviation in concentration of three analyses $(C 1-C 3)$.

Although the primary objective of the experiments was to identify possible causes of the $\mathrm{C}_{\mathrm{F}}>\mathrm{C}_{\mathrm{UF}}$ issue, a secondary objective was to evaluate practices that could potentially negatively affect method performance. Solutions that could decrease $\mathrm{C}_{\mathrm{F}}$ or increase $\mathrm{C}_{\mathrm{UF}}$ by removing bias, while also achieving acceptable recoveries for trace-element analyses in filtered and unfiltered samples, were considered.

\section{Matrix Matching Filtered and Unfiltered Samples}

A subset of filtered samples were treated with $\mathrm{HCl}$ to match the matrix of the unfiltered samples that were treated with $\mathrm{HCl}$ during the in-bottle digestion procedure (modified from Hoffman and others, 1996). Comparisons were made between the analytical results for filtered samples preserved in the field with $\mathrm{HNO}_{3}$ to filtered samples preserved in the field with $\mathrm{HNO}_{3}$ and then subsequently treated with $\mathrm{HCl}$ at the NWQL in preparation for in-bottle digestion (Supplemental Information B; figs. B1-B7). Ambient (unspiked) concentration ranges varied among trace elements (table 3). Evaluation of the slopes for the linear least square regressions for the full range of concentrations showed that the addition of $\mathrm{HCl}$ to matrix match the filtered samples to associated unfiltered samples for $\mathrm{Al}, \mathrm{As}, \mathrm{Cd}, \mathrm{Pb}, \mathrm{Mo}$, and $\mathrm{Zn}$ had no effect on analytical results (figs. B1-B5 and B7). The slopes for these trace elements (within \pm 1.2 percent from 1.00) indicate a nearly 1:1 response between filtered samples with and without $\mathrm{HCl}$. The slopes for Se indicates that the signal for this trace element was about 2 percent higher (relative to a 1:1 line), when $\mathrm{HCl}$ was added (fig. $\mathrm{B} 6$ ). For the full range of ambient trace-element concentrations, the slopes of the regression analyses show the deviations from the 1:1 line were within reasonable limits for all trace elements evaluated, indicating little or no influence of $\mathrm{HCl}$ on the analytical results; however, it is recognized that the analytical response for Se appears to be somewhat elevated by the addition of $\mathrm{HCl}$. The slopes for the linear least square regressions ranged from 0.988 to 1.021 (mean=1.00 \pm 0.01 ) for the entire range of ambient trace-element concentrations suggest that overall, there were minimal to no differences between analytical results when filtered samples were or were not treated with $\mathrm{HCl}$ (figs. B1-B7). The addition of $\mathrm{HCl}$ appeared to slightly decrease the number of instances where concentrations were greater in filtered samples than in associated unfiltered samples when samples were analyzed on the same instrument for $\mathrm{Al}$, As, $\mathrm{Cd}, \mathrm{Pb}, \mathrm{Mo}$, and $\mathrm{Zn}$ (table 4); this was not the case for Se.

Although the wide range in concentrations should caution conclusions made using linear regression analyses that can be influenced by high-value end members through a phenomenon called "leverage" (Helsel and Hirsch, 1992, p. 247), the evaluation performed by Water-Quality Specialists in the Western States largely confirm the conclusions of the NWQL that the addition of $\mathrm{HCl}$ to filtered samples does not substantially change the analytical results of trace-element concentrations from those in filtered samples not treated with HCl (figs. B1-B7). The results of the Wilcoxon Signed Rank test for paired data did show a significant difference between median concentrations of Mo and Se as determined in the $\mathrm{HNO}_{3}$ and the $\mathrm{HNO}_{3}: \mathrm{HCl}$ matrices (fig. 1A). Filtered samples evaluated for the effects of matrix matching were analyzed on instrument 6 (designated for unfiltered sample analyses). Samples treated with $\mathrm{HCl}$ were corrected by 2-percent to account for the small dilution resulting from the addition of $\mathrm{HCl}$. Filtered samples evaluated for instrumental variability were analyzed on instrument 7 (designated for filtered sample analyses) and instrument 6 (fig. 1B). Instrument 6 was calibrated using standards prepared in $\mathrm{HNO}_{3}$ and $\mathrm{HCl}$ matrix; instrument 7 was calibrated with standards prepared in $\mathrm{HNO}_{3}$ matrix (see also, Supplementary Information B and C).

The differences in Mo concentration between the $\mathrm{HNO}_{3}$ and $\mathrm{HNO}_{3}: \mathrm{HCl}$ matrices ranged from -0.02 to $0.28 \mu \mathrm{g} / \mathrm{L}$ (mean $=0.05 \pm 0.08 \mu \mathrm{g} / \mathrm{L}$ ) where the $\mathrm{HNO}_{3}: \mathrm{HCl}$ treatment concentrations were the same or higher than those for the $\mathrm{HNO}_{3}$ matrix in about 79 percent of the comparisons. 
Table 3. Ambient and spiked trace-element concentrations and matrix spike recoveries in paired filtered and unfiltered samples.

[X, times (magnitude of spike relative to ambient). Mann-Whitney Rank Sum test for difference was used to evaluate new and original experimental median spike recovery results $(\alpha=0.05) . \mu \mathrm{g} / \mathrm{L}$, microgram per liter; $<$, less than]

\begin{tabular}{|c|c|c|c|c|c|c|c|c|}
\hline $\begin{array}{l}\text { Trace } \\
\text { element }\end{array}$ & $\begin{array}{l}\text { Sample } \\
\text { type }\end{array}$ & \multicolumn{2}{|c|}{ Original experiment $(\mu \mathrm{g} / \mathrm{L})$} & $\begin{array}{c}\begin{array}{c}\text { Range in magnitude } \\
\text { of spike relative to } \\
\text { ambient concentration }\end{array} \\
\begin{array}{c}\text { Original } \\
\text { experiment }\end{array}\end{array}$ & \multicolumn{4}{|c|}{$\begin{array}{c}\text { Original experiment }{ }^{2} \\
\text { Spike recoveries (percent) }\end{array}$} \\
\hline Aluminum & Filtered & $<2.2-54.8$ & $34.0-156$ & $1-9 X$ & $91 \pm 7$ & 90 & 75 & 105 \\
\hline \multirow[t]{2}{*}{ Arsenic } & Filtered & $0.15-303$ & $3.9-726$ & $1-24 X$ & $102 \pm 5$ & 101 & 88 & 111 \\
\hline & Unfiltered & $<0.28-303$ & $3.4-734$ & $<1-9 X$ & $95 \pm 7$ & 97 & 75 & 108 \\
\hline \multirow[t]{2}{*}{ Cadmium } & Filtered & $<0.03-5.4$ & $0.49-24.0$ & $3-22 X$ & $103 \pm 7$ & 102 & 87 & 124 \\
\hline & Unfiltered & $<0.03-5.4$ & $0.45-20.6$ & $3-14 X$ & $95 \pm 5$ & 95 & 82 & 105 \\
\hline Lead & Filtered & $<0.04-1.2$ & $0.94-2.2$ & $<1-25 X$ & $92 \pm 4$ & 92 & 82 & 100 \\
\hline \multirow[t]{2}{*}{ Selenium } & Filtered & $<0.05-6.2$ & $2.2-23.7$ & $1-39 X$ & $113 \pm 7$ & 114 & 99 & 128 \\
\hline & Unfiltered & $<0.1-5.4$ & $1.9-19.1$ & $1-28 X$ & $92 \pm 7$ & 93 & 78 & 105 \\
\hline \multirow[t]{2}{*}{ Zinc } & Filtered & $<2-942$ & $10.7-2,178$ & $1-5 X$ & $97 \pm 11$ & 96 & 70 & 132 \\
\hline & Unfiltered & $<2-862$ & $9.4-1,872$ & $<1-4 X$ & $89 \pm 11$ & 90 & 71 & 125 \\
\hline
\end{tabular}

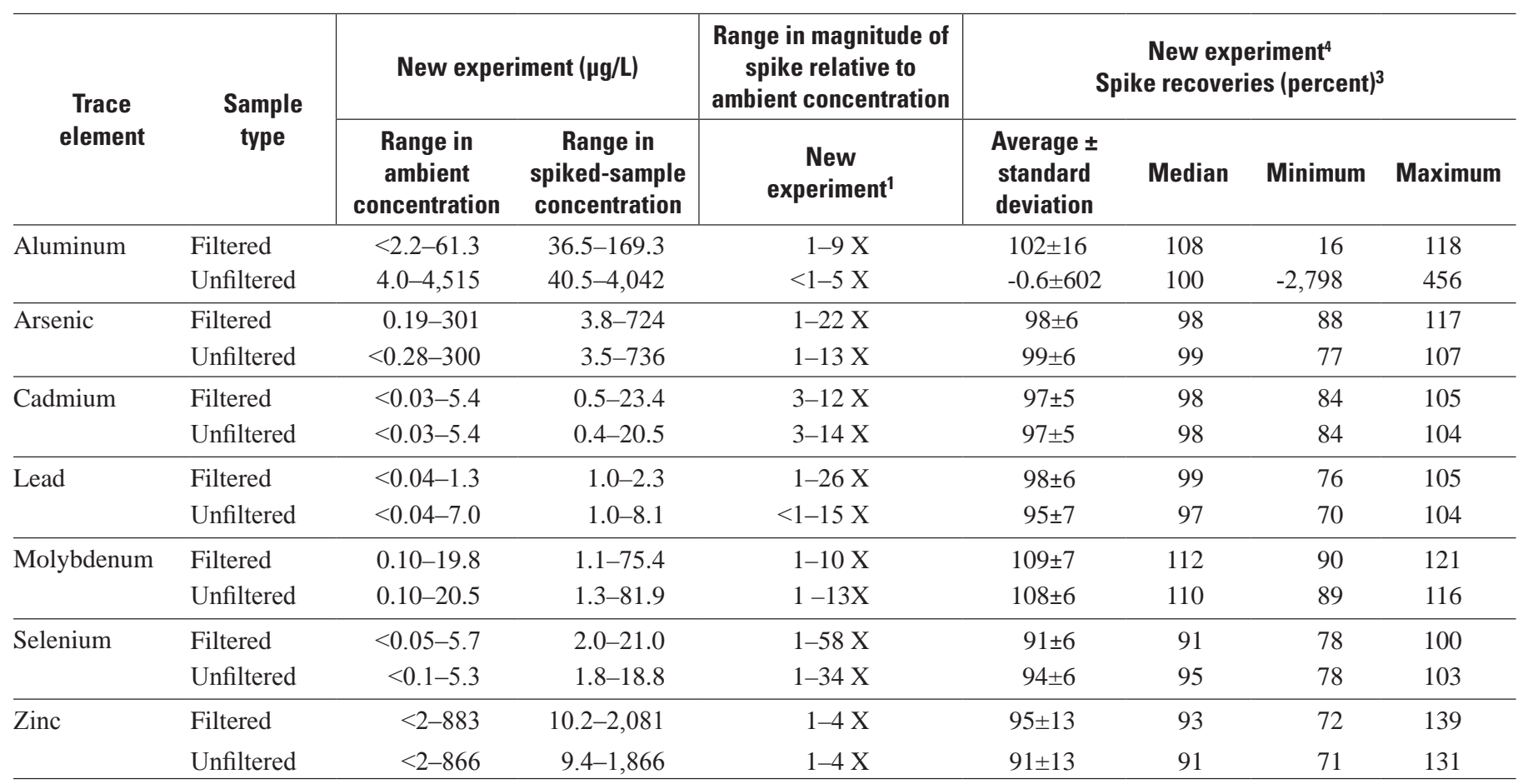


Table 3. Ambient and spiked trace-element concentrations and matrix spike recoveries in paired filtered and unfiltered samples.Continued

\begin{tabular}{|c|c|c|c|c|}
\hline \multirow{3}{*}{$\begin{array}{l}\text { Trace } \\
\text { element }\end{array}$} & \multirow{3}{*}{$\begin{array}{l}\text { Sample } \\
\text { type }\end{array}$} & \multicolumn{3}{|c|}{$\begin{array}{l}\text { Difference between median } \\
\text { spike recoveries between }\end{array}$} \\
\hline & & \multirow[t]{2}{*}{$\begin{array}{l}\text { Original and new } \\
\text { experiments } \\
\text { (p-value) }\end{array}$} & \multicolumn{2}{|c|}{$\begin{array}{l}\text { Filtered and unfiltered samples } \\
\text { within the same experiment } \\
\text { (p-value) }\end{array}$} \\
\hline & & & Original & New \\
\hline \multirow[t]{2}{*}{ Aluminum } & Filtered & $<0.001$ & \multirow{2}{*}{0.177} & \multirow{2}{*}{0.317} \\
\hline & Unfiltered & 0.158 & & \\
\hline \multirow[t]{2}{*}{ Arsenic } & Filtered & 0.009 & \multirow{2}{*}{$<0.001$} & \multirow{2}{*}{0.140} \\
\hline & Unfiltered & 0.006 & & \\
\hline \multirow[t]{2}{*}{ Cadmium } & Filtered & $<0.001$ & \multirow{2}{*}{$<0.001$} & \multirow{2}{*}{0.703} \\
\hline & Unfiltered & 0.190 & & \\
\hline \multirow[t]{2}{*}{ Lead } & Filtered & $<0.001$ & \multirow{2}{*}{0.093} & \multirow{2}{*}{0.093} \\
\hline & Unfiltered & 0.093 & & \\
\hline \multirow[t]{2}{*}{ Molybdenum } & Filtered & $<0.001$ & \multirow{2}{*}{0.016} & \multirow{2}{*}{0.404} \\
\hline & Unfiltered & 0.002 & & \\
\hline \multirow[t]{2}{*}{ Selenium } & Filtered & $<0.001$ & \multirow{2}{*}{$<0.001$} & \multirow{2}{*}{0.071} \\
\hline & Unfiltered & 0.158 & & \\
\hline \multirow[t]{2}{*}{ Zinc } & Filtered & 0.392 & \multirow{2}{*}{0.003} & \multirow{2}{*}{0.205} \\
\hline & Unfiltered & 0.503 & & \\
\hline
\end{tabular}

\footnotetext{
${ }^{1}$ The magnitude of spike added relative to the ambient concentrations in samples; water samples with ambient concentrations less than LT-MDL were not included in the summary as the spike could be relative to a nonexistent (zero) concentration.

${ }^{2}$ During the original experiment, filtered and unfiltered samples were analyzed on different instruments; filtered samples were analyzed on instrument 7 and unfiltered samples were analyzed on instrument 6. Samples analyzed were in the same matrix as analytical standards used to calibrate the respective instruments.

${ }^{3}$ Spike recoveries include those where ambient concentrations were less than LT-MDL; instances where ambient concentrations were less than LT-MDL, the ambient concentrations provided by the laboratory were used as the best estimate of the concentration of analyte in the sample; instances where environmental concentrations were negative, zero was used to represent the environmental concentration.

${ }^{4}$ During the new experiment, filtered and unfiltered samples were analyzed on the same instrument (instrument 6 ). Instrument 6 was calibrated with standards prepared in a nitric:hydrochloric acid matrix. Filtered samples were not matrix matched to the matrix of the calibration standards. The matrix of the unfiltered samples matched that of the standards.
}

Table 4. Instances of trace-element concentrations in ambient and spiked filtered samples exceeding those in associated unfiltered samples when analyzed on different and the same instrumentation.

\begin{tabular}{|c|c|c|c|c|c|c|c|c|}
\hline \multirow{2}{*}{ Instrumentation } & \multirow{2}{*}{ Treatment } & \multicolumn{7}{|c|}{$\begin{array}{l}\text { Instances of trace-element concentrations in filtered samples } \\
\text { exceeding those in associated unfiltered samples (percent) }\end{array}$} \\
\hline & & $\begin{array}{l}\text { Aluminum } \\
\text { (AI) }\end{array}$ & $\begin{array}{l}\text { Arsenic } \\
\text { (As) }\end{array}$ & $\begin{array}{l}\text { Cadmium } \\
\text { (Cd) }\end{array}$ & $\begin{array}{l}\text { Lead } \\
(\mathrm{Pb})\end{array}$ & $\begin{array}{l}\text { Molybdenum } \\
\text { (Mo) }\end{array}$ & $\begin{array}{l}\text { Selenium } \\
\quad \text { (Se) }\end{array}$ & $\begin{array}{l}\text { Zinc } \\
(\text { Zn) }\end{array}$ \\
\hline Different & $\begin{array}{l}\text { Filtered and unfiltered samples; } \\
\text { no hydrochloric acid }\end{array}$ & 0 & 44 & 65 & 19 & 29 & 81 & 56 \\
\hline \multirow[t]{2}{*}{ Same } & $\begin{array}{l}\text { Filtered and unfiltered samples; } \\
\text { no hydrochloric acid }\end{array}$ & 21 & 29 & 36 & 29 & 56 & 23 & 44 \\
\hline & $\begin{array}{l}\text { Filtered samples with added } \\
\text { hydrochloric acid }\end{array}$ & 4 & 21 & 29 & 15 & 46 & 33 & 33 \\
\hline
\end{tabular}

\footnotetext{
${ }^{1}$ Hydrochloric acid added at 2-percent by volume (v/v) to filtered water samples to matrix match these samples with the matrix of paired unfiltered samples.
} 


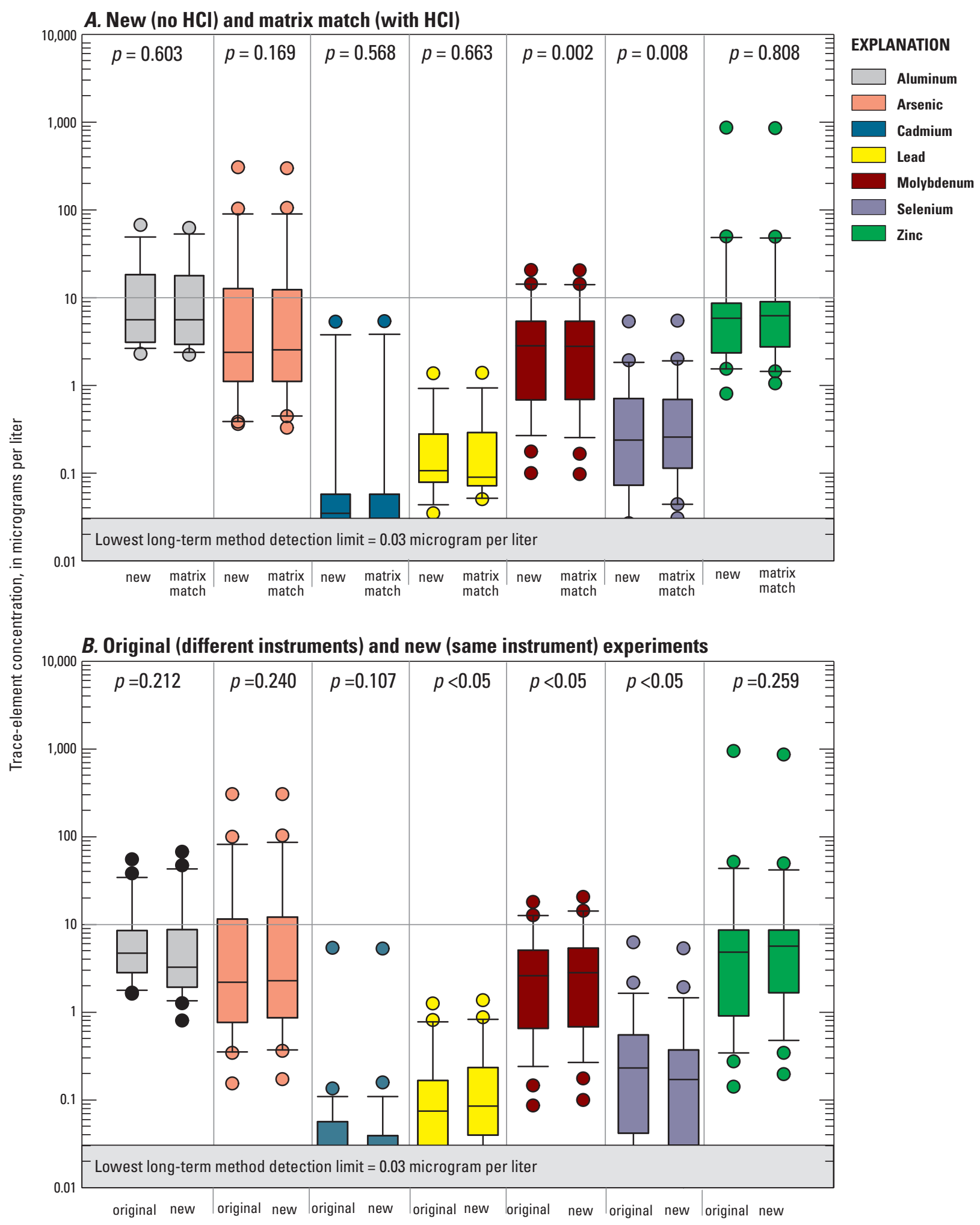

Figure 1. Trace element concentrations in filtered samples for evaluating the effects of $(A)$ the addition of hydrochloric $(\mathrm{HCl})$ acid and $(B)$ instrumental variability on filtered sample analytical results. 
Results were similar for Se, where the differences in Se concentrations between the two treatments ranged from -0.10 to $+0.13 \mu \mathrm{g} / \mathrm{L}$ (mean $=0.02 \pm 0.04 \mu \mathrm{g} / \mathrm{L}$ ). About 83 percent of the comparisons showed that Se concentrations determined from the $\mathrm{HNO}_{3}: \mathrm{HCl}$ matrix were higher than those from the $\mathrm{HNO}_{3}$ matrix (fig. 1A). Evaluation of both the deviation of the slopes with respect to the 1:1 line and the results of the Wilcoxon Sign Rank test on paired data for Mo and Se, shows that the addition of $\mathrm{HCl}$ does not influence the analytical responses of either trace elements substantially; although there may be evidence of a small amount of high bias from results obtained from the addition of $\mathrm{HCl}$. Given that the analytical results for samples in the mixed acid matrix are either essentially the same or higher than those in the $\mathrm{HNO}_{3}$ only matrix, it is unlikely that the sample matrix is contributing to instances where concentrations are higher in filtered samples than in associated unfiltered samples.

For all three experiments, the dilution effect of adding $\mathrm{HCl}$ to the unfiltered samples for the digestion process was identified and evaluated as a source of error. Although this source of error was relatively small (less than 3 percent), the error was systematically documented and could be controlled by performing a simple volume correction. The quantitative effect of applying the volume correction is that the concentrations of trace elements in the unfiltered samples would increase by approximately 2 percent. This small increase was considered beneficial toward minimizing the $\mathrm{CF}>\mathrm{CUF}$ issue for most analytes, while also satisfying the principle of correcting any systematic sources of error. Therefore, volume-corrected data were used for the evaluations of results from these experiments. For the matrix match experiment, volume corrections also were performed on the filtered samples to which the $\mathrm{HCl}$ was added. As of May 15, 2015, the NWQL began routinely incorporating the volume correction into all analyses of unfiltered samples for trace elements that are treated with $\mathrm{HCl}$ during the in-bottle acid-digestion procedure (National Water Quality Laboratory, written commun., 2015).

\section{Influence of Instrumentation}

The NWQL evaluated the results for filtered samples $\left(\mathrm{HNO}_{3}\right.$ matrix) analyzed on instrument 7 (designated for filtered sample analyses) to those obtained on instrument 6 (designated for unfiltered sample analyses) (Supplemental Information C, figs. C1-C7). Instrument 7 was calibrated with standards prepared in a $\mathrm{HNO}_{3}$ matrix (to mimic the 0.4 percent acid matrix resulting from field preservation); instrument 6 was calibrated with standards in a $\mathrm{HNO}_{3}: \mathrm{HCl}$ matrix (to mimic the combined effects of field preservation and the in-bottle-acid digestion procedure used for unfiltered samples). For select analyses, instrument 7 was accidently calibrated with standards prepared in 1 percent $\mathrm{HNO}_{3}$ matrix; however, it is not certain which analyses were performed under those conditions and the NWQL is investigating. Currently, it is assumed that changes in strength of the $\mathrm{HNO}_{3}$ matrix from 0.4 to 1 percent during respective calibrations of instrument 7 had little to no effect on the analytical results obtained from that instrument.

Filtered samples used to evaluate the influence of instrumentation on analytical results were not treated with $\mathrm{HCl}$. The linear least square slopes for the full range of concentrations for As and Cd suggest that there were minimal influences on the analytical results from instrumentation or calibration matrix composition (figs. C2A and C3A); slopes for these analyses were 1.4 and -1.4 percent of a 1:1 line, respectively. Additionally, the results of the Wilcoxon Sign Rank test on paired data show that there were no statistical differences in median concentrations of either trace element as determined by either instrument ( $p \geq 0.107$; fig. $1 B$ ).

Instrumentation and matrix influences were most evident when evaluating the analytical results for $\mathrm{Al}, \mathrm{Pb}, \mathrm{Mo}$, and $\mathrm{Se}$. Over the full range of $\mathrm{Al}$ concentrations, the response on instrument 6 deviated from the 1:1 line by almost 29 percent showing a higher response on instrument 6 relative to instrument 7 (fig. $\mathrm{C} 1 A$ ). However, at $\mathrm{Al}$ concentrations less than $10 \mu \mathrm{g} / \mathrm{L}$, the response on instrument 6 appeared to be lower (fig. $\mathrm{C} 1 B$ ). At the lower range of $\mathrm{Al}$ concentrations the 1:1 response line falls within the 95-percent confidence limits indicating that these differences were not significant. Using the Wilcoxon Sign Rank test on paired data, the difference in the median response for $\mathrm{Al}$ between instruments 6 and 7 was not significant ( $p=0.212$; fig. $1 B$ ). Lead and Mo concentrations were higher when analyzed on instrument 6 than on instrument 7; both at the higher and lower concentration ranges (figs. C4 and $\mathrm{C5}$ ). The median response for $\mathrm{Pb}$ and $\mathrm{Mo}$ on instrument 6 were slightly higher than on instrument 7 ( $p<0.05$; fig. $1 B$ ). The response of Se on instrument 6 was considerably less than that on instrument 7; the slope was about -13.7 percent from the 1:1 line (fig. C6A). There was a 2 percent higher response for Se when $\mathrm{HCl}$ was added to filtered samples (see section, "Matrix Matching Filtered and Unfiltered Samples"); some of the apparent bias could be due to differences in matrices between the calibration standards and filtered samples. The NWQL suggests that due to some of the biases observed during analysis, the best analytical practice is to use calibration standards prepared in matrices that reasonably match the matrix of the samples being analyzed. The linear least square slope for the full range of $\mathrm{Zn}$ concentrations deviated from the 1:1 line by -9.2 percent; however, this relation was influenced by a high concentration value exceeding $800 \mu \mathrm{g} / \mathrm{L}$ (fig. C7A). At Zn concentrations less than $10 \mu \mathrm{g} / \mathrm{L}$, the regression line describing the relation between analytical results obtained from instruments 6 and 7 crosses the 1:1 line; the slope of the regression deviates from the 1:1 relation by -23.5 percent. Although the linear least square 
slope deviates substantially from that of the 1:1 line, the Wilcoxon Sign Rank test on paired data indicates that there is no statistical difference between the median $\mathrm{Zn}$ concentrations for samples analyzed on either instrument 6 or 7 ( $p=0.259$ ).

Within each experiment (original or new; table 2), the number of instances where trace-element concentrations were greater in filtered samples than in associated unfiltered samples were similar in unspiked and spiked samples for Mo and $\mathrm{Zn}$ (table 5). Spiking samples, and therefore increasing the sample concentration in the filtered and unfiltered samples, did not necessarily decrease the number of incidences where concentrations in filtered samples exceeded those in unfiltered samples and showed varied response depending on the trace element (table 5). The number of instances where concentrations in filtered samples exceeded those in associated unfiltered samples decreased when samples were analyzed on (1) the same instrumentation for $\mathrm{As}, \mathrm{Cd}, \mathrm{Se}$, and $\mathrm{Zn}$ and (2) different instrumentation for $\mathrm{Al}$ and Mo. The data suggests

Table 5. Trace-element concentrations in ambient and spiked paired filtered and unfiltered samples as determined during the original and new experiments.

[Concentrations less than the long-term method detection limit (LT-MDL) and samples spiked with less than 25 percent of the ambient concentration were excluded from data analysis. $\mathrm{C}_{\mathrm{F}}$ was considered markedly greater than that of the corresponding $\mathrm{C}_{\mathrm{UF}}$ if the relative difference between the concentrations exceeded 10 percent $\left(\mathrm{C}_{\mathrm{F}}>110\right.$ percent of $\left.\mathrm{C}_{\mathrm{UF}}\right)$. $\mathrm{C}_{\mathrm{F}}$, concentration in filtered sample; $\mathrm{C}_{\mathrm{UF}}$, concentration in unfiltered sample. Within experiment: $\mathrm{D}$, different; S, similar. Between experiments: (Tie), no difference between the original and new experimental results where $\mathrm{C}_{\mathrm{F}}>\mathrm{C}_{\mathrm{UF}} ;\left(\right.$ new), fewer instances of $\mathrm{C}_{\mathrm{F}}>\mathrm{C}_{\mathrm{UF}}$; (original), fewer instances of $\mathrm{C}_{\mathrm{F}}>\mathrm{C}_{\mathrm{UF}^{*}}>$, greater than]

\begin{tabular}{|c|c|c|c|c|c|c|c|}
\hline \multirow[t]{2}{*}{$\begin{array}{c}\text { Trace } \\
\text { element }\end{array}$} & \multirow[t]{2}{*}{ Experiment } & \multirow[t]{2}{*}{ Treatment } & \multirow{2}{*}{$\begin{array}{l}\text { Number of } \\
\text { samples } \\
\text { represented in } \\
\text { treatment }\end{array}$} & \multicolumn{2}{|c|}{$\begin{array}{l}\text { Instances of trace-element } \\
\text { concentrations in filtered } \\
\text { samples exceeding those in } \\
\text { associated unfiltered samples }\end{array}$} & \multicolumn{2}{|c|}{$\begin{array}{l}\text { Qualitative assessment of the } \\
\text { similarity between instances } \\
\text { where } C_{F}>C_{U F}\end{array}$} \\
\hline & & & & Number & Percent & $\begin{array}{c}\text { Within } \\
\text { experiment }\end{array}$ & $\begin{array}{c}\text { Between } \\
\text { experiments }\end{array}$ \\
\hline \multirow[t]{2}{*}{ Aluminum } & Original & $\begin{array}{l}\text { Unspiked } \\
\text { Spiked }\end{array}$ & $\begin{array}{l}24 \\
22\end{array}$ & $\begin{array}{l}0 \\
3\end{array}$ & $\begin{array}{r}0 \\
14\end{array}$ & $\mathrm{D}$ & \multirow{2}{*}{$\begin{array}{c}\mathrm{D} \\
\text { (Original) }\end{array}$} \\
\hline & New & $\begin{array}{l}\text { Unspiked } \\
\text { Spiked }\end{array}$ & $\begin{array}{l}24 \\
23\end{array}$ & $\begin{array}{l}0 \\
5\end{array}$ & $\begin{array}{r}0 \\
22\end{array}$ & $\mathrm{D}$ & \\
\hline \multirow[t]{2}{*}{ Arsenic } & Original & $\begin{array}{l}\text { Unspiked } \\
\text { Spiked }\end{array}$ & $\begin{array}{l}24 \\
24\end{array}$ & $\begin{array}{l}2 \\
6\end{array}$ & $\begin{array}{r}8 \\
25\end{array}$ & $\mathrm{D}$ & \multirow{2}{*}{$\begin{array}{c}\mathrm{D} \\
(\mathrm{New})\end{array}$} \\
\hline & New & $\begin{array}{l}\text { Unspiked } \\
\text { Spiked }\end{array}$ & $\begin{array}{l}24 \\
24\end{array}$ & $\begin{array}{l}1 \\
3\end{array}$ & $\begin{array}{r}4 \\
12 \\
\end{array}$ & $\mathrm{D}$ & \\
\hline \multirow[t]{2}{*}{ Cadmium } & Original & $\begin{array}{l}\text { Unspiked } \\
\text { Spiked }\end{array}$ & $\begin{array}{l}18 \\
24\end{array}$ & $\begin{array}{l}4 \\
7\end{array}$ & $\begin{array}{l}22 \\
29\end{array}$ & S & \multirow{2}{*}{$\begin{array}{c}\mathrm{D} \\
(\mathrm{New})\end{array}$} \\
\hline & New & $\begin{array}{l}\text { Unspiked } \\
\text { Spiked }\end{array}$ & $\begin{array}{l}22 \\
24\end{array}$ & $\begin{array}{l}2 \\
0\end{array}$ & $\begin{array}{l}9 \\
0\end{array}$ & $\mathrm{D}$ & \\
\hline \multirow[t]{2}{*}{ Lead } & Original & $\begin{array}{l}\text { Unspiked } \\
\text { Spiked }\end{array}$ & $\begin{array}{l}22 \\
24\end{array}$ & $\begin{array}{l}4 \\
1\end{array}$ & $\begin{array}{r}18 \\
4\end{array}$ & $\mathrm{D}$ & \multirow{2}{*}{$\begin{array}{c}\mathrm{S} \\
(\mathrm{Tie})\end{array}$} \\
\hline & New & $\begin{array}{l}\text { Unspiked } \\
\text { Spiked }\end{array}$ & $\begin{array}{l}21 \\
24\end{array}$ & $\begin{array}{l}1 \\
4\end{array}$ & $\begin{array}{r}5 \\
17\end{array}$ & $\mathrm{D}$ & \\
\hline \multirow[t]{2}{*}{ Molybdenum } & Original & $\begin{array}{l}\text { Unspiked } \\
\text { Spiked }\end{array}$ & $\begin{array}{l}24 \\
24\end{array}$ & $\begin{array}{l}1 \\
0\end{array}$ & $\begin{array}{l}4 \\
0\end{array}$ & $\mathrm{~S}$ & \multirow{2}{*}{$\begin{array}{c}\mathrm{D} \\
\text { (Original) }\end{array}$} \\
\hline & New & $\begin{array}{l}\text { Unspiked } \\
\text { Spiked }\end{array}$ & $\begin{array}{l}24 \\
24\end{array}$ & $\begin{array}{l}1 \\
1\end{array}$ & $\begin{array}{l}4 \\
4\end{array}$ & S & \\
\hline \multirow[t]{2}{*}{ Selenium } & Original & $\begin{array}{l}\text { Unspiked } \\
\text { Spiked }\end{array}$ & $\begin{array}{l}22 \\
24\end{array}$ & $\begin{array}{r}9 \\
21\end{array}$ & $\begin{array}{l}41 \\
87\end{array}$ & $\mathrm{D}$ & \multirow{2}{*}{$\begin{array}{c}\mathrm{D} \\
(\mathrm{New})\end{array}$} \\
\hline & New & $\begin{array}{l}\text { Unspiked } \\
\text { Spiked }\end{array}$ & $\begin{array}{l}23 \\
24\end{array}$ & $\begin{array}{l}1 \\
0\end{array}$ & $\begin{array}{l}4 \\
0\end{array}$ & S & \\
\hline \multirow[t]{2}{*}{ Zinc } & Original & $\begin{array}{l}\text { Unspiked } \\
\text { Spiked }\end{array}$ & $\begin{array}{l}24 \\
24\end{array}$ & $\begin{array}{l}8 \\
9\end{array}$ & $\begin{array}{l}33 \\
37\end{array}$ & S & \multirow{2}{*}{$\begin{array}{c}\mathrm{D} \\
(\mathrm{New})\end{array}$} \\
\hline & New & $\begin{array}{l}\text { Unspiked } \\
\text { Spiked }\end{array}$ & $\begin{array}{l}23 \\
24\end{array}$ & $\begin{array}{l}5 \\
6\end{array}$ & $\begin{array}{l}22 \\
25\end{array}$ & S & \\
\hline
\end{tabular}


that instrumentation had no influence on the analytical results for $\mathrm{Pb}$ (table 5). The assessment performed by the NWQL largely supported the findings of the Water-Quality Specialists, as described above (table 4); the exception was with $\mathrm{Pb}$ where the number of instances of $\mathrm{Pb}$ concentrations in filtered samples exceeded those in unfiltered samples decreased when samples (without the addition of $\mathrm{HCl}$ ) were analyzed on different instrumentation (table 4). Matrix matching and instrumentation appear to influence the analytical results for Se (fig. 1; tables 4 and 5).

\section{Spike Recoveries}

The spiking concentration of each respective trace element was targeted to be within 2-10 times the ambient concentration or greater than 10 times the LT-MDL, whichever was greater. In this study, the greater the spiking concentration relative to ambient concentrations, the greater the likelihood that spike recoveries fell within the acceptable data quality objective (DQO) range of 80 to 120 percent determined by the Quality Assurance Research Group (2010). There is greater variability in spike recovery results where the spiking concentration is less than 5 times the ambient concentration (fig. 2). Data in figure 2 were obtained from the new experiment results where ambient concentrations exceeded long-term method detection limits. Percent recoveries not shown in figure 2 are: $-2,049,-22,+256$, and +456 percent for aluminum in unfiltered samples (fig. 2B). The outlying recovery values for unfiltered aluminum were associated with samples that were spiked with equal to or less than 0.05 times the ambient aluminum concentration as determined in the associated ambient (unspiked) unfiltered sample.

In samples with ambient concentrations exceeding the LT-MDL, spiking concentrations ranged from less than 1 to 58 times ambient concentration (table 3). Based on the spike recovery data obtained from filtered and unfiltered samples analyzed on the same instrument (new experiment), the greater the magnitude of the spike concentration relative to the ambient concentration the more likely the recoveries fell within 80-120 percent (fig. 2), which is similar to previous research findings (Quality Assurance Research Group, 2010). Greater variability in spike recoveries occurred when trace elements were spiked at concentrations closer to the ambient concentration regardless of whether the samples were filtered or unfiltered (fig. 2). Given that the purpose of spiking samples is to determine the possible influence of the sample matrix on analytical results, the greater variability at spiking concentrations near ambient concentrations indicates the importance of spiking samples at concentrations reasonably close to what is expected in the sample (approximately 1 and 5 times ambient). There remains differing opinions regarding what is considered "reasonably close" to ambient sample concentration; however, the data collected as part of this investigation show that spiking at concentrations less than 10 times the ambient concentration should provide a reasonable evaluation of the possible influences of sample matrices on analytical results. For instances where concentrations of an analyte are near the LT-MDL, it becomes increasingly important to evaluate the potential for matrix effects on the determination of the concentration of the analyte in the sample.

During the original experiment, where filtered and unfiltered samples were analyzed on two different instruments, the median trace-element spike recoveries in filtered samples ranged from 90 to 114 percent; median recoveries in unfiltered samples ranged from 90 to 105 percent (table 3). During the new experiment, where the same instrument was used to analyze filtered and unfiltered samples, most spike recoveries for the filtered samples were statistically different from those observed during the original experiment (table 3). Spike recoveries for $\mathrm{Al}, \mathrm{Pb}$, and $\mathrm{Mo}$ in filtered samples were higher and $\mathrm{As}, \mathrm{Cd}$, and Se spike recoveries lower during the new experiment (instrument 6 ) compared to the original experiment (instrument 7) (table 3; $p \leq 0.009$ ). The exception was for $\mathrm{Zn}$, where median spike recoveries in filtered samples were not statistically different between experiments ( $p=0.392$; table 3 ). With the exception of median spiked recoveries in unfiltered samples for As and Mo, median spike recoveries in unfiltered samples were similar between the two experiments ( $p \geq 0.093$; table 3). Median As (97 versus 99 percent) and Mo (105 versus 110 percent) spike recoveries in unfiltered samples were higher during the new experiment than the original experiment $(p \leq 0.006)$; despite being analyzed on the same instrument during both experiments. Although some spike recoveries varied depending on instrumentation, all median recoveries were within the data-quality objective for spike recovery ( \pm 20 percent) during both experiments.

Individual spike recovery results for $\mathrm{Al}$ in unfiltered samples that fell outside the data-quality objective during the original $(n=7)$ and new $(n=9)$ experiments were the result of low spiking concentrations relative to the ambient concentration in the sample and possible matrix influences on analytical results. Matrix effects were not ruled out for the $\mathrm{Al}$ analyses because of the magnitude of spike recovery results (table 3; fig. 2B). During the original experiment, unfiltered samples where $\mathrm{Zn}$ concentrations exceeded the LT-MDL were spiked with $\mathrm{Zn}$ ranging from 0.6 to 4 times ambient concentrations. There were five instances where spike recoveries for $\mathrm{Zn}$ in unfiltered samples fell outside the data-quality objective; spike recoveries ranged from 71 to 78 percent $(n=4)$ and 125 percent $(n=1)$. The spike recovery results for $\mathrm{Zn}$ in unfiltered samples improved during the new experiment with only three results falling outside the data-quality objective indicating possible influences of instrumentation and matrix on the analytical results. Other noted instances where spike recoveries in filtered samples fell outside data-quality objectives occurred in one to two samples for $\mathrm{Al}, \mathrm{Pb}, \mathrm{Mo}, \mathrm{Se}$, and $\mathrm{Zn}$; there were one to two instances in unfiltered samples for $\mathrm{As}, \mathrm{Pb}$, and $\mathrm{Se}$ (fig. 2). 

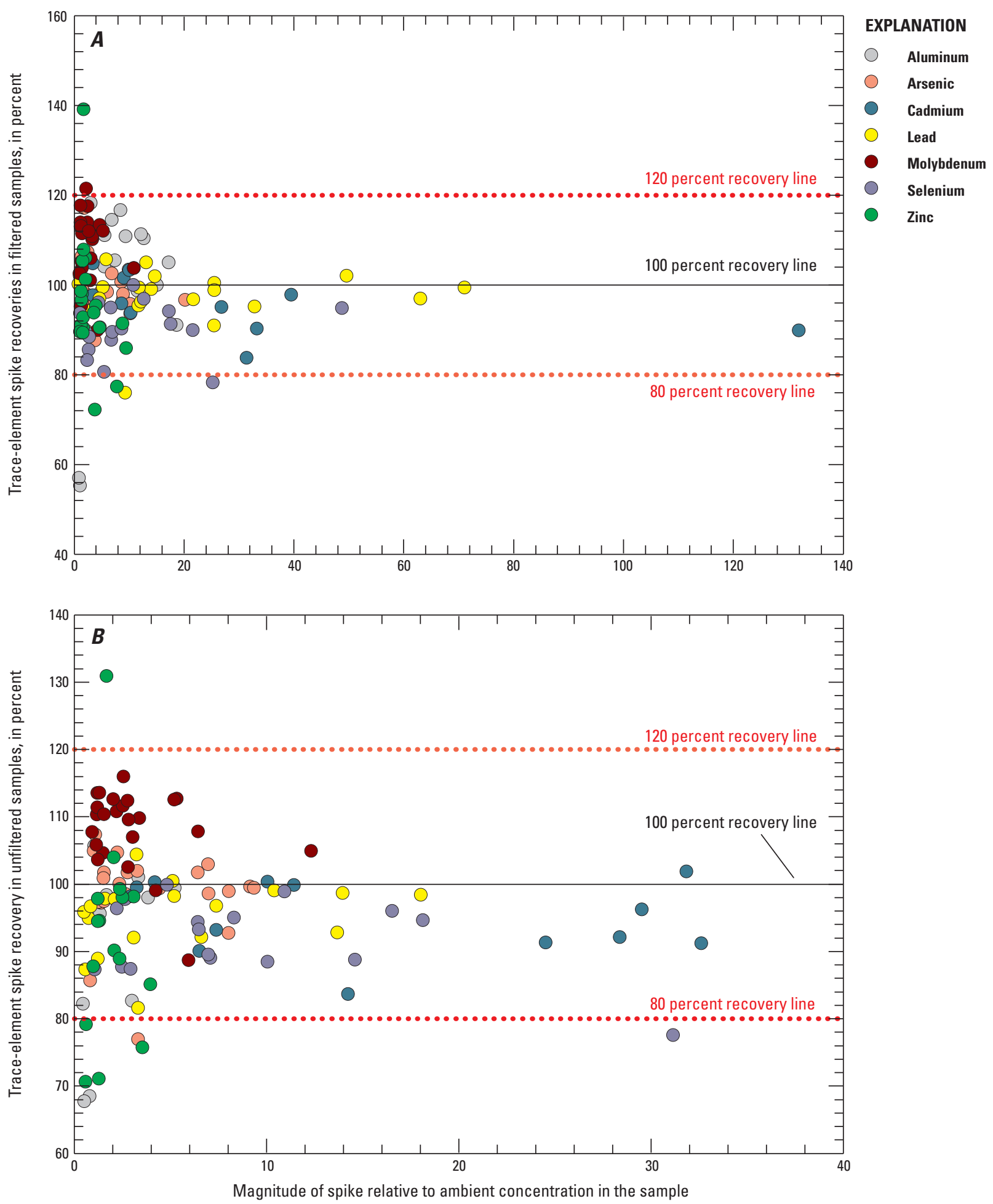

Figure 2. Spike recoveries for trace elements in $(A)$ filtered and $(B)$ unfiltered samples with respect to the magnitude of the trace-element spiking concentration relative to the ambient concentration in the sample. 
Within the same experiment (original and new, respectively), trace-element spike recoveries were evaluated between filtered and unfiltered samples (table 3). Median $\mathrm{As}, \mathrm{Cd}, \mathrm{Se}$, and $\mathrm{Zn}$ recoveries were lower in unfiltered than in filtered samples when samples were analyzed on different instruments (table $3 ; p \leq 0.003$ ); the opposite was true for Mo spike recoveries where unfiltered spike recoveries were higher than filtered recoveries when analyzed on different instruments $(p=0.016)$. Aluminum and $\mathrm{Pb}$ spike recoveries were similar between filtered and unfiltered samples when analyzed on different instruments (table $3 ; p \geq 0.093$ ). When trace elements were analyzed on the same instrument, there were no statistical differences between spike recoveries between filtered and unfiltered samples ( $p \geq 0.071$; table 3$)$. On the whole, analyzing filtered and unfiltered samples on the same instrument improved overall significant differences in median spiked recovery results between filtered and unfiltered samples for the trace elements evaluated.
The evaluation of spike recovery results by the NWQL provided different ranges in recoveries than that performed by the Water Quality Specialists; however, the conclusions were fairly similar between the two assessments. The NWQL examined spike recovery results for filtered and unfiltered samples analyzed on different instruments (original) and determined that the spike recoveries for all trace elements determined in the filtered samples ranged from 91 to 113 whereas unfiltered samples ranged from 89 to 104 (table 6). Overall, the spike recoveries for the filtered and unfiltered samples are not considered to be significantly different. Selected percentages that fell outside the 90 to 100 percent range were due to either relatively low spike levels or to spike concentrations that were significantly lower than the elemental concentrations originally present in the sample.

Table 6. Percent matrix spike recoveries for trace elements in filtered and unfiltered sample pairs.

[Filtered and unfiltered samples were analyzed on different instrumentation (original experiment)]

\begin{tabular}{llccrc}
\hline $\begin{array}{c}\text { Trace } \\
\text { element }\end{array}$ & Sample & $\begin{array}{c}\text { Average } \\
\text { ( } \begin{array}{c}\text { standard } \\
\text { deviation) }\end{array}\end{array}$ & Minimum & Median & Maximum \\
\hline Aluminum (Al) & Filtered & $91 \pm 7$ & 76 & 90 & 105 \\
& Unfiltered & $61 \pm 314$ & 64 & 98 & 156 \\
\hline Arsenic (As) & Filtered & $102 \pm 5$ & 88 & 101 & 111 \\
& Unfiltered & $95 \pm 7$ & 75 & 97 & 108 \\
\hline Cadmium (Cd) & Filtered & $103 \pm 7$ & 88 & 102 & 124 \\
& Unfiltered & $95 \pm 5$ & 82 & 95 & 105 \\
\hline Lead (Pb) & Filtered & $92 \pm 4$ & 82 & 92 & 100 \\
& Unfiltered & $93 \pm 9$ & 63 & 95 & 111 \\
\hline Molybdenum (Mo) & Filtered & $100 \pm 7$ & 83 & 101 & 110 \\
& Unfiltered & $104 \pm 6$ & 85 & 105 & 112 \\
\hline Selenium (Se) & Filtered & $113 \pm 7$ & 99 & 114 & 128 \\
& Unfiltered & $92 \pm 7$ & 78 & 93 & 105 \\
\hline Zinc (Zn) & Filtered & $97 \pm 11$ & 70 & 96 & 132 \\
& Unfiltered & $89 \pm 11$ & 71 & 89 & 125 \\
\hline
\end{tabular}




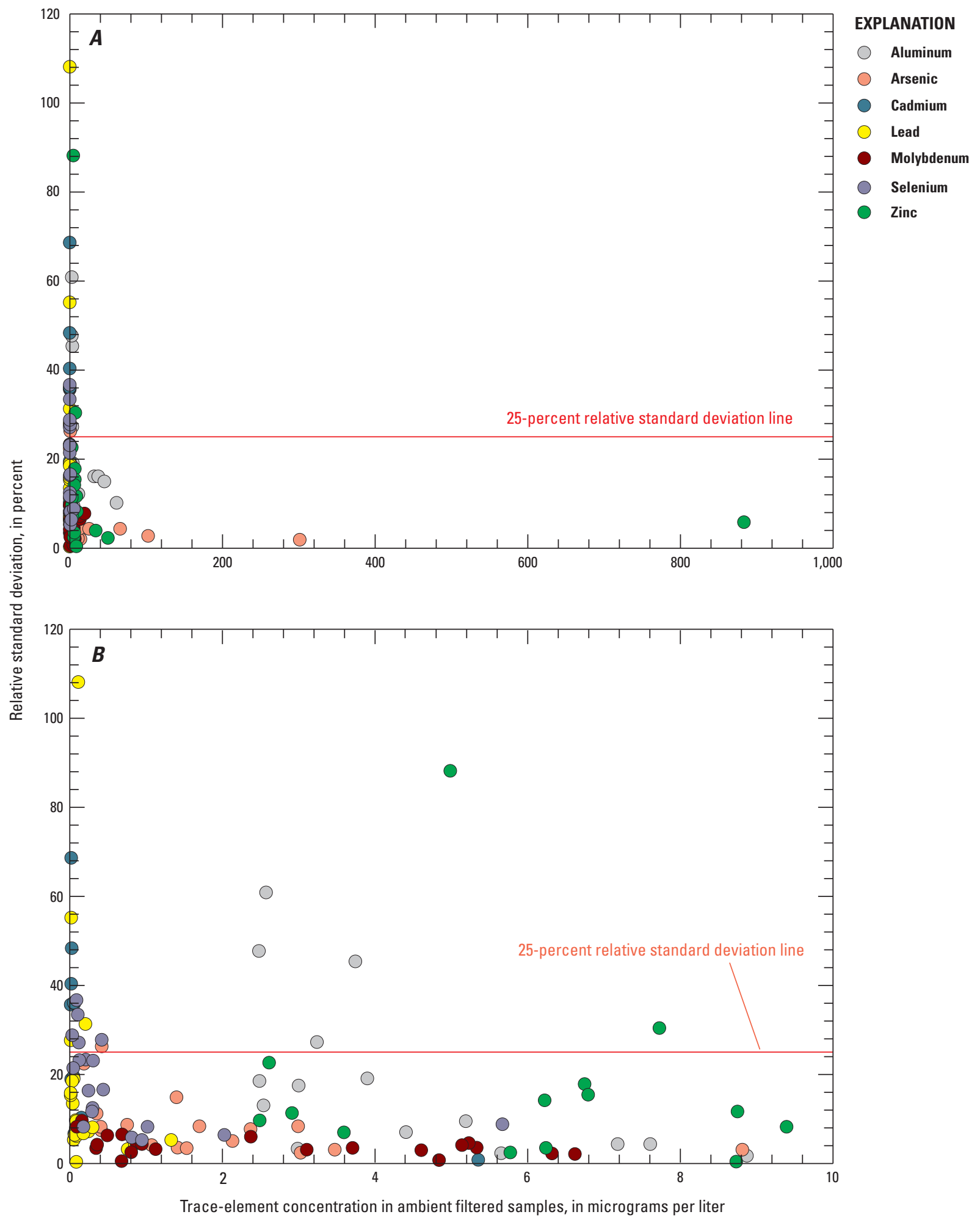

Figure 3. Percent relative standard deviation (RSD) among analyses for each trace element in ambient filtered samples where concentrations exceeded LT-MDLs for $(A)$ full range of concentrations and $(B)$ for concentrations less than 10 micrograms per liter. 


\section{Analytical Precision}

Analytical precision was determined by evaluating the percent relative difference $(\% \mathrm{RD})$ between and relative standard deviation (\%RSD) among replicate analytical measurements. The \%RSD was used for filtered samples as there were more than two analytical measurements. The original, new, and matrix-matched analyses were evaluated together as previous interpretation showed that there was generally no effect from the addition of $\mathrm{HCl}$ to the filtered analytical results. The $\% \mathrm{RD}$ was used to evaluate unfiltered results as there were only two analytical results to compare.

Analytical precision for ambient filtered trace-element concentrations greater than $10 \mu \mathrm{g} / \mathrm{L}$ were within the dataquality objective for precision of $\pm 25 \% \mathrm{RSD}$ (Quality Assurance Research Group, 2010). The summary of filtered results presented in figure 3 included analyses performed on different instrumentation, same instrumentation, and for samples that were matrix matched with $\mathrm{HCl}$ (dilution corrected value). Targeted re-run analyses were not included in the data presented. Samples were considered relative to the LT-MDL provided by the NWQL (http://wwwnwql.cr.usgs. gov/USGS/, accessed April 2014). Molybdenum analyses always demonstrated acceptable analytical precision (fig. 3). The analytical precision for filtered ambient analyses for $\mathrm{Al}$, $\mathrm{As}, \mathrm{Cd}, \mathrm{Se}$, and $\mathrm{Zn}$ concentrations occasionally failed to meet the data quality control objective (fig. 3; table 7). The DQO was not met for at least one trace-element analysis in about 54 percent of filtered samples (ambient) analyzed where trace-element concentrations exceeded the respective LT-MDL but were less than $10 \mu \mathrm{g} / \mathrm{L}$. In the few instances where samples were targeted for re-analysis for these trace elements, precision improved upon re-analysis (table 7).

Analytical precision for all ambient unfiltered traceelement concentrations greater than $40 \mu \mathrm{g} / \mathrm{L}$ were within the data quality control limit of $\pm 25 \% \mathrm{RD}$ (Quality Assurance Research Group, 2010). The precision of ambient unfiltered As, Cd, and Mo concentrations was always within $\pm 25 \% \mathrm{RD}$, even at concentrations less than $10 \mu \mathrm{g} / \mathrm{L}$. At concentrations less than $40 \mu \mathrm{g} / \mathrm{L}$, there were 19 instances where analytical precision fell outside the data-quality objective collectively for $\mathrm{Al}, \mathrm{Pb}, \mathrm{Se}$, and $\mathrm{Zn}$ (fig. 4; table 7). Targeted re-run analyses were not included in the data presented in figure 4. Samples were considered relative to the LT-MDL provided by the NWQL (http://wwwnwql.cr.usgs.gov/USGS/, accessed April 2014). The DQO was not met for at least one trace-element analysis in about 58 percent of ambient unfiltered samples analyzed where trace-element concentrations exceeded LT-MDL values. In the few instances where samples were targeted for re-analysis for these trace elements, precision improved upon re-analysis (table 7).

Generally, there were very few instances where spiked samples had repeated measurements failing to meet the dataquality control objective for precision of $\pm 25 \% \mathrm{RD}$ or $\% \mathrm{RSD}$ (figs. 5 and 6).

All spiked samples represented in figures 5 and 6 had trace-element concentrations exceeding their respective LT-MDLs. Filtered analyses shown in figure 5 included those performed on instruments 6 and 7; and for samples that were matrix matched with $\mathrm{HCl}$ (dilution corrected value). Targeted re-run analyses were not included in the data presented in either figures 5 or 6 . The two spiked filtered $\mathrm{Zn}$ concentrations exceeding $25 \%$ RSD occurred because one result was likely associated with a possible typographical error (decimal point misplacement); the other represents a sample treated with $\mathrm{HCl}$, which may have slightly influenced the result $(\% \mathrm{RSD}=28.9$; fig. 5). Subsequent re-analysis of the possible typographical error resulted in concentrations similar to the other analytical results for $\mathrm{Zn}$ and an improved \%RSD value of 5; the other sample was not re-analyzed for $\mathrm{Zn}$ (table 7). The grouping observed in the spiked concentrations at concentrations less than $50 \mu \mathrm{g} / \mathrm{L}$ is likely an artifact of the relatively high spiking concentration to the ambient concentration in the samples. Unfiltered samples were not corrected for dilution resulting from the use of $\mathrm{HCl}$ during the in-bottle digestion procedure (figs. 5 and 6).

All but one of the relative differences in spiked traceelement analytical results for unfiltered samples were within the data quality control limit of 25 percent (fig. 6). Similar to spiked filtered samples, the grouping observed in spiked concentrations less than $100 \mu \mathrm{g} / \mathrm{L}$ is likely due to the lower ambient sample concentrations for these trace elements relative to the concentration used to spike the sample (fig. 6; table 3). 
Table 7. Assessment of analytical precision of ambient and spiked trace-element concentrations in filtered and unfiltered samples.

[Samples where ambient concentrations were less than the LT-MDL (long-tern method detection limit) for the trace element were not included in this evaluation. LT-MDLs used were those available for the designated laboratory code (http://wwwnwql.cr.usgs.gov/USGS/, accessed April 2014). Average ambient concentration: Initial average concentration before re-analysis. Before and after targeted re-analysis: Difference between initial and final percent relative difference and percent relative standard deviation is the manner in which these metrics were evaluated. $\mu \mathrm{g} / \mathrm{L}$, microgram per liter]

\begin{tabular}{|c|c|c|c|c|c|c|}
\hline \multirow[b]{2}{*}{$\begin{array}{c}\text { Trace } \\
\text { element }\end{array}$} & \multirow[b]{2}{*}{ Sample } & \multirow[b]{2}{*}{$\begin{array}{c}\text { Average ambient } \\
\text { concentration } \\
(\mu \mathrm{g} / \mathrm{L})\end{array}$} & \multicolumn{2}{|c|}{ Before targeted re-analysis } & \multicolumn{2}{|c|}{ After targeted re-analysis } \\
\hline & & & $\begin{array}{c}\text { Relative } \\
\text { difference } \\
\text { (percent) }\end{array}$ & $\begin{array}{l}\text { Relative } \\
\text { standard } \\
\text { deviation } \\
\text { (percent) }\end{array}$ & $\begin{array}{l}\text { Relative } \\
\text { difference } \\
\text { (percent) }\end{array}$ & $\begin{array}{l}\text { Relative } \\
\text { standard } \\
\text { deviation } \\
\text { (percent) }\end{array}$ \\
\hline \multicolumn{7}{|c|}{ Ambient samples } \\
\hline \multirow[t]{14}{*}{ Aluminum } & \multirow[t]{5}{*}{ Filtered } & 3.2 & - & 27 & - & 7 \\
\hline & & 2.1 & - & 27 & \multicolumn{2}{|c|}{ Not performed } \\
\hline & & 2.6 & - & 61 & - & 14 \\
\hline & & 3.7 & - & 45 & - & 26 \\
\hline & & 2.5 & - & 48 & - & 23 \\
\hline & \multirow[t]{9}{*}{ Unfiltered } & 6.6 & 110 & - & 8 & - \\
\hline & & 12.6 & 45 & - & 5 & - \\
\hline & & 33.3 & 26 & - & 6 & - \\
\hline & & 4.8 & 113 & - & 3 & - \\
\hline & & 7.0 & 125 & - & 10 & - \\
\hline & & 4.0 & 35 & - & \multicolumn{2}{|c|}{ Not performed } \\
\hline & & 6.5 & 134 & - & 17 & - \\
\hline & & 8.4 & 128 & - & 13 & - \\
\hline & & 6.4 & 146 & - & 16 & - \\
\hline Arsenic & Filtered & 0.42 & - & 26 & \multicolumn{2}{|c|}{ Not performed } \\
\hline \multirow[t]{2}{*}{ Cadmium } & \multirow[t]{2}{*}{ Filtered } & 0.06 & - & 36 & \multirow{2}{*}{\multicolumn{2}{|c|}{ Not performed }} \\
\hline & & 0.05 & - & 36 & & \\
\hline \multirow[t]{5}{*}{ Lead } & \multirow[t]{2}{*}{ Filtered } & 0.11 & - & 108 & \multirow{2}{*}{\multicolumn{2}{|c|}{ Not performed }} \\
\hline & & 0.21 & - & 31 & & \\
\hline & \multirow[t]{3}{*}{ Unfiltered } & 0.08 & 46 & - & \multirow{3}{*}{\multicolumn{2}{|c|}{ Not performed }} \\
\hline & & 0.10 & 32 & - & & \\
\hline & & 0.06 & 30 & - & & \\
\hline \multirow[t]{5}{*}{ Selenium } & \multirow[t]{4}{*}{ Filtered } & 0.09 & - & 37 & \multicolumn{2}{|c|}{ Not performed } \\
\hline & & 0.12 & - & 27 & - & 11 \\
\hline & & 0.11 & - & 33 & \multirow{2}{*}{\multicolumn{2}{|c|}{ Not performed }} \\
\hline & & 0.42 & - & 28 & & \\
\hline & Unfiltered & 0.26 & 32 & - & Not $p$ & med \\
\hline Zinc & Filtered & 7.7 & - & 30 & Not 1 & med \\
\hline & Unfiltered & 3.3 & 29 & - & Not 1 & med \\
\hline & & 3.2 & 98 & - & 14 & - \\
\hline & & 2.3 & 36 & - & Not $\mathrm{p}$ & med \\
\hline & & 5.2 & 35 & - & 15 & - \\
\hline & & 7.6 & 49 & - & 27 & - \\
\hline & & 2.2 & 33 & - & Not 1 & med \\
\hline & & & iked sample & & & \\
\hline Aluminum & Unfiltered & 62.5 & 28 & - & - & 6 \\
\hline & & 1.2 & - & 27 & - & 3 \\
\hline Lead & Filtered & 1.8 & - & 57 & - & 7 \\
\hline Zinc & Filtered & 18.0 & - & 51 & - & 5 \\
\hline & & 18.7 & - & 29 & Not 1 & med \\
\hline
\end{tabular}




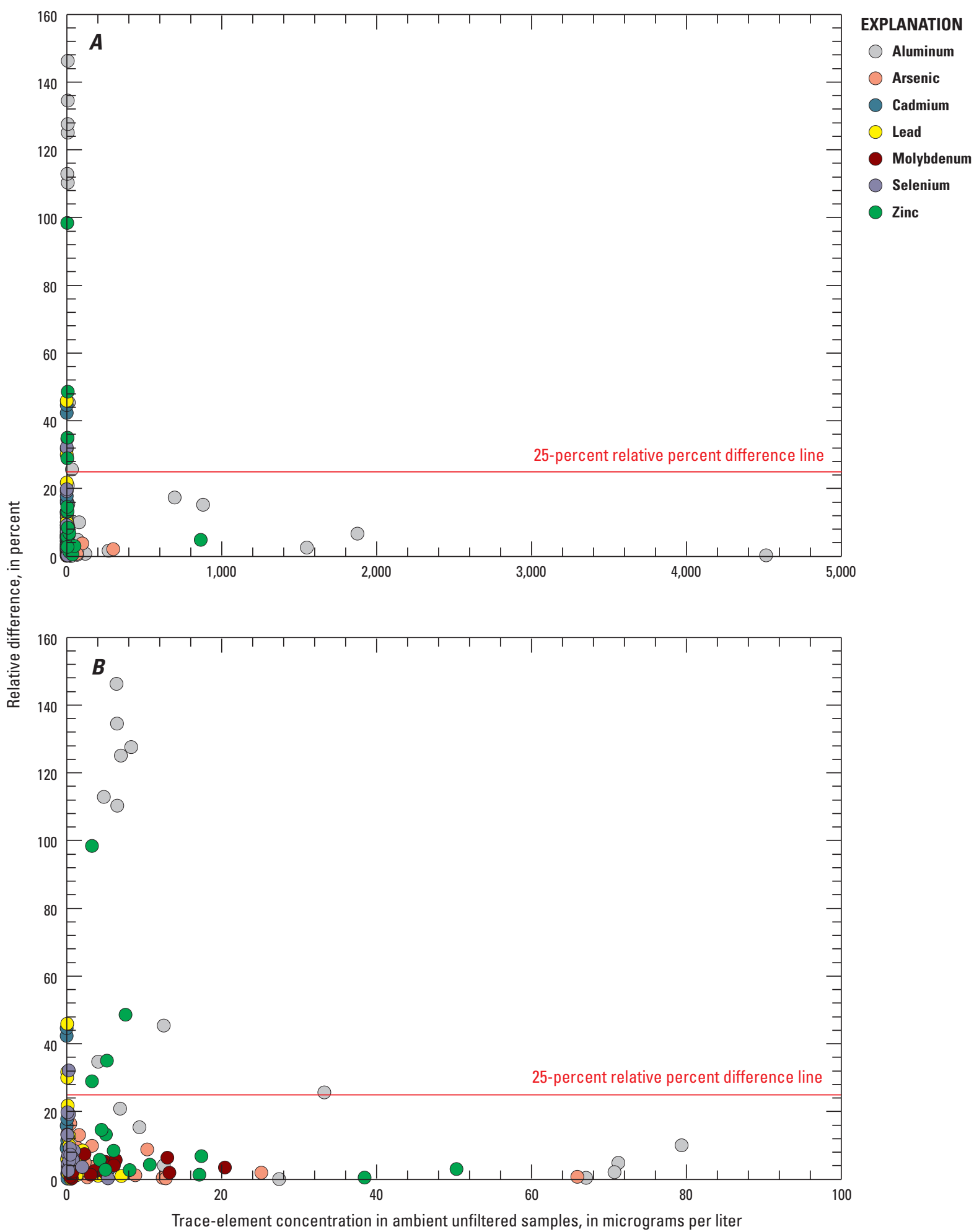

Figure 4. Percent relative difference (RD) between analyses for each trace element in ambient unfiltered samples where concentrations exceeded LT-MDLs for $(A)$ full range of concentrations and $(B)$ for concentrations less than 80 micrograms per liter. Unfiltered samples were not corrected for dilution resulting from the use of hydrochloric acid during the in-bottle digestion procedure. 


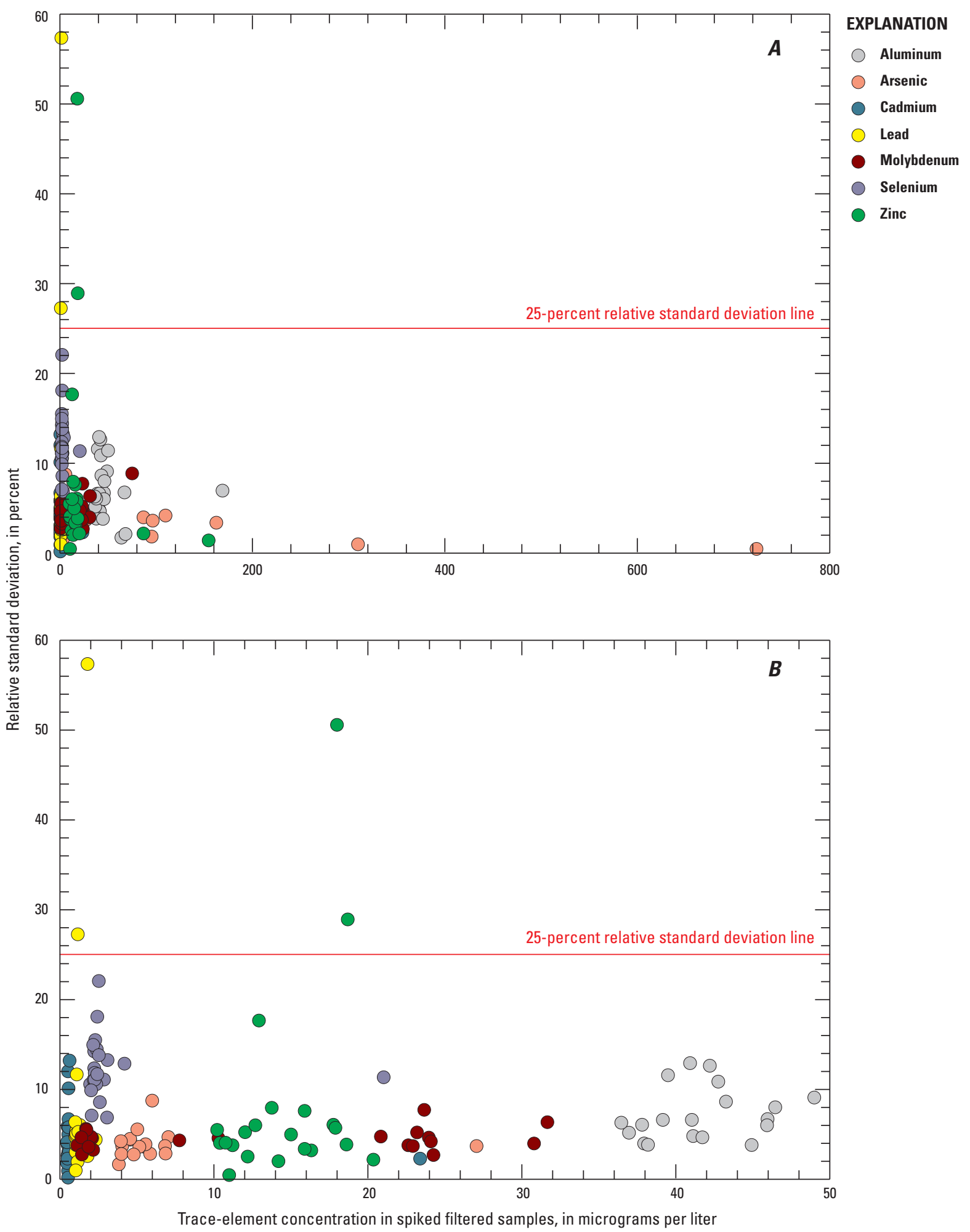

Figure 5. Percent relative standard deviation (RSD) between analyses for each trace element in spiked filtered samples for $(A)$ full range of concentrations and $(B)$ for concentrations less than 50 micrograms per liter. 


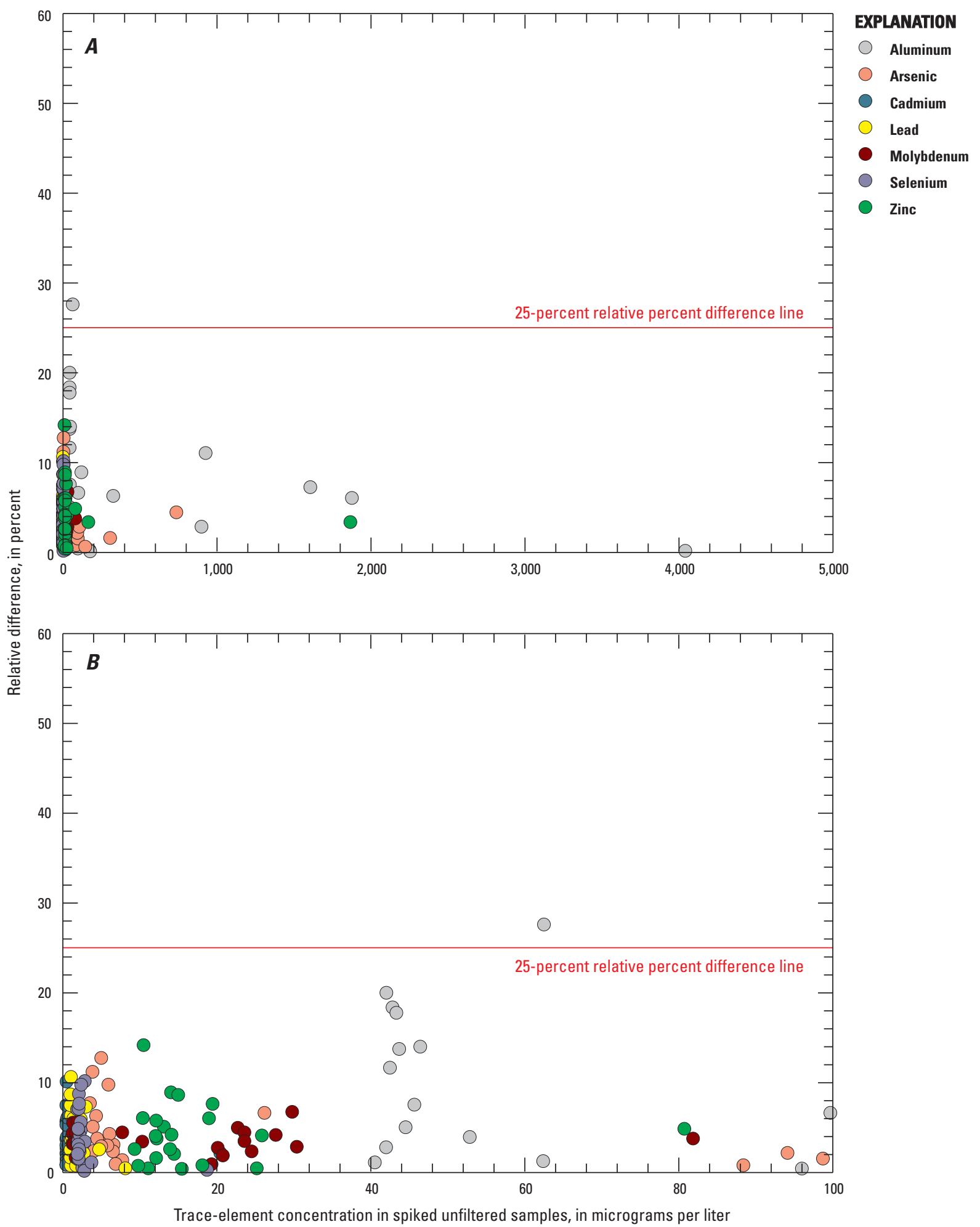

Figure 6. Percent relative difference (RD) between analyses for each trace element in spiked unfiltered samples for $(A)$ full range of concentrations and $(B)$ for concentrations less than 100 micrograms per liter. 


\section{Standard Reference Materials}

The SRMs are filtered aqueous-phase solutions that contain no suspended sediment. Natural-water samples that have suspended sediment may be affected by the digestion procedure because of trace element loss from their re-adsorption onto sediment particles that are subsequently removed by filtration. Hoffman and others (1996) determined that there was 80-100 percent recovery of $\mathrm{Cd}, \mathrm{Pb}$, and $\mathrm{Zn}$ in freshwater sediment during the in-bottle digestion procedure. The NWQL evaluated the influence of the in-bottle digestion procedure on the SRMs by comparing digested and undigested concentrations from analyses performed on instrument 6 . The data suggest that the in-bottle digestion procedure does not substantially affect trace-element results (table 8). Concentrations that differed from SRM certified values (CV) appeared to differ by approximately the same amount and in the same direction in both SRM samples that were subjected to the digestion procedure and in those that were not. The results of this investigation indicate that As, $\mathrm{Cd}$, Se, and $\mathrm{Zn}$ determinations may be somewhat negatively biased (Supplemental Information D; figs. D2, D3, D6, D7). Although As, Cd, and for the most part $\mathrm{Zn}$ show a low bias, the bias largely is within 25 percent of the certified value (CV). Selenium analyses for both the NIST and NMIJ SRM materials show distinctive negative analytical bias where data are lower than 25 percent of the CVs (fig. D6). The only Se analytical result that was within 10 percent of the CV for both SRMs were from analyses on instrument 7 . Aluminum shows evidence of high analytical bias for NIST analyses, the high bias is within 10 percent of the $\mathrm{CV}$; the NMIJ analyses are within 25 percent of the CV (fig. D1). NIST SRM analyses for Mo do not show a distinct bias; however, Mo concentrations determined from NMIJ SRM analyses are biased high and some data are greater than 25 percent of the CV (fig. D5); lead shows no appreciable bias (fig. D4).

Table 8. Comparison of trace-element concentrations in digested and undigested standard reference materials.

[Digested: Samples were processed using a modified in-bottle digestion procedure (Hoffman and others, 1996). NIST, National Institute of Standards and Technology; NMIJ, National Metrology Institute of Japan; SRM, standard reference material; $\mu \mathrm{g} / \mathrm{L}$, microgram per liter; \%RD, percent relative difference; \%RSD, percent relative standard deviation]

\begin{tabular}{|c|c|c|c|c|c|c|}
\hline $\begin{array}{l}\text { Element } \\
\text { SRM }\end{array}$ & & $\begin{array}{c}\text { Certified } \\
\text { value } \\
\text { ( } \mu \mathrm{g} / \mathrm{L})\end{array}$ & $\begin{array}{c}\text { Undigested } \\
\text { ( } \mu \mathrm{g} / \mathrm{L})\end{array}$ & $\begin{array}{l}\text { Precision } \\
\text { undigested } \\
\text { samples } \\
\text { (\%RSD) }\end{array}$ & $\begin{array}{c}\text { Digested } \\
(\mu \mathrm{g} / \mathrm{L})\end{array}$ & $\begin{array}{c}\text { Precision } \\
\text { digested } \\
\text { samples } \\
\text { (\%RD) }\end{array}$ \\
\hline \multirow[t]{2}{*}{ Aluminum (Al) } & NIST & 53.0 & 55.0 & 4.8 & 56.6 & 1.8 \\
\hline & NMIJ & 17.2 & 18.6 & 5.7 & 20.0 & 7.4 \\
\hline \multirow[t]{2}{*}{ Arsenic (As) } & NIST & 8.075 & 7.3 & 6.7 & 6.7 & 3.7 \\
\hline & NMIJ & 1.11 & 0.9 & 10.8 & 1.0 & 15.0 \\
\hline \multirow[t]{2}{*}{ Cadmium (Cd) } & NIST & 3.992 & 3.6 & 4.8 & 3.5 & 1.8 \\
\hline & NMIJ & 0.99 & 0.87 & 3.9 & 0.85 & 2.6 \\
\hline \multirow[t]{2}{*}{ Lead $(\mathrm{Pb})$} & NIST & 12.101 & 11.8 & 5.0 & 11.7 & 9.9 \\
\hline & NMIJ & 1.013 & 1.01 & 6.2 & 1.01 & 5.8 \\
\hline \multirow[t]{2}{*}{ Molybdenum (Mo) } & NIST & 45.60 & 45.0 & 5.2 & 45.6 & 3.9 \\
\hline & NMIJ & 0.186 & 0.19 & 7.3 & 0.21 & 13.4 \\
\hline \multirow[t]{2}{*}{ Selenium (Se) } & NIST & 20.13 & 16.0 & 14.6 & 14.6 & 5.9 \\
\hline & NMIJ & 1.01 & 0.73 & 17.9 & 0.67 & 7.9 \\
\hline \multirow[t]{2}{*}{ Zinc (Zn) } & NIST & 55.64 & 49.1 & 6.6 & 45.0 & 6.7 \\
\hline & NMIJ & 9.94 & 8.4 & 6.1 & 7.8 & 15.2 \\
\hline
\end{tabular}




\section{Findings for Each Selected Trace Element}

\author{
Aluminum.-Analyses of SRMs showed that Al
} analyses were biased high on average by about 6-13 percent and the greater bias was associated with the NMIJ SRM analytical results (fig. D1). There was a considerable issue with precision regarding analyses of unfiltered samples where 33 percent of the samples fell outside the acceptable limit for precision with relative differences (RD) ranging from 26 to 146 percent (table 7). Re-analyses of these unfiltered samples generally improved the overall precision of replicate analyses. For the full range of $\mathrm{Al}$ concentrations evaluated during this study, the analytical response of $\mathrm{Al}$ was almost 29 percent higher on instrument 6 than on instrument 7 (fig. C1). Over the entire range of $\mathrm{Al}$ concentrations studied, the addition of $\mathrm{HCl}$ to filtered samples decreased the $\mathrm{Al}$ signal by only about 1.2 percent (fig. B1). Recoveries in spiked filtered samples were lower on instrument 7 than on instrument 6 (Supplemental Information E, fig. E1). Median $\mathrm{Al}$ recoveries in spiked filtered samples were significantly higher $(p<0.001)$ when samples were analyzed on instrument 6 (new experiment) than on instrument 7 (original experiment). There were no statistical differences between median Al spike recoveries in filtered and unfiltered samples when analyzed on either instrument 6 or 7 during either the original $(p=0.177)$ or new ( $p=0.317)$ experiments (table 3$)$. Analyses of unfiltered samples show higher variability in recoveries at higher concentrations (fig. E1). There was no statistical difference in median $\mathrm{Al}$ spike recoveries in unfiltered samples during either experiment-new or original $(p=0.158)$. Generally, the results of analyzing samples on different instruments without matrix matching filtered to unfiltered samples showed a decreased incidence of $\mathrm{Al}$ concentrations in filtered samples exceeding those in unfiltered samples; the same observation was made when $\mathrm{HCl}$ was added to filtered samples and analysis was done on the same instrument (tables 4 and 5).

Arsenic.-Arsenic recoveries showed slight low bias as evidenced by SRM analyses but analytical results were largely within control limits for this trace element. Arsenic was biased low on average during the analyses of both SRM samples by about 12 to 14 percent (fig. D2). Spiked concentrations of As in filtered samples showed slightly higher recoveries ( $p=0.009$; table 3 ) when analyzed on instrument 7 than on instrument 6 . Arsenic recoveries for spiked unfiltered samples were higher $(p=0.006)$ during the new experiment than the original experiment; however, the range of recoveries was similar between the two experiments (table 3; fig. E2). Because unfiltered samples were analyzed on the same instrument during both experiments, instrument differences were not a contributing factor. Generally, analytical precision for As in both filtered and unfiltered samples was within the DQO of \pm 25 percent (figs. 3 and 4). The median spike recovery for As was statistically higher in filtered samples than in unfiltered samples when samples were analyzed on different instruments ( $p<0.001$; table 3 ); there was no difference in median spike recoveries of As in filtered and unfiltered samples when samples were analyzed on the same instrument ( $p=0.140$; table 3 ). With only two exceptions, the results for As spike recoveries in filtered and unfiltered samples were within acceptable limits (80-120 percent; figs. 2 and E2).The use of $\mathrm{HCl}$ to matrix-match filtered to unfiltered samples was associated with a 1.2 percent decrease in signal for As when evaluated for the entire range of As concentrations studied indicating that matrix-matching for the analysis of As to match unfiltered samples is unnecessary. The number of instances where As concentrations were greater in filtered samples than in associated unfiltered samples was lower when samples were analyzed on the same instrument.

Cadmium.-Analyses of SRMs showed that $\mathrm{Cd}$ analyses were biased low on average by about 9-13 percent (fig. D3). Concentrations of $\mathrm{Cd}$ were low in filtered and unfiltered samples and analytical precision and spike recovery results were largely within DQO's for precision and recovery. With one exception during the original experiment (filtered sample on instrument 7), spike recovery results for filtered and unfiltered samples were within 80-100 percent (figs. 2 and E3). Spike recoveries for $\mathrm{Cd}$ were greater in filtered samples when analyzed on instrument 7 than on instrument 6 (fig. E3; $p<0.001$; table 3). When filtered and unfiltered samples were analyzed on different instruments, spike recovery for $\mathrm{Cd}$ was statistically lower in unfiltered samples than in filtered samples $(p<0.001$; table 3). There were no statistical differences in median $\mathrm{Cd}$ spike recovery in filtered and unfiltered samples when they were analyzed on the same instrument ( $p=0.703)$. There were two instances where analytical precision for $\mathrm{Cd}$ concentrations in filtered samples were outside the DQO of $\pm 25 \%$ RSD. In both cases, Cd concentrations were higher when analyzed on instrument 7 than on instrument 6 . Results for analytical precision between the measurements of $\mathrm{Cd}$ concentration in unfiltered samples were always within \pm 25 percent. These results might suggest a lower sensitivity to $\mathrm{Cd}$ when samples are analyzed on instrument 6; however, there was essentially no influence of instrumentation on $\mathrm{Cd}$ analyses (fig. C3). Matrix matching the filtered to unfiltered samples did not influence the analytical results for $\mathrm{Cd}$ (figs. 1A and B3). Cadmium concentrations were very low in the unspiked filtered and unfiltered samples evaluated as part of this investigation (fig. 1). The LT-MDL for filtered and unfiltered samples was $0.03 \mu \mathrm{g} / \mathrm{L}$ and more than one-half of the filtered and unfiltered Cd concentrations neared this value. Analyses of filtered and unfiltered samples for $\mathrm{Cd}$ on the same instrument decreased the number of instances where concentrations in filtered samples exceeded those in associated unfiltered samples from 4 of 18 pairs (original experiment) to 2 of 22 pairs (new experiment) (table 5). Similarly, the number of instances in which the recoveries were greater in the filtered samples than in unfiltered samples decreased from 7 of 24 pairs (original experiment) to 0 of 24 pairs (new experiment) (table 5). 
Lead.-Analyses of SRMs showed essentially no analytical bias for $\mathrm{Pb}$ (fig. D4). Lead spike recoveries show evidence of low bias, irrespective of which instrumentation was used; however, most of the analytical results were within the DQO for spike recovery (80-100 percent; figs. 2 and $\mathrm{E} 4)$. Median $\mathrm{Pb}$ spike recovery was higher in filtered samples analyzed on instrument 6 (new experiment) than on instrument 7 (original experiment; $p<0.001$; table 3); there was no statistical difference in spike recoveries in unfiltered samples between the two experiments ( $p=0.093)$. There were no statistical differences between $\mathrm{Pb}$ spike recoveries in filtered and unfiltered samples during either new or original experiments ( $p=0.093$; table 3 ). Lead generally showed a higher response when analyzed on instrument 6 than on instrument 7 (figs. $1 B$ and C4). There was no effect of adding $\mathrm{HCl}$ to filtered samples to matrix match these samples to unfiltered samples (figs. $1 \mathrm{~A}$ and $\mathrm{B} 4$ ). The addition of $\mathrm{HCl}$ decreased the number of instances where $\mathrm{Pb}$ concentrations were higher in filtered samples than in associated unfiltered samples when samples were analyzed on instrument 6 (table 4); however, the influence of instrumentation varied on instances where concentrations were higher in filtered samples than in unfiltered samples (table 5). For concentrations greater than the LT-MDL, there were four instances where repeated analyses of ambient $\mathrm{Pb}$ concentrations (two filtered; three unfiltered) and two instances where spiked concentrations in filtered samples fell outside the acceptable DQO of 25 percent for precision (table 7; figs. 3, 4, and 5). Ambient concentrations were not always near the LT-MDL $(0.04 \mu \mathrm{g} / \mathrm{L})$; ranging from 0.06 to $0.21 \mu \mathrm{g} / \mathrm{L}$. Re-analysis, when performed, improved analytical precision.

Molybdenum.-For the NIST reference material, Mo analyses distributed evenly around the certified value showing no apparent bias; however, on average, there was a high bias of about 11 percent with respect to the NMIJ SRM (fig. D5). During the original experiment, when filtered and unfiltered samples were analyzed on different instruments, Mo spike recovery was statistically higher in unfiltered than in filtered samples ( $p=0.016$; table 3; fig. E5). Molybdenum spike recovery was higher in filtered samples when analyzed on instrument 6 than on instrument 7 ( $p<0.001$, table 3$)$. There were no statistical differences in median Mo spike recoveries between filtered and unfiltered samples when they were analyzed on the same instrument (instrument 6; $p=0.404$ ). Evaluation of the slope of the linear least square regression of Mo concentrations between analyses using instruments 6 and 7 relative to the 1:1 line showed there was a 12.6 percent greater response for Mo on instrument 6 than instrument 7 (figs. $1 B$ and C5). Median Mo spike recoveries in unfiltered samples were higher during the new than the original experiment $(p=0.002$, table 3$)$. Because unfiltered samples were analyzed on the same instrumentation during both experiments, instrumentation was not the cause of this unexplained apparent increase in recovery. Using linear least square regression, the addition of $\mathrm{HCl}$ to matrix match filtered samples to associated unfiltered samples had essentially no effect on the analytical results for Mo (figs. 1A and B5). The slope for Mo was within 1.2 percent from the 1:1 response indicating good agreement between filtered samples with and without the $\mathrm{HCl}$ treatment. Analyses of all filtered and unfiltered samples were within the precision DQO of \pm 25 percent (figs. 3 and 4). With one to two exceptions, Mo recoveries also were acceptable (80-120 percent; figs. 2 and E5). Although there may be a slight high bias in Mo results, precision and spike recoveries largely fell within acceptable limits, matrix effects were minimal, and SRM analyses were largely within 90-110 percent of the certified value. The number of instances where Mo concentrations were greater in filtered samples than in unfiltered samples generally was lower when filtered and unfiltered samples were analyzed on different instruments (tables 4 and 5).

Selenium.-Selenium was biased low for both SRM analyses on average by about 22-29 percent, regardless of instrumentation used (fig. D6). Selenium spike recoveries showed distinct biases from instruments and matrices (fig. E6). During the original experiment, median Se spike recovery was higher for filtered samples analyzed on instrument 7 than for unfiltered samples on instrument 6 ( $p<0.001$; table 3 ; fig. E6); there was no statistical difference in unfiltered Se spike recoveries between the original and new experiments $(p=0.158)$. There was no statistical difference at the 95-percent confidence level in median Se spike recoveries between filtered and unfiltered samples when they were analyzed on the same instrument $(p=0.071)$. Using linear least square regression, the response of Se was lower on instrument 6 than on instrument 7; the slope of the regression relating the full range of analytical results obtained from the two instruments was about -13.7 percent from the 1:1 line (fig. C6A). Although there was an apparent suppression in signal on instrument 6 , the addition of $\mathrm{HCl}$ caused an almost 2.1 percent higher response for Se (fig. B6A). Evaluation of precision among measurements of Se concentration in filtered samples showed that when control limits of \pm 25 percent were exceeded $(\mathrm{n}=4)$, the concentrations were higher in samples analyzed on instrument 7 than on instrument 6 . Reanalysis on instrument 6 , designated for unfiltered sample analysis, brought the precision of measurements within the accepted DQO. The number of instances where Se concentrations were higher in filtered samples than in unfiltered samples decreased when filtered and unfiltered samples were analyzed on the same instrument (tables 4 and 5). The marked difference in instrument responsiveness to Se suggests that instrument sensitivity and the addition of $\mathrm{HCl}$ may be contributing factors in the $\mathrm{C}_{\mathrm{F}}>\mathrm{C}_{\mathrm{UF}}$ issue for Se. 
Zinc.-SRM analyses showed a marked low bias for $\mathrm{Zn}$, on average, by about $14-16$ percent (fig. D7). With the exception of recoveries of $\mathrm{Al}$ and $\mathrm{Se}$ in filtered samples, $\mathrm{Zn}$ spike recoveries were biased low more often than the other trace elements evaluated and outside the DQO for recovery (fig. 2). Zn spike recoveries generally showed greater variability at lower concentrations and were less than 100 percent (fig. E7). There were no statistical differences in median spike recoveries between the original and new experiments in filtered $(p=0.392)$ or unfiltered $(p=0.503)$ samples, respectively. During the original experiment, $\mathrm{Zn}$ recovery was statistically higher in filtered than in unfiltered samples ( $p=0.003$; table 3 ). There were no statistical differences in $\mathrm{Zn}$ recoveries between filtered and unfiltered samples when they were analyzed on the same instrument $(p=0.205)$. Matrix matching filtered samples to paired unfiltered samples by adding $\mathrm{HCl}$ had no effect on the analytical results for Zn (fig. B7). There was an identifiable issue with the analytical precision for $\mathrm{Zn}$, particularly in unfiltered samples (table 7). Precision, as evidenced by the $\% \mathrm{RD}$, for 6 of 24 unfiltered samples ranged from 29 to 98 percent; re-analysis of 3 of 6 samples brought the analytical results into acceptable limits. The remaining three samples for which precision ranged from 29 to 36 percent, were not re-analyzed. The number of instances where $\mathrm{Zn}$ concentrations were greater in filtered samples than in unfiltered samples decreased when samples were analyzed on the same instrument (tables 4 and 5).

\section{Conclusions and Steps Forward}

When analyzing filtered samples on instrument 6 (calibrated using standards prepared in $\mathrm{HNO}_{3}: \mathrm{HCl}$ matrix), the addition of $\mathrm{HCl}$ to filtered samples to matrix match the filtered samples to that of associated unfiltered samples treated with $\mathrm{HCl}$ during the in-bottle digestion procedure, appeared to decrease the number of instances where concentrations of $\mathrm{Al}, \mathrm{As}, \mathrm{Cd}, \mathrm{Pb}, \mathrm{Mo}$, and $\mathrm{Zn}$ were greater in filtered samples than in unfiltered samples; however, this was not the case for Se. Over the entire range of concentrations evaluated for $\mathrm{Al}$ and Mo, there was a stronger response on instrument 6 than on instrument 7; Se a weaker response on instrument 6. Because instrument 6 was calibrated using standards prepared in a $\mathrm{HNO}_{3}: \mathrm{HCl}$ matrix, the differences in signal strength could be due, at least in part, to the differences in calibration standard and sample matrices. The NWQL suggests that the best analytical practice is to use calibration standards prepared in matrices that reasonably match the matrix of the samples being analyzed. Analyzing filtered and unfiltered samples on the same instrument generally provided improved similarities in median spiked recovery results and concentration comparisons between paired filtered and unfiltered samples for the trace elements evaluated. Controlling for variability attributable to differences in matrices and instrumentation can improve analytical accuracy and precision. However, residual chloride arising from the analysis of unfiltered samples in the $\mathrm{HCl}$ containing matrix can build up in the gas chromatography-mass spectrometry instrument resulting in a long-lasting background chloride signal that can interfere with trace-element analyses (Grégoire and others, 1994; Sarah Stetson, U.S. Geological Survey, oral commun., 2016). For this reason, NWQL will not run filtered and unfiltered samples on the same instrument.

The NWQL is replacing older cICP-MS instrumentation. Sample analyses will shift to the new instruments after installation, performance testing, a training period, and instrument evaluations have been completed. Performance testing of the equipment will include using the same samples analyzed as part of this evaluation to determine if there are any differences in concentration. Although holding times will be exceeded, all samples have been acidified with $\mathrm{HNO}_{3}$ and should be stable through the testing period. The target date to move trace-element analyses to new instruments is on or before October 2016.

As of May 2015, the NWQL has implemented the correction of results from whole water (unfiltered) sample analyses for the 2 percent (by volume) addition of $\mathrm{HCl}$ during the in-bottle digestion procedure. The implementation of the correction will eliminate any possible bias introduced into the reported results due to the dilution of the natural sample from the addition of the hydrochloric digestion acid. At this time, there are no plans to make corrections to historical data.

Spike recovery and SRM analyses showed appreciable low bias in $\mathrm{As}, \mathrm{Cd}, \mathrm{Se}$, and $\mathrm{Zn}$ concentrations in digested samples. It may be, at least in part, that these biases contributed to the number of $\mathrm{C}_{\mathrm{F}}>\mathrm{C}_{\mathrm{UF}}$ instances reported by USGS Water-Quality Specialists. Analytical results for Al, Pb, and Mo also showed evidence of bias; however, the magnitude of these biases was small enough to unlikely influence data interpretations. This is an important finding, as the objective of many USGS water-quality related projects are to determine the status or changes in ambient water chemistry. USGS scientists and other researchers evaluating water-quality issues oftentimes require low-concentration trace-element analyses. Ultimately, it is the objectives of these types of projects that make it crucial that trace element analytical results be evaluated for accuracy and precision. The concern with finding instances of $\mathrm{C}_{\mathrm{F}}>\mathrm{C}_{\mathrm{UF}}$ outside acceptable data-quality control limits is the potential influence these biased data can have on conclusions made from data interpretation if personnel in charge of water-quality studies are not aware of the issue.

Because the NWQL participates in the BQS Inorganic Blind Sample Project, the NWQL routinely analyzes blind SRMs, which evaluate analytical performance. The blind SRMs are prepared at concentrations relevant to the typical environmental concentrations of samples analyzed at the NWQL. For water-quality projects that demonstrate concentration ranges not covered by the IBSP, commercially available SRMs, from sources such 
as NIST, NMIJ, and Natural Resources Canada, may offer more appropriate concentrations and may be submitted along with environmental samples. It is recommended that for constituents that commonly occur at concentrations greater than LT-MDLs, performance standards should target between the 25th and 75th percentile of trace-element concentrations routinely detected in sampled waters submitted to the laboratory. For trace elements that generally occur at concentrations near or less than LT-MDLs, SRM materials that represent concentrations between the LT-MDLs and 90th percentile concentration should be considered. Scheduling of SRM sample analyses into the laboratory process should be a coordinated effort between the NWQL and researchers so that SRMs can meet individual project requirements.

Project chiefs conducting trace element studies should consider submitting additional samples for laboratory traceelement spiking for the purpose of evaluating spike recoveries of targeted trace elements in natural water matrices. Greater variability in spike recoveries occurred when trace elements were spiked at concentrations near ambient concentrations regardless of whether the samples were filtered or unfiltered. Given that the purpose of spiking samples is to determine the possible influence of the sample matrix on analytical results, the greater variability in analytical results as spiking concentrations near ambient concentrations indicates the importance of spiking samples at concentrations reasonably close to what is expected in the sample. There remains differing opinions regarding what is considered "reasonably close" to ambient sample concentration; however, the data collected as part of this investigation show that spiking at concentrations less than 10 times ambient should provide a reasonable evaluation of the possible influences of sample matrices on analytical results. The NWQL should consider offering low, moderate, and high concentration spiking options to USGS Water Science Center personnel and other customers.

In collaboration with the USGS Idaho Water Science Center, on February 5, 2015, the NWQL provides a custom spiking option (proposal number CL15008) to USGS Water Science Center personnel for duplicate matrix-spike analyses for ambient samples. Ambient filtered and unfiltered samples are collected in duplicate and one set identified for spiking. The NWQL will determine the appropriate spike concentration based on existing data for the analyte at the specified sample collection site. It is recommended that USGS Water Science Centers collect paired filtered and unfiltered samples and include an additional pair for matrix spikes as part of their routine project quality-control procedures. It is recommended that USGS Water Science Centers initially include one set of paired filtered and unfiltered water samples specifically for matrix spikes at one pair per 10 or 20 sites included in the project study; a similar rate of quality-control sample collection for many studies. The continued frequency, concentration of spike, and numbers of matrix spike sample submissions can be adjusted in relation to analytical variability, bias, and project goals.
Finally, continued dialogue between the NWQL, USGS Water Science Field Team, and USGS Water Science Center personnel will greatly benefit the shared objectives of ensuring that data provided continue to meet the mission and vision of the USGS. In addition, open discussion between the NWQL, Water Science Field Team, and USGS Water Science Center personnel will result in USGS Water Science Centers conveying the analytical needs of their projects to the laboratory and the NWQL will be better informed on matters of concern to those that use the data they provide.

\section{Acknowledgments}

The authors of this work wish to acknowledge the staff from the California, Idaho, Wyoming-Montana, New Mexico, Nevada, and Oregon Water Science Centers for collecting surface water and groundwater samples used for the purposes of this investigation. Discussions with the Water Quality Specialists from the California, Idaho, Wyoming-Montana, Washington, Nevada, Alaska, Pacific Islands, and Oregon Water Science Centers greatly improved the design and scope of the study. In addition, the efforts of the USGS National Water Quality Laboratory analysts who analyzed the test samples and provided the results was greatly appreciated. Gratitude is also extended to the conscientious reviews of Joe Ayotte, Amanda Fredrickson, and Sarah Stetson of the USGS and Tony Bednar of the U.S. Army Engineer Research and Development Center.

\section{References Cited}

Garbarino, J.R., Kanagy, L.K., and Cree, M.E., 2006, Determination of elements in natural-water, biota, sediment, and soil samples using collision/reaction cell inductively coupled plasma-mass spectrometry: U.S. Geological Survey Techniques and Methods, book 5, chap. B1, 88 p.

Grégoire, D.C., Goltz, D.M., Lamoureux, M.M., Chakrabarti, C.L., 1994, Vaporization of acids and their effect on analyte signal in electrothermal vaporization inductively coupled plasma mass spectrometry: Journal of Analytical Atomic Spectrometry, v. 9, p. 919-926.

Helsel, D.R., and Hirsch, R.M., 1992, Statistical methods in water resources: Studies in Environmental Science, v. 49, Elsevier, New York, 522 p.

Hoffman, G.L., Fishman, M.J., and Garbarino, J.R., 1996, Methods of analysis by the U.S. Geological Survey National Water Quality Laboratory-In-bottle acid digestion of whole-water samples: U.S. Geological Survey Open-File Report 96-225, 28 p. 
National Institute of Standards and Technology, 2010, Trace elements in natural water, Standard Reference Material 1640a, Certificate of Analysis, Department of Commerce, United States of America, accessed May 28, 2015, at https:// www-s.nist.gov/srmors/certificates/1640a.pdf.

National Metrology Institute of Japan, 2011, Trace elements in river water (elevated level), Reference Material Certificate, NMIJ CRM 7202-b, No. +++, National Institute of Advanced Industrial Science and Technology, 4 p.

Nitrogen and Selenium Management Program, 2006, A comparison of methods for measuring total selenium and selenium species in water-Final report: Task 1.6. Report to the Orange County Nitrogen and Selenium Management Program, 201 p., accessed June 10, 2014, at http://www. ocnsmp.com/pdf/Se_Speciation_Methods_Final $\% 20$ Report_8May06.pdf.

Quality Assurance Research Group, 2010, Quality systems assessment for contract laboratories: Surface Water Ambient Monitoring Program, California State Water Resources Control Board and California Environmental Protection Agency, Process Document (Supplemental Information B); accessed October 20, 2014, at http://www.waterboards. ca.gov/water_issues/programs/swamp/docs/guidance/4 proc_lab_assmt_070110.pdf.
Thomas, R., 2002, A Beginner's Guide to ICP-MS: Part IXMass Analyzers: Collision/Reaction Cell Technology. Spectroscopy, v. 17, no. 2, p. 42-48.

U.S. Geological Survey, 2006, Collection of water samples (ver. 2.0): U.S. Geological Survey Techniques of WaterResources Investigations, book 9, chap. A4, accessed July 2014, at http://pubs.water.usgs.gov/twri9A4/.

Wilde, F.D., 2005, Preparations for water sampling: U.S. Geological Survey Techniques of Water-Resources Investigations, book 9, chap. A1, accessed July 2014, at http://pubs.water.usgs.gov/twri9A1/.

Wilde, F.D., Radtke, D.B., Gibs, Jacob, and Iwatsubo, R.T., eds., 2004 with updates through 2009, Processing of water samples (ver. 2.2): U.S. Geological Survey Techniques of Water-Resources Investigations, book 9, chap. A5, accessed July 2014, at http://pubs.water.usgs.gov/twri9A5/.

Wilde, F.D., Sandstrom, M.W., and Skrobialowski, S.C., 2014, Selection of equipment for water sampling (ver. 3.1): U.S. Geological Survey Techniques of Water-Resources Investigations, book 9, chap. A2, accessed July 2014, at http://pubs.water.usgs.gov/twri9A2/. 


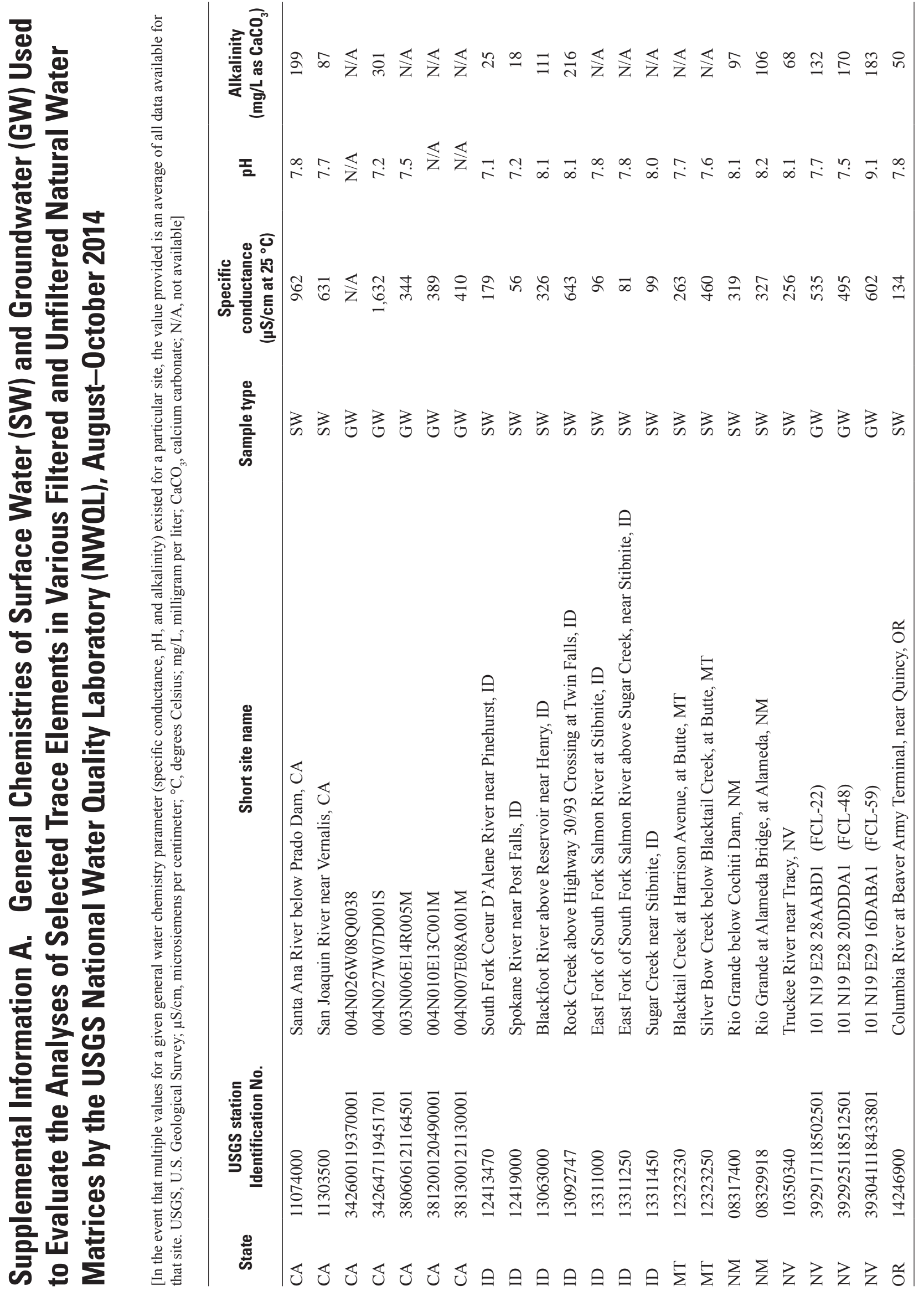




\section{Supplemental Information B. Influence of the Addition of Hydrochloric Acid (HCI) To Filtered Samples To Matrix Match the Filtered Samples To the Matrix of Unfiltered Samples Treated with HCI during the In-Bottle Digestion Procedure}

Samples were analyzed on Instrument 6 (designated for the analysis of unfiltered samples). Standards used to calibrate the ICP-MS for the analysis of matrix-matched samples were prepared in a $\mathrm{HNO}_{3}: \mathrm{HCl}$ matrix. Spiked samples were not included in the evaluation. Filtered samples were preserved in the field with $\mathrm{HNO}_{3}$ (nitric acid matrix). Matrix matched filtered samples were preserved in the field with $\mathrm{HNO}_{3}$ and matrix matched in the laboratory with 2-percent (v/v) $\mathrm{HCl}$ $\left(\mathrm{HNO}_{3}: \mathrm{HCl}\right.$ matrix). All concentrations represented were greater than the long-term method detection limit. 


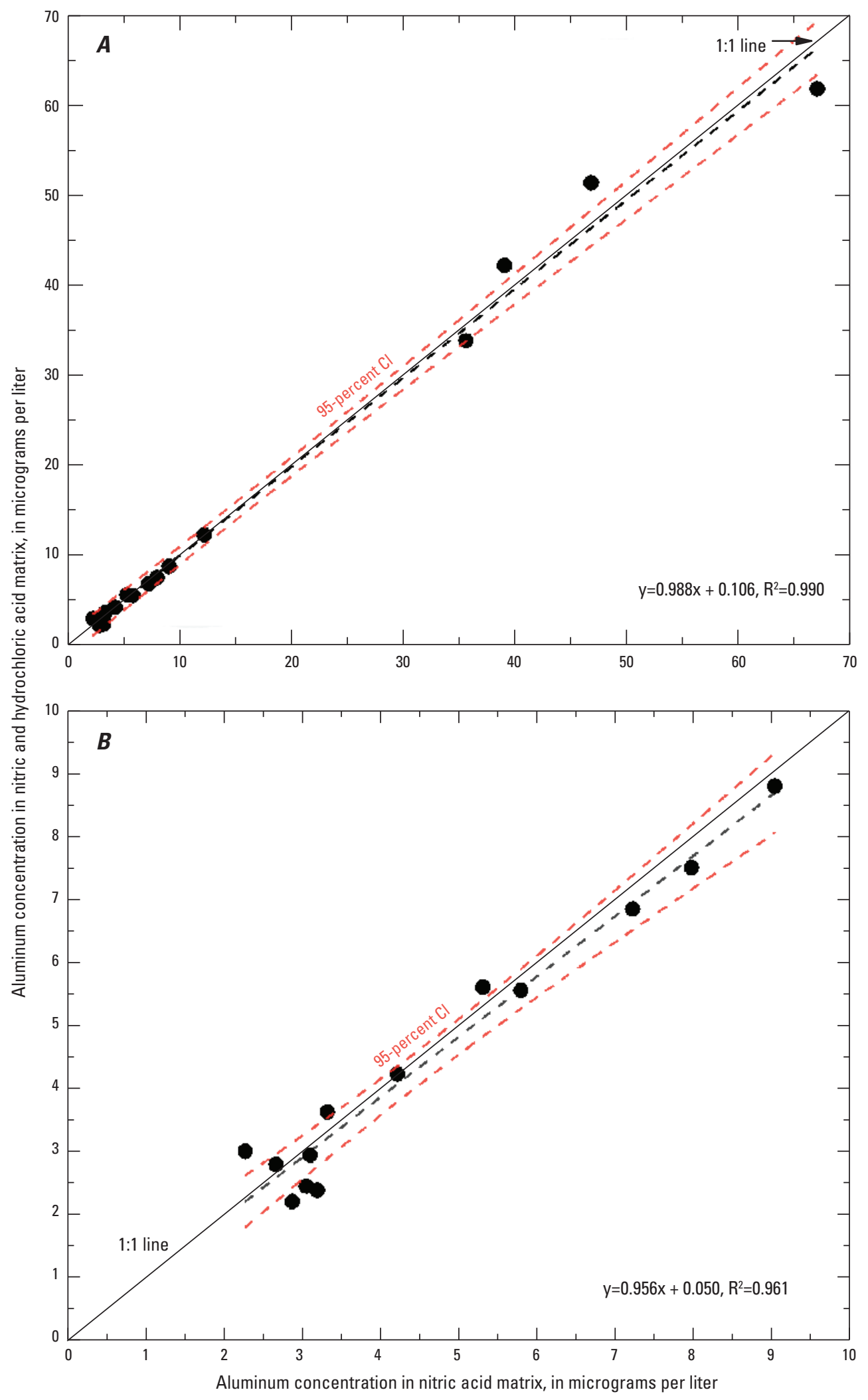

Figure B1. Aluminum concentrations in $(A)$ all filtered samples and $(B)$ filtered samples with concentrations less than 10 micrograms per liter. 


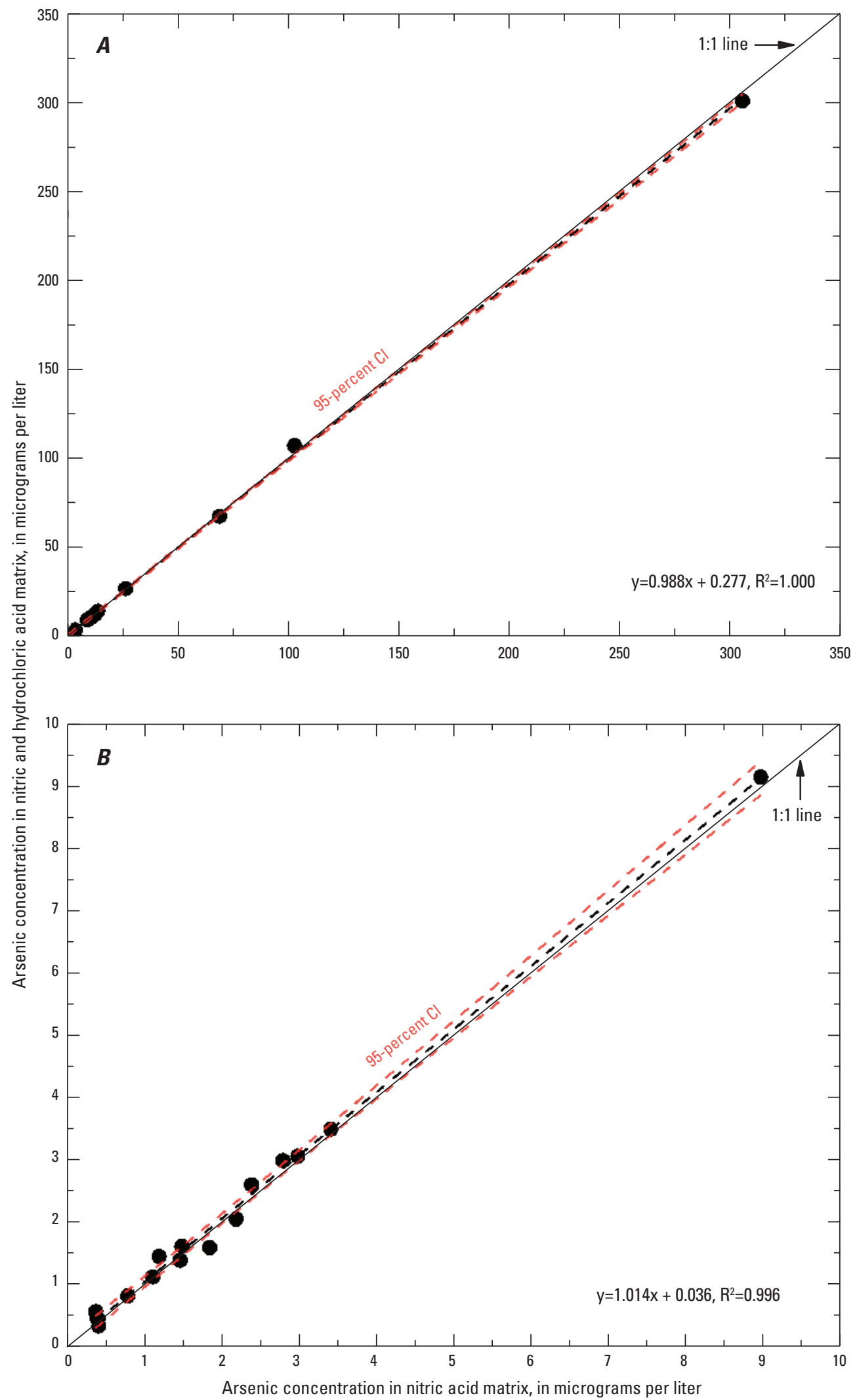

Figure B2. Arsenic concentrations in $(A)$ all filtered samples and $(B)$ filtered samples with concentrations less than 10 micrograms per liter. 


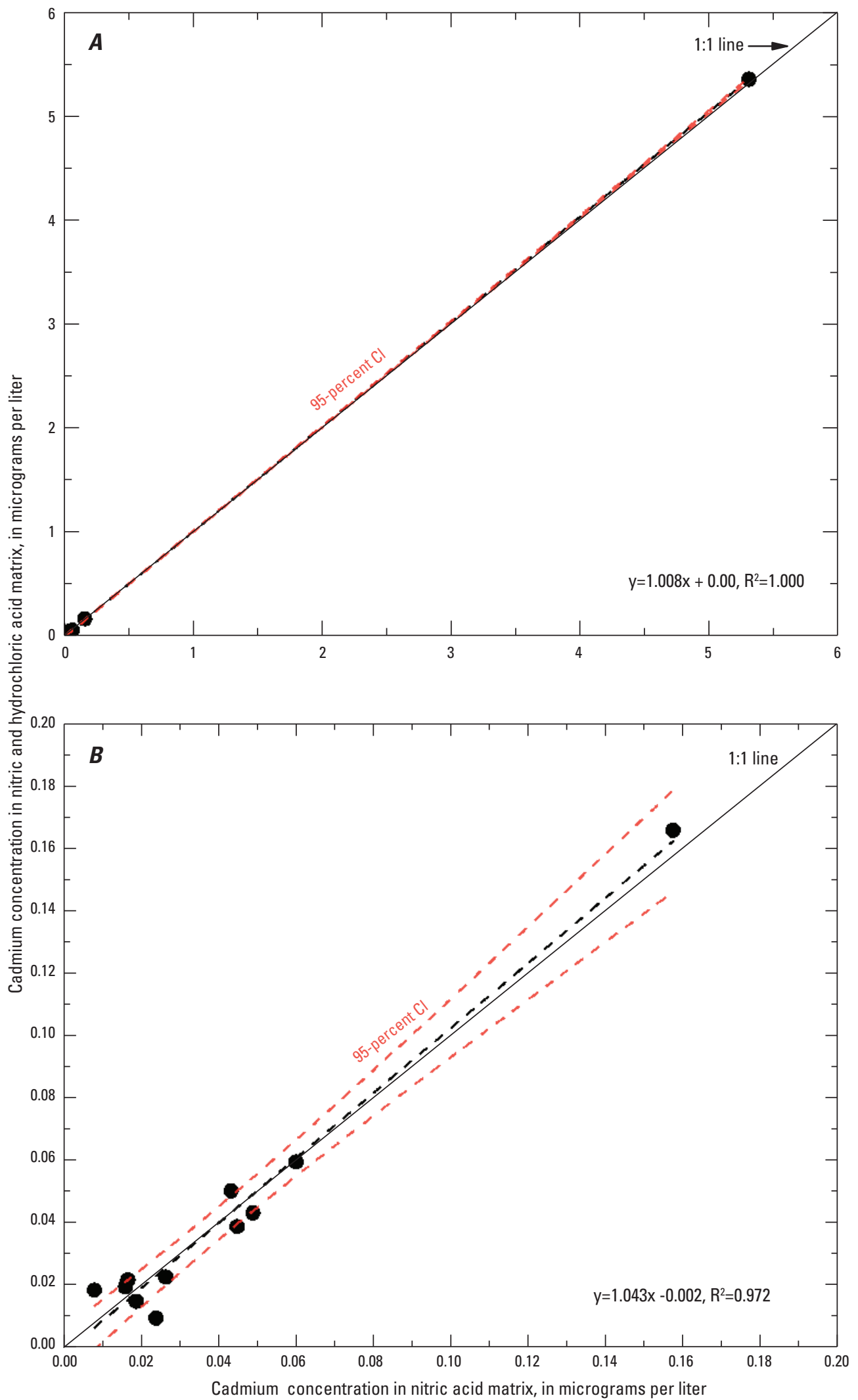

Figure B3. Cadmium concentrations in $(A)$ all filtered samples and $(B)$ filtered samples with concentrations less than 0.20 micrograms per liter. 


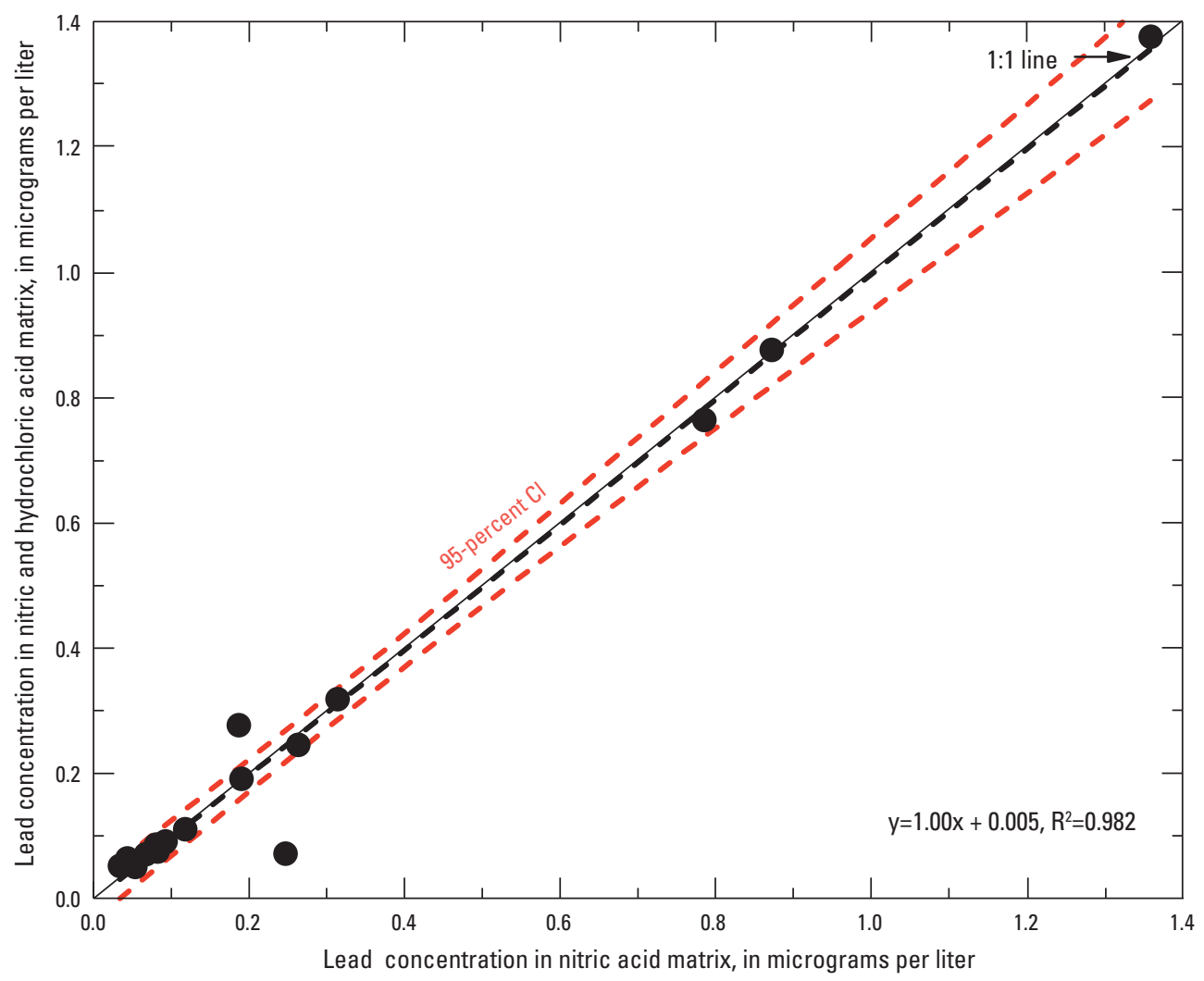

Figure B4. Lead concentrations in all filtered samples. 


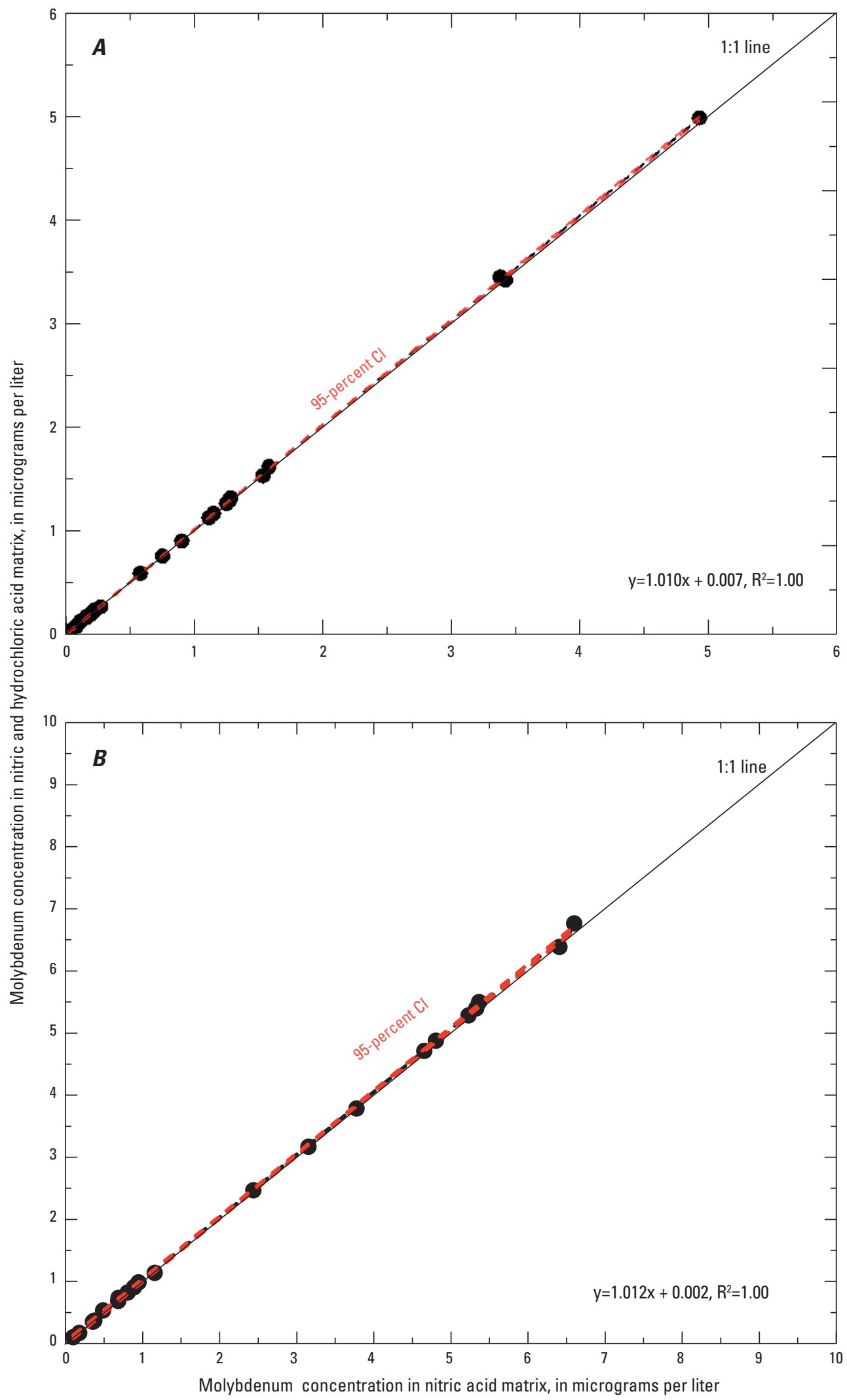

Figure B5. Molybdenum concentrations in $(A)$ all filtered samples and $(B)$ filtered samples with concentrations less than 10 micrograms per liter. 


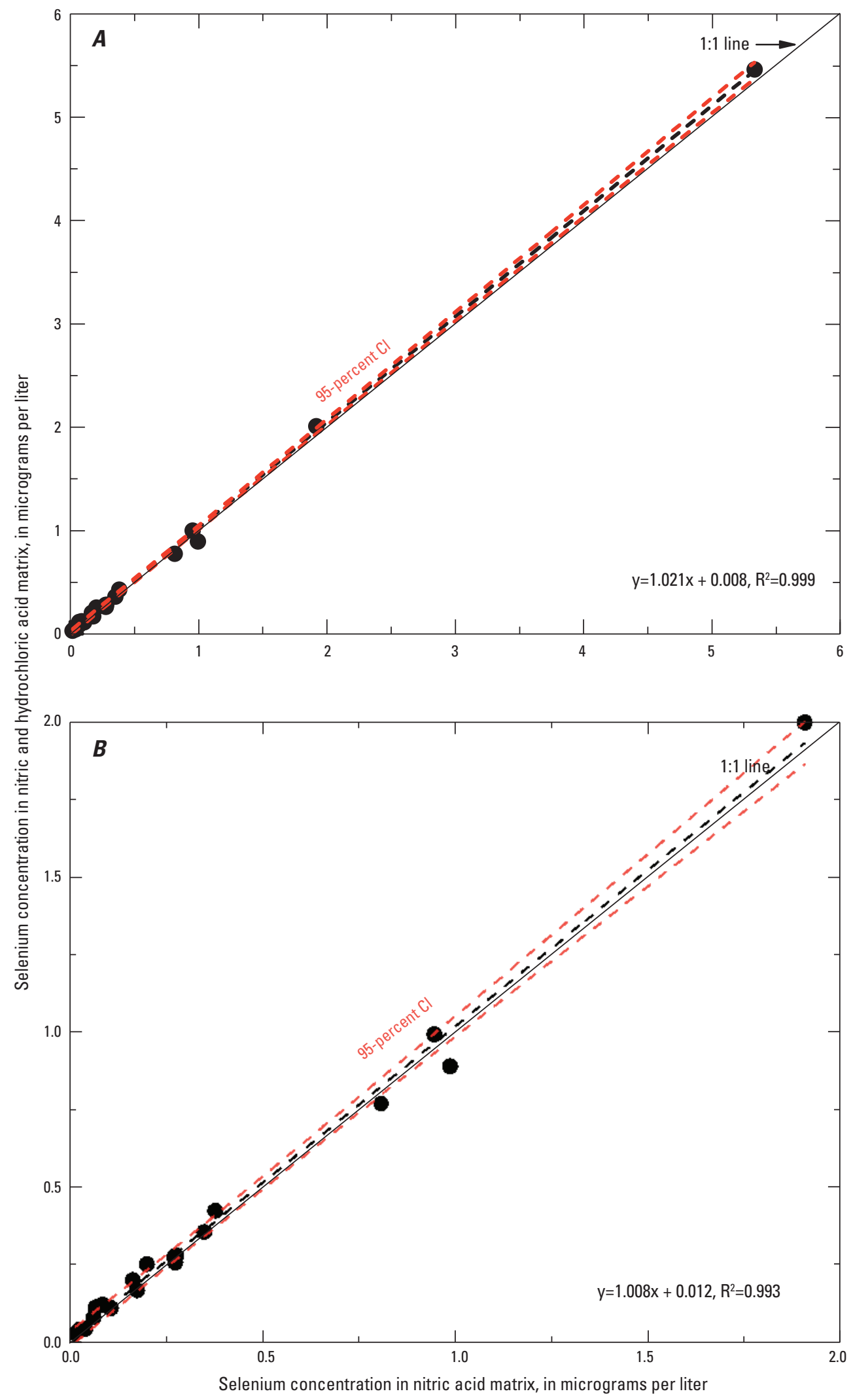

Figure B6. Selenium concentrations in $(A)$ all filtered samples and $(B)$ filtered samples with concentrations less than 2.0 micrograms per liter. 


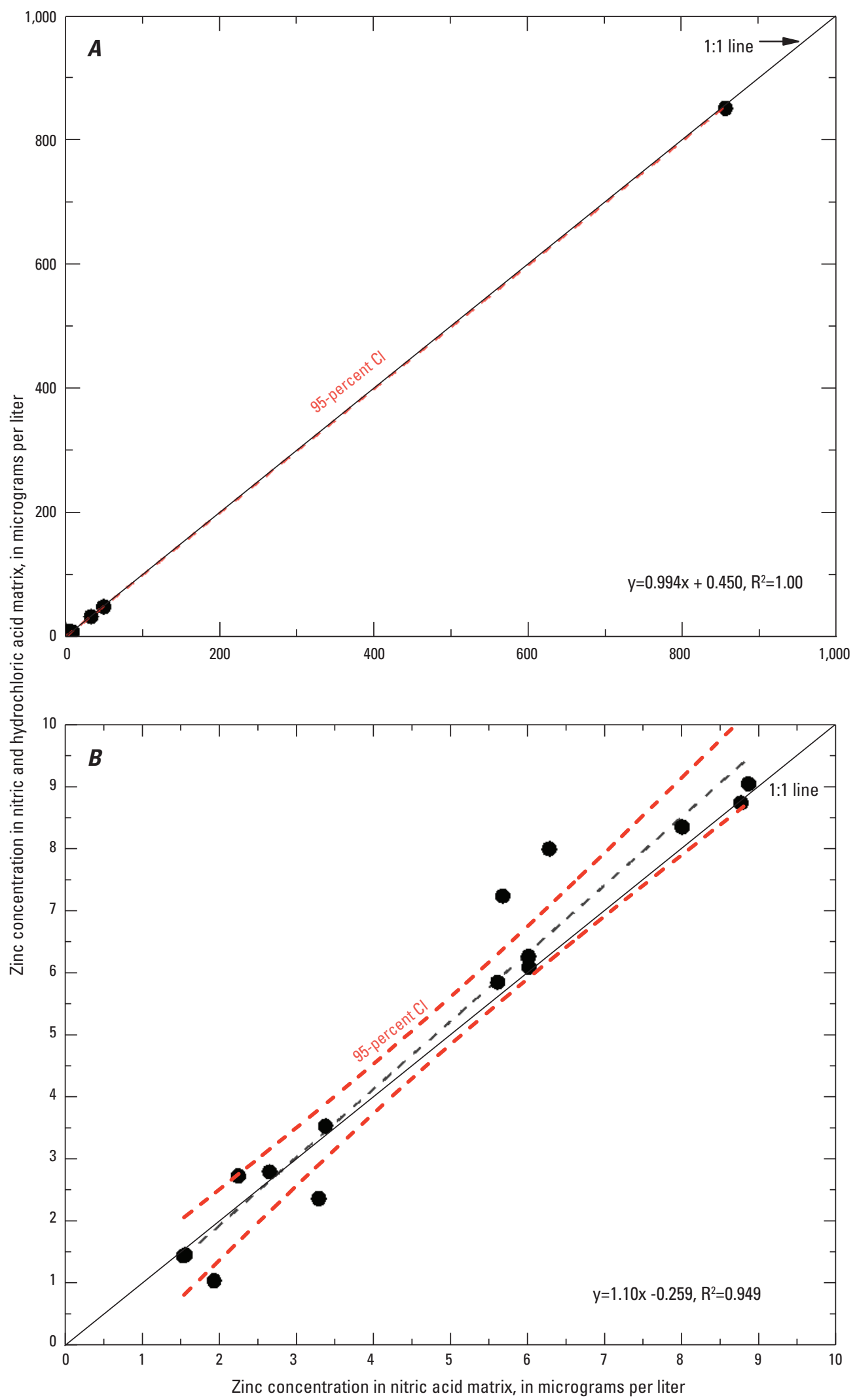

Figure B7. Zinc concentrations in $(A)$ all filtered samples and $(B)$ filtered samples with concentrations less than 10 micrograms per liter. 


\section{Supplemental Information C. Instrument Variability on Filtered Trace-Element Analyses Using Inductively Coupled Plasma Mass Spectrometry (ICP-MS), Instruments 6 and 7}

Trace element concentrations from instrument 6 represent analyses of filtered samples using the instrument designated for unfiltered samples (new experiment dataset; refer to table 2). Trace element concentrations from instrument 7 represent analytical results for filtered samples analyzed on the instrument designated for filtered samples (original experiment dataset; refer to table 2). Instrument 6 was calibrated using standards prepared in an $\mathrm{HNO}_{3}: \mathrm{HCl}$ matrix. Filtered samples were in an $\mathrm{HNO}_{3}$ matrix. Each trace element concentration was evaluated with respect to its long-term method detection limit; only results exceeding the long-term method detection limit were considered. Each evaluation considered the entire concentration range for samples submitted for analysis and a more focused evaluation for concentrations less than or equal to 10 micrograms per liter. 


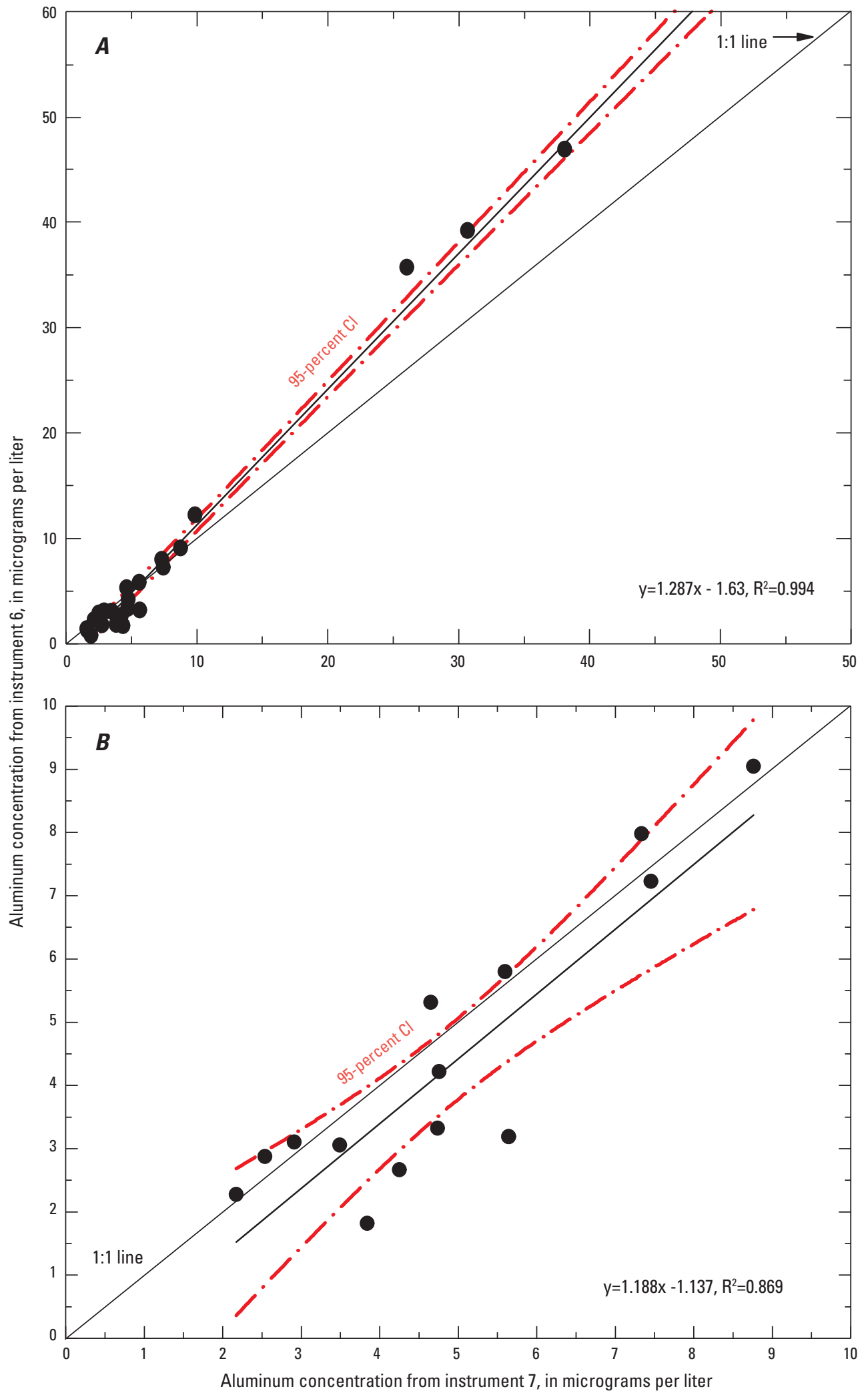

Figure C1. Aluminum concentrations in filtered samples analyzed on instrument 6 (designated for unfiltered sample analyses) and instrument 7 (designated for filtered sample analyses) for $(A)$ the entire range of aluminum concentrations and $(B)$ concentrations less than or equal to 10 micrograms per liter. 


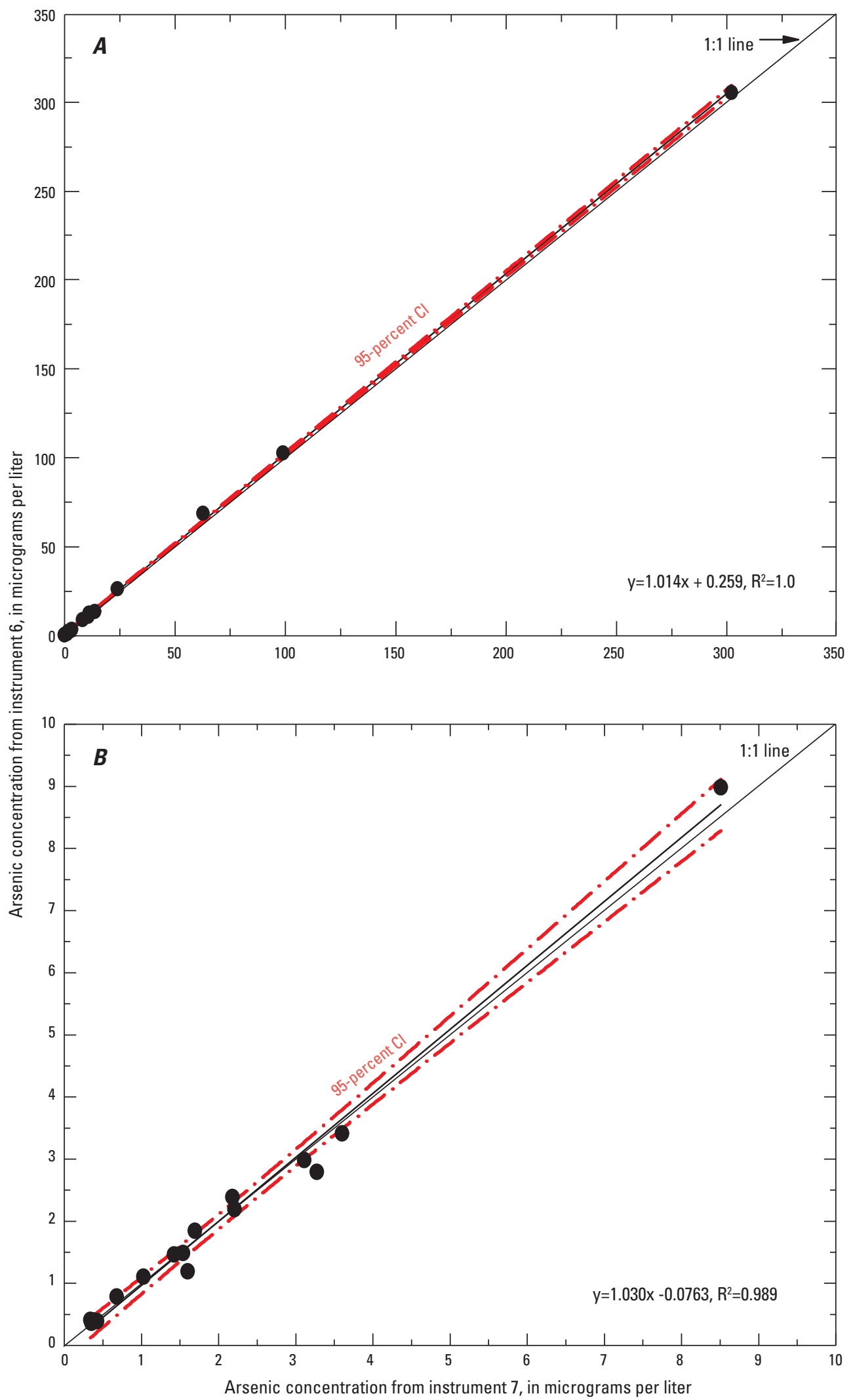

Figure C2. Arsenic concentrations in filtered samples analyzed on instrument 6 (designated for unfiltered sample analyses) and instrument 7 (designated for filtered sample analyses) for $(A)$ the entire range of aluminum concentrations and $(B)$ concentrations less than or equal to 10 micrograms per liter. 


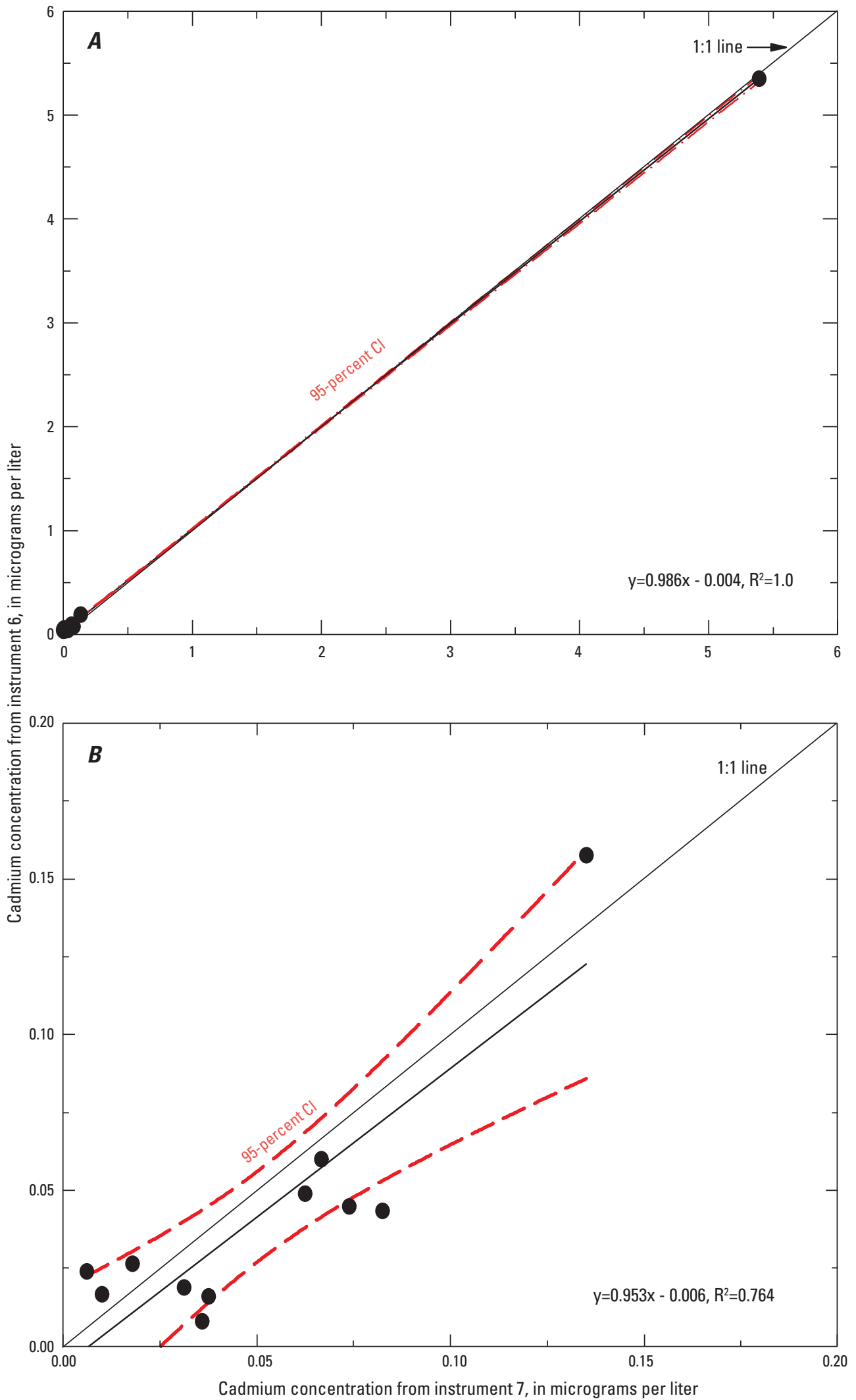

Figure C3. Cadmium concentrations in filtered samples analyzed on instrument 6 (designated for unfiltered sample analyses) and instrument 7 (designated for filtered sample analyses) for $(A)$ the entire range of aluminum concentrations and $(B)$ concentrations less than or equal to 10 micrograms per liter. 


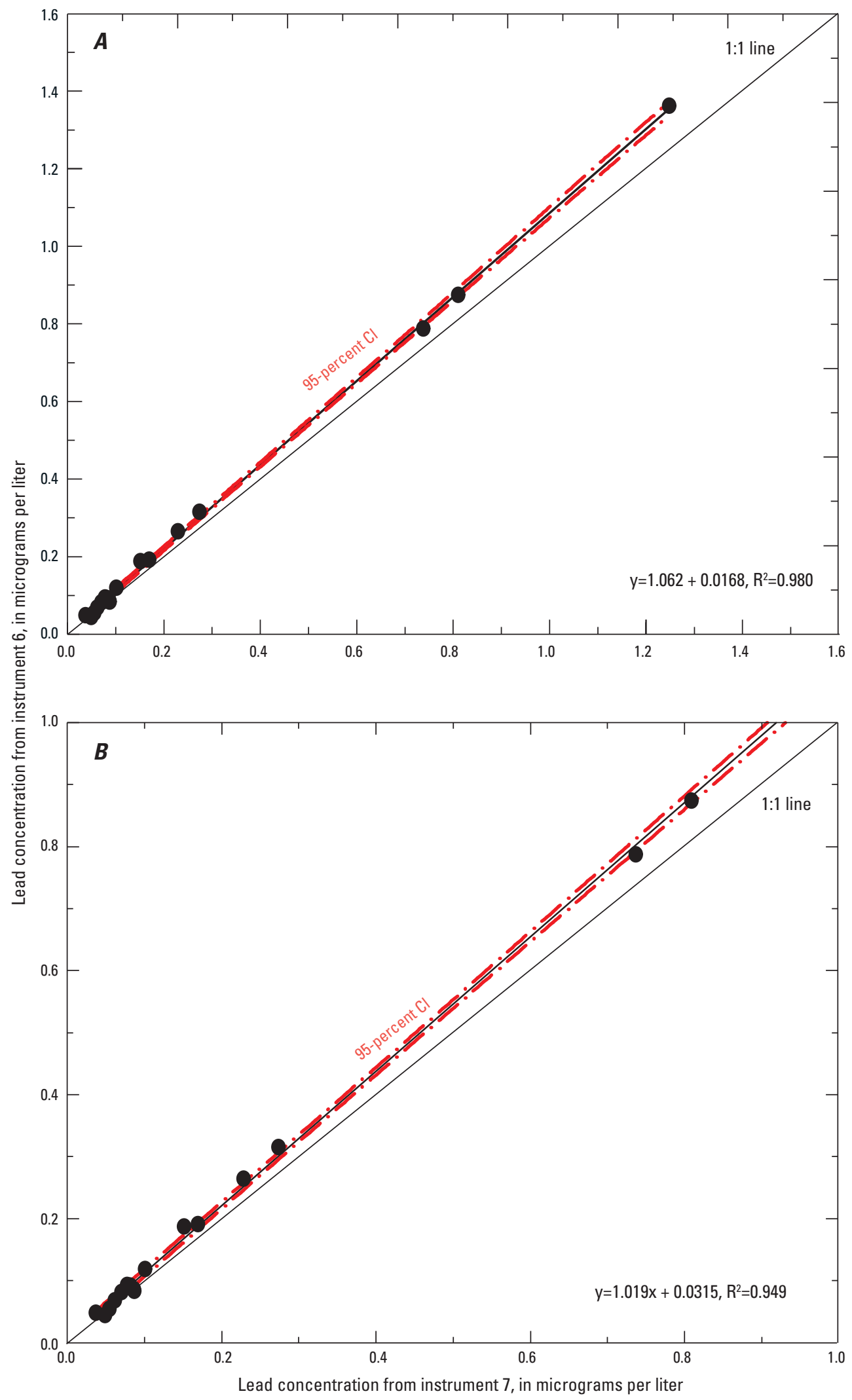

Figure C4. Lead concentrations in filtered samples analyzed on instrument 6 (designated for unfiltered sample analyses) and instrument 7 (designated for filtered sample analyses) for $(A)$ the entire range of aluminum concentrations and $(B)$ concentrations less than or equal to 10 micrograms per liter. 


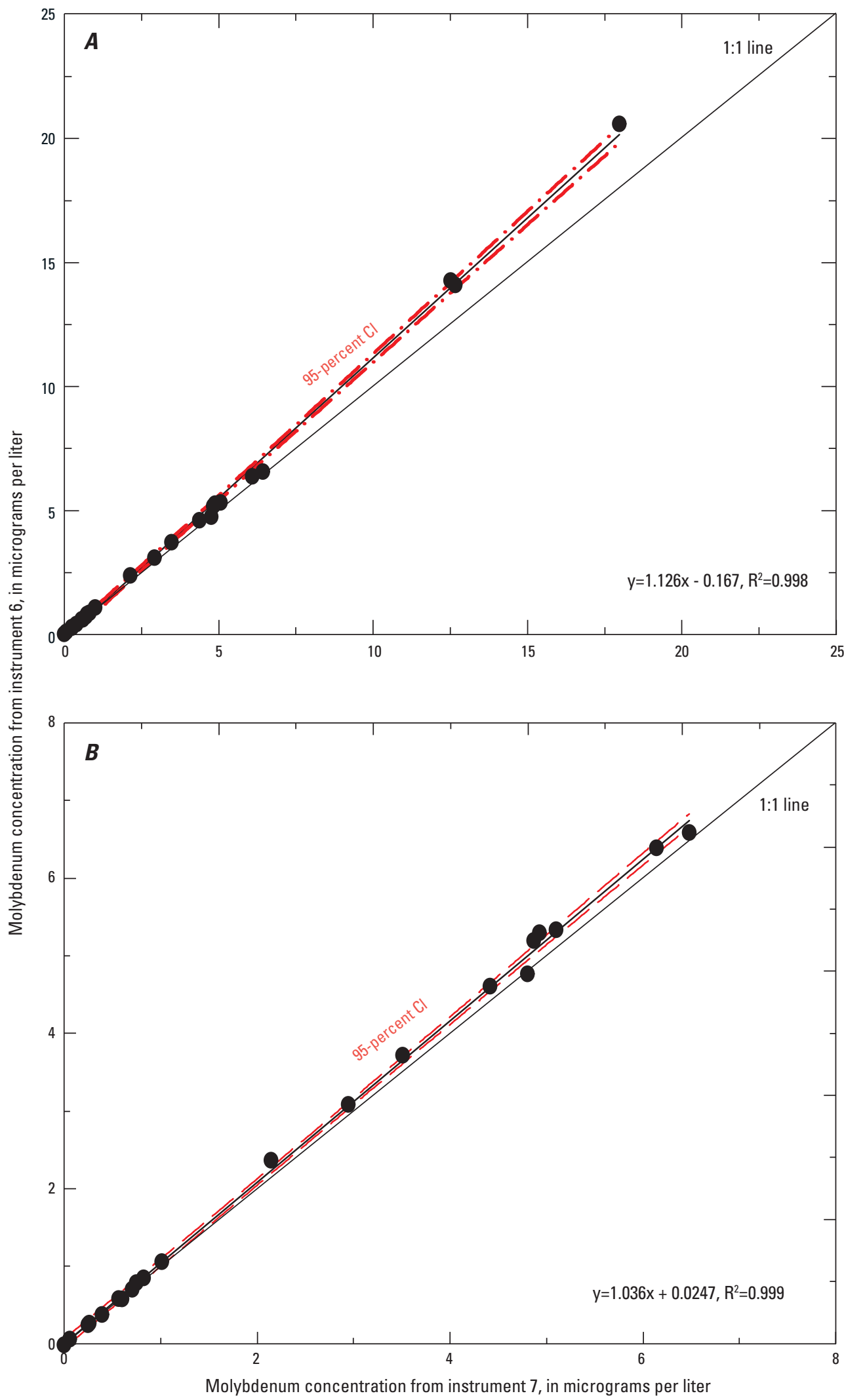

Figure C5. Molybdenum concentrations in filtered samples analyzed on instrument 6 (designated for unfiltered sample analyses) and instrument 7 (designated for filtered sample analyses) for $(A)$ the entire range of aluminum concentrations and $(B)$ concentrations less than or equal to 10 micrograms per liter. 


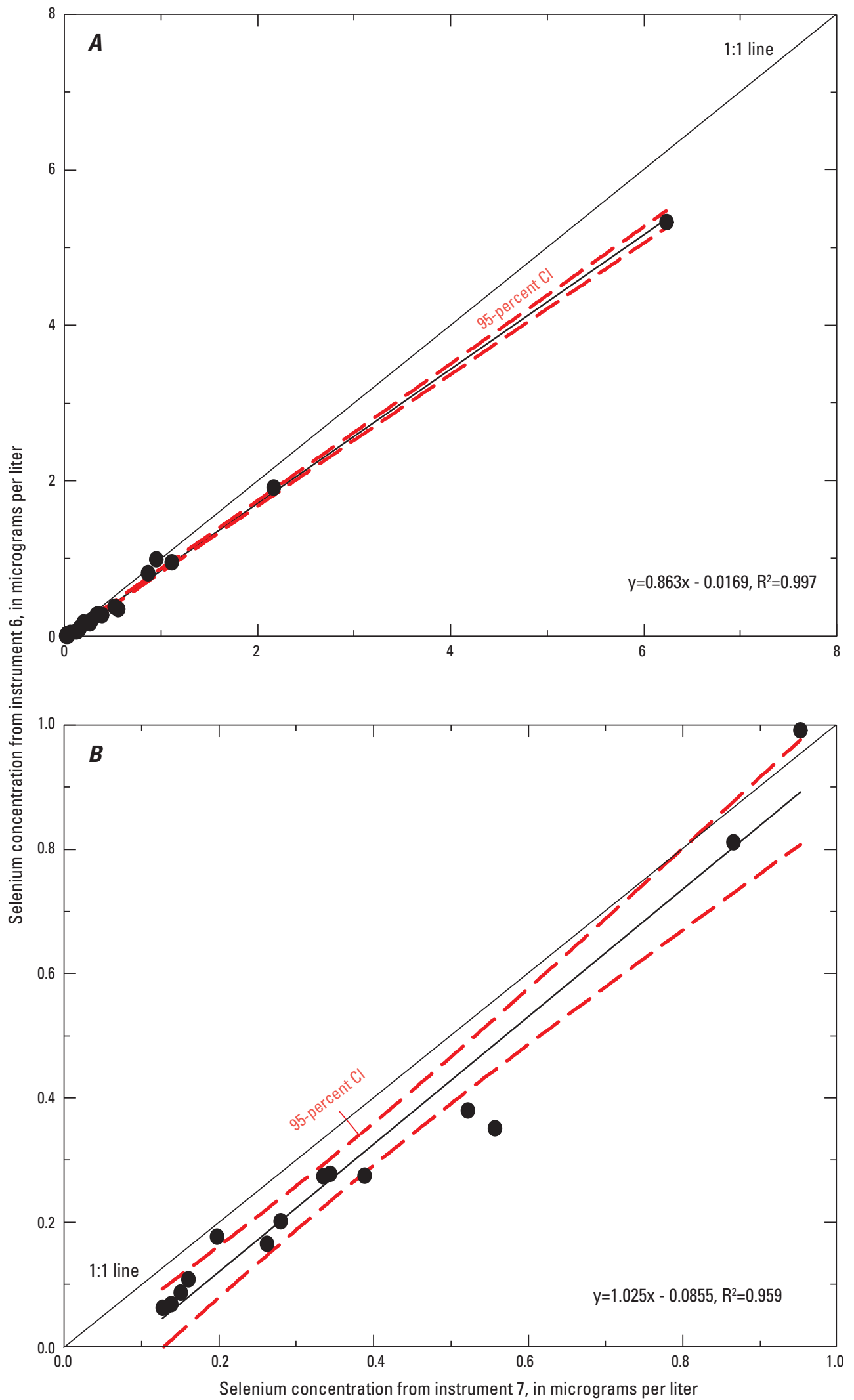

Figure C6. Selenium concentrations in filtered samples analyzed on instrument 6 (designated for unfiltered sample analyses) and instrument 7 (designated for filtered sample analyses) for $(A)$ the entire range of aluminum concentrations and $(B)$ concentrations less than or equal to 10 micrograms per liter. 


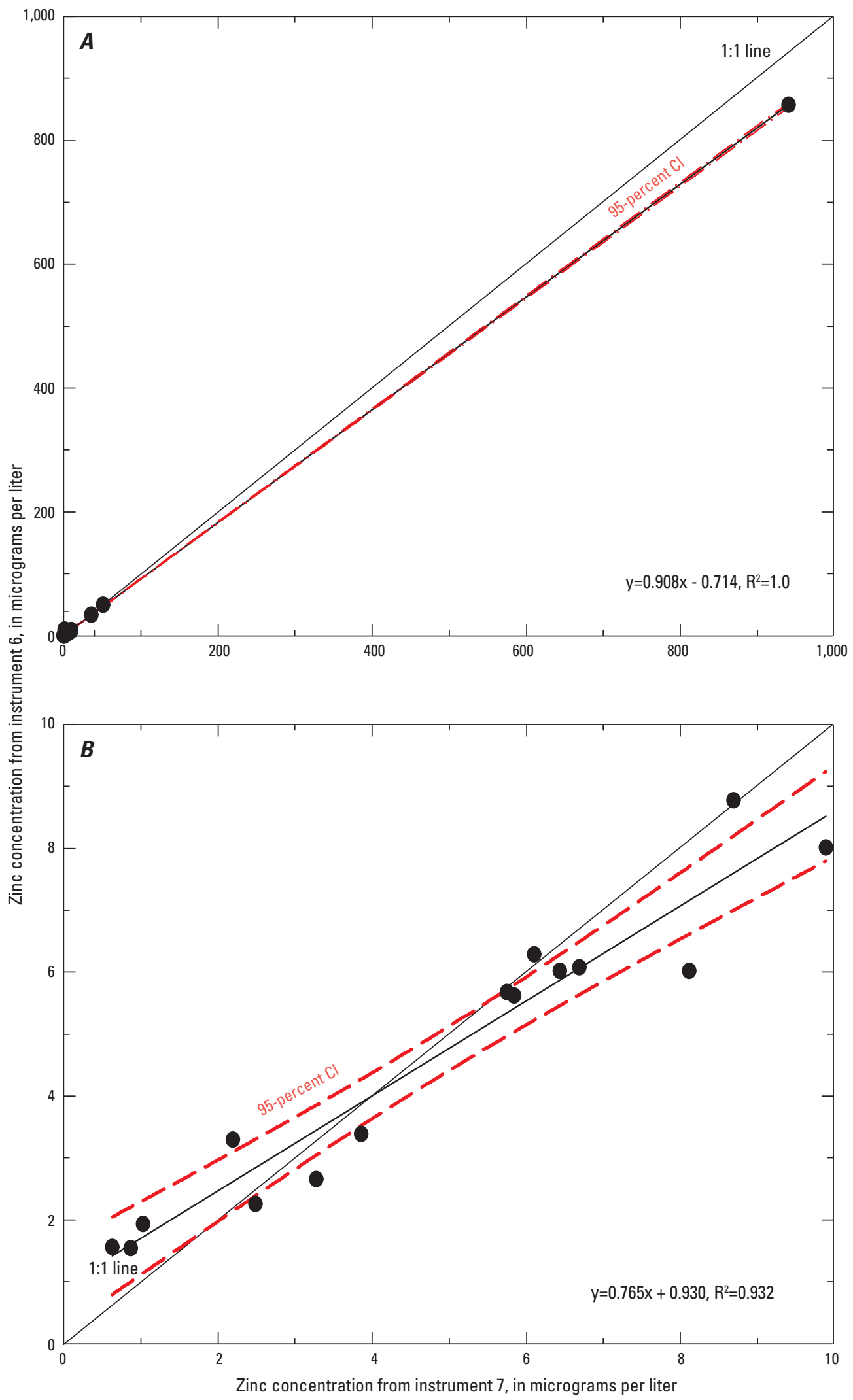

Figure C7. Zinc concentrations in filtered samples analyzed on instrument 6 (designated for unfiltered sample analyses) and instrument 7 (designated for filtered sample analyses) for $(A)$ the entire range of aluminum concentrations and $(B)$ concentrations less than or equal to 10 micrograms per liter. 


\section{Supplemental Information D. Standard Reference Materials (SRMs) from the National Institute of Standards and Technology (NIST) and the National Institute of Advanced Industrial Science and Technology, National Metrology Institute of Japan (NMIJ)}

The NIST standard (1640A) is a commercially available filtered spring water acidified with $\mathrm{HNO}_{3}$ to a volume fraction of approximately 2 percent. The NMIJ standard (CRM 7202B) is filtered natural river water preserved with $\mathrm{HNO}_{3}$ (National Institute of Standards and Technology, 2010; National Metrology Institute of Japan, 2011). SRM results indicated as unfiltered analyses (for example, unfiltered 3139) are filtered materials that were subjected to the in-bottle digestion procedure. Analytical results indicating that they were dilution corrected, were corrected to account for the 2 percent (v/v) addition of $\mathrm{HCl}$ either during the in-bottle digestion procedure or as part of the matrix matching evaluation. 


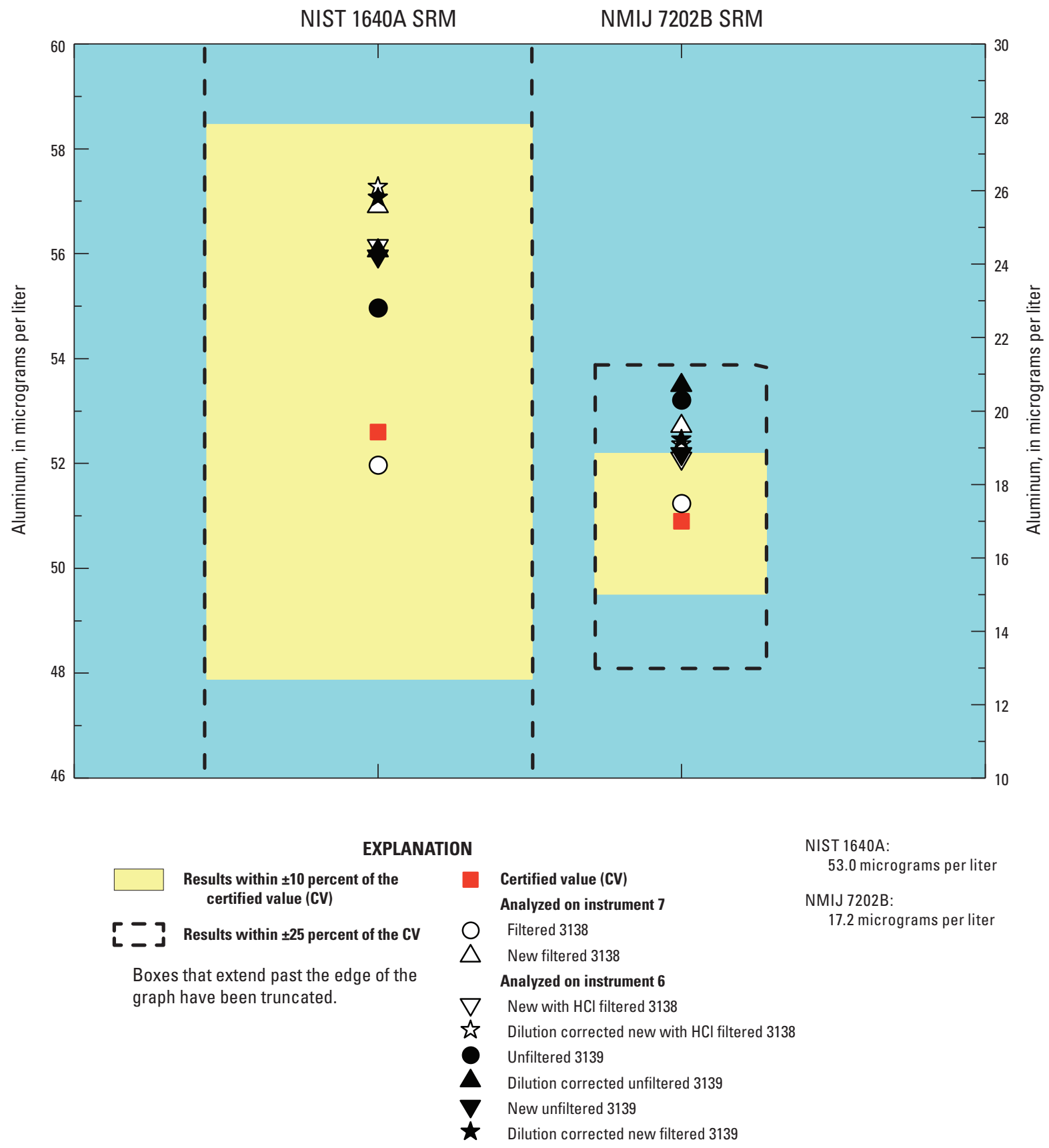

Figure D1. Aluminum concentrations in standard reference materials (SRMs) analyzed on instruments 6 and 7. 


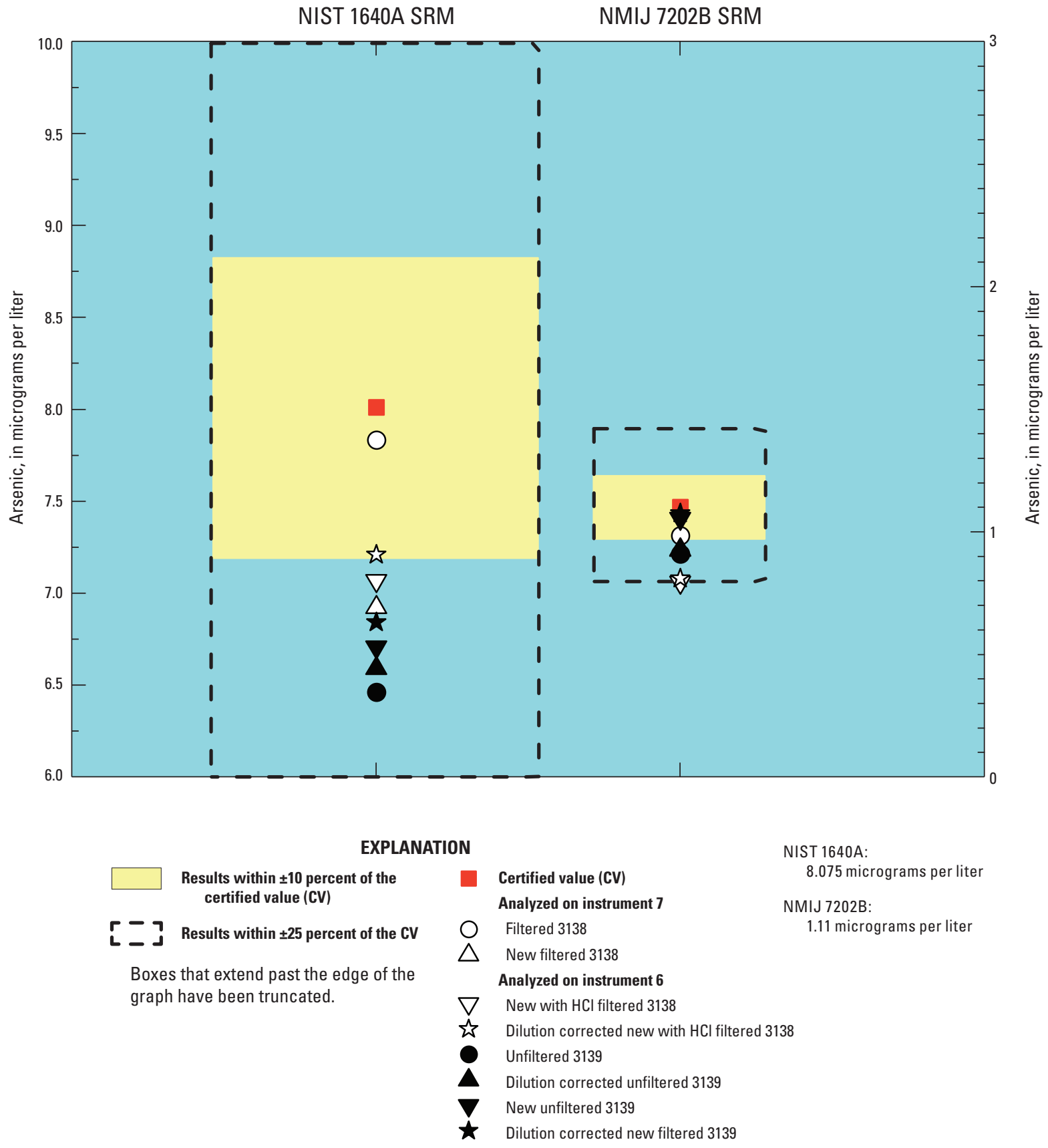

Figure D2. Arsenic concentrations in standard reference materials (SRMs) analyzed on instruments 6 and 7. 


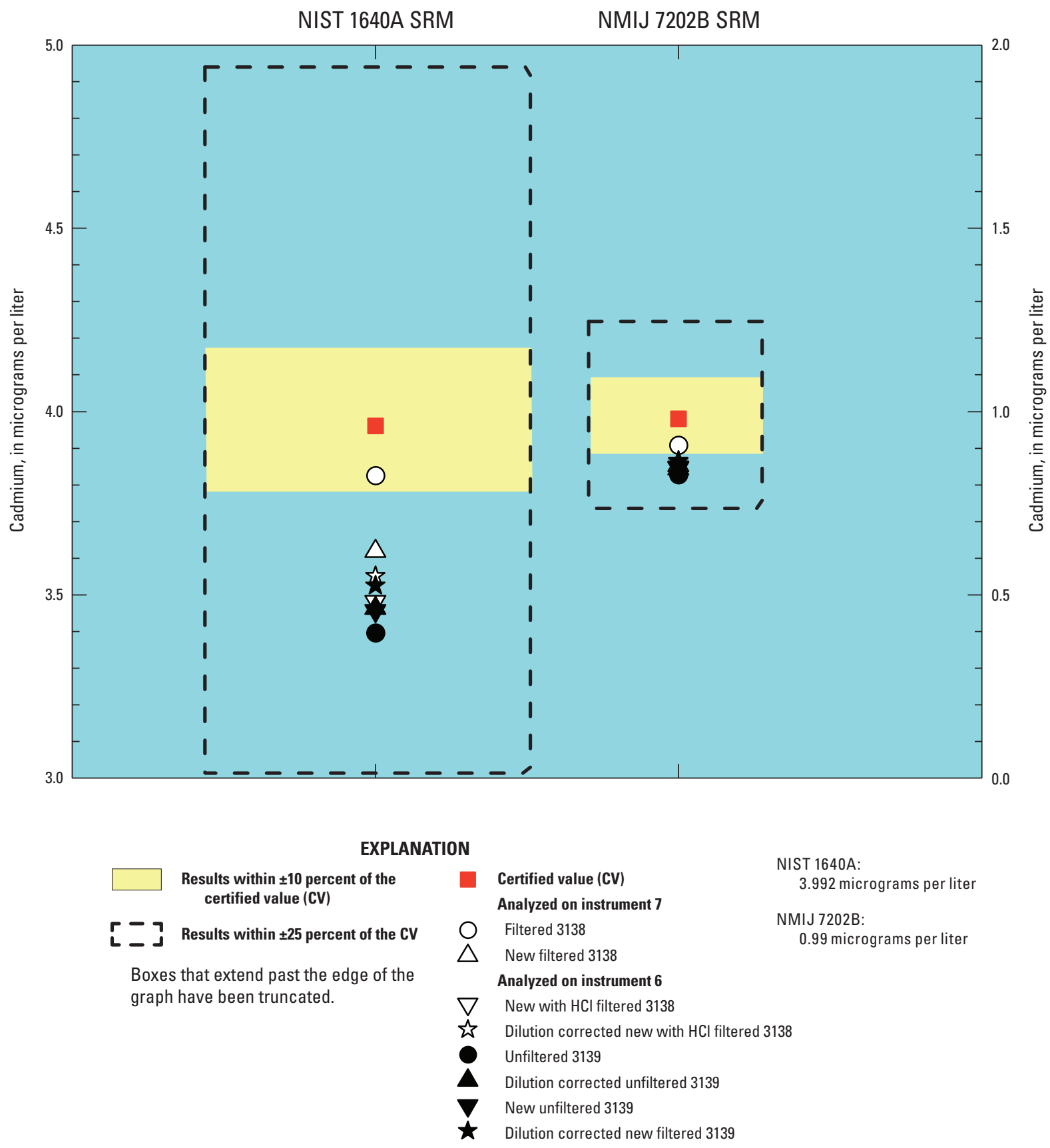

Figure D3. Cadmium concentrations in standard reference materials (SRMs) analyzed on instruments 6 and 7 . 


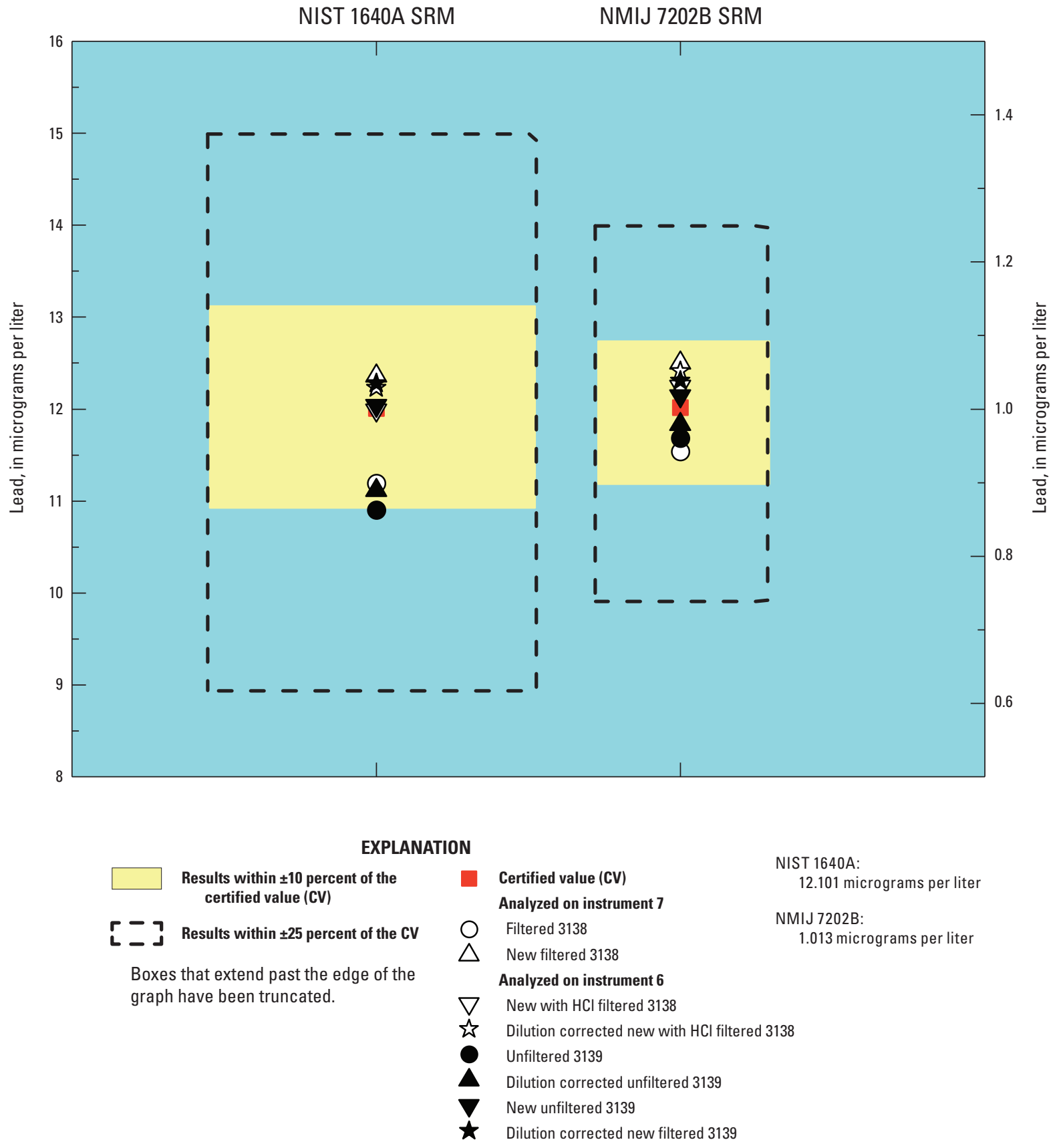

Figure D4. Lead concentrations in standard reference materials (SRMs) analyzed on instruments 6 and 7. 


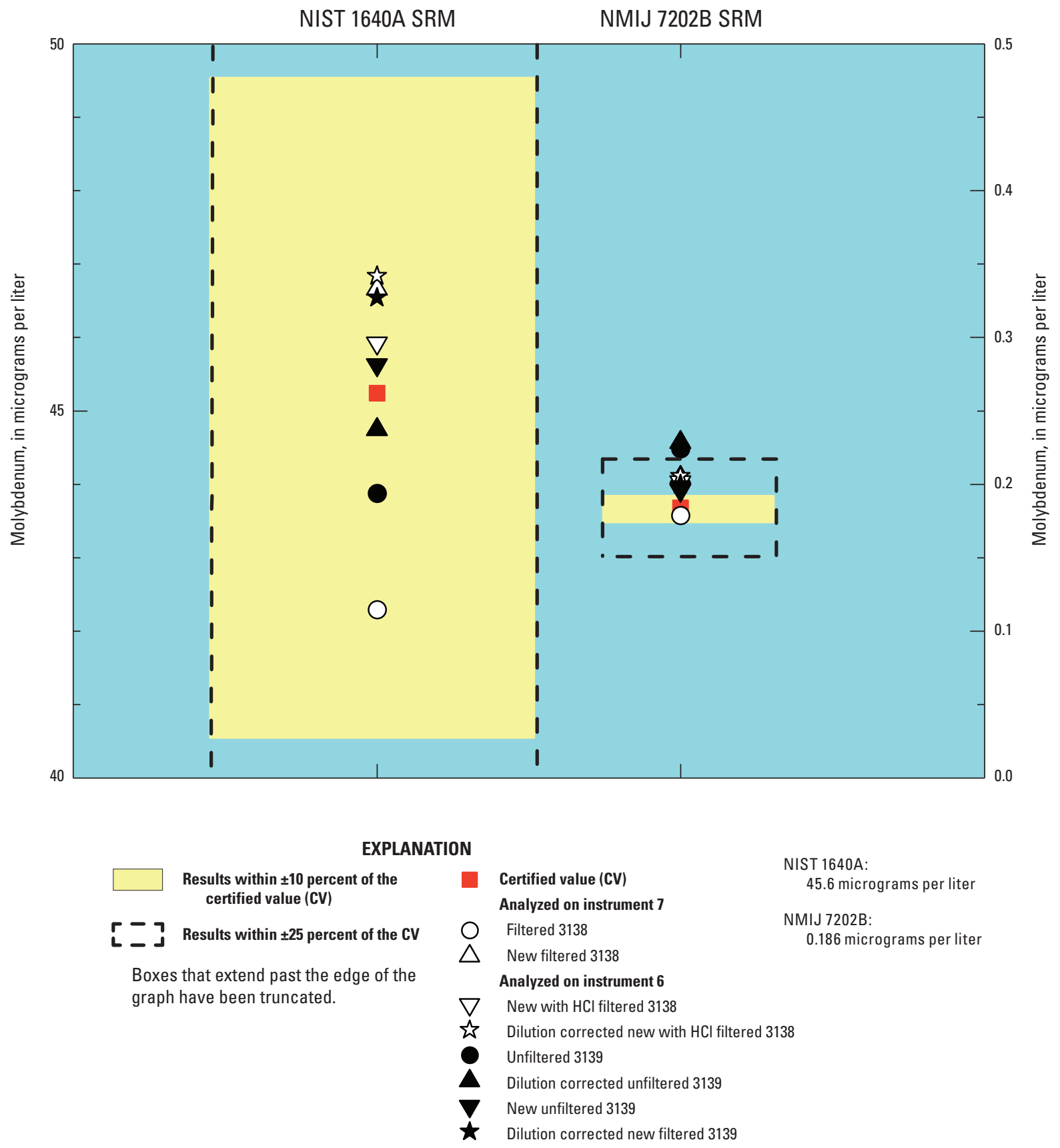

Figure D5. Molybdenum concentrations in standard reference materials (SRMs) analyzed on instruments 6 and 7. 


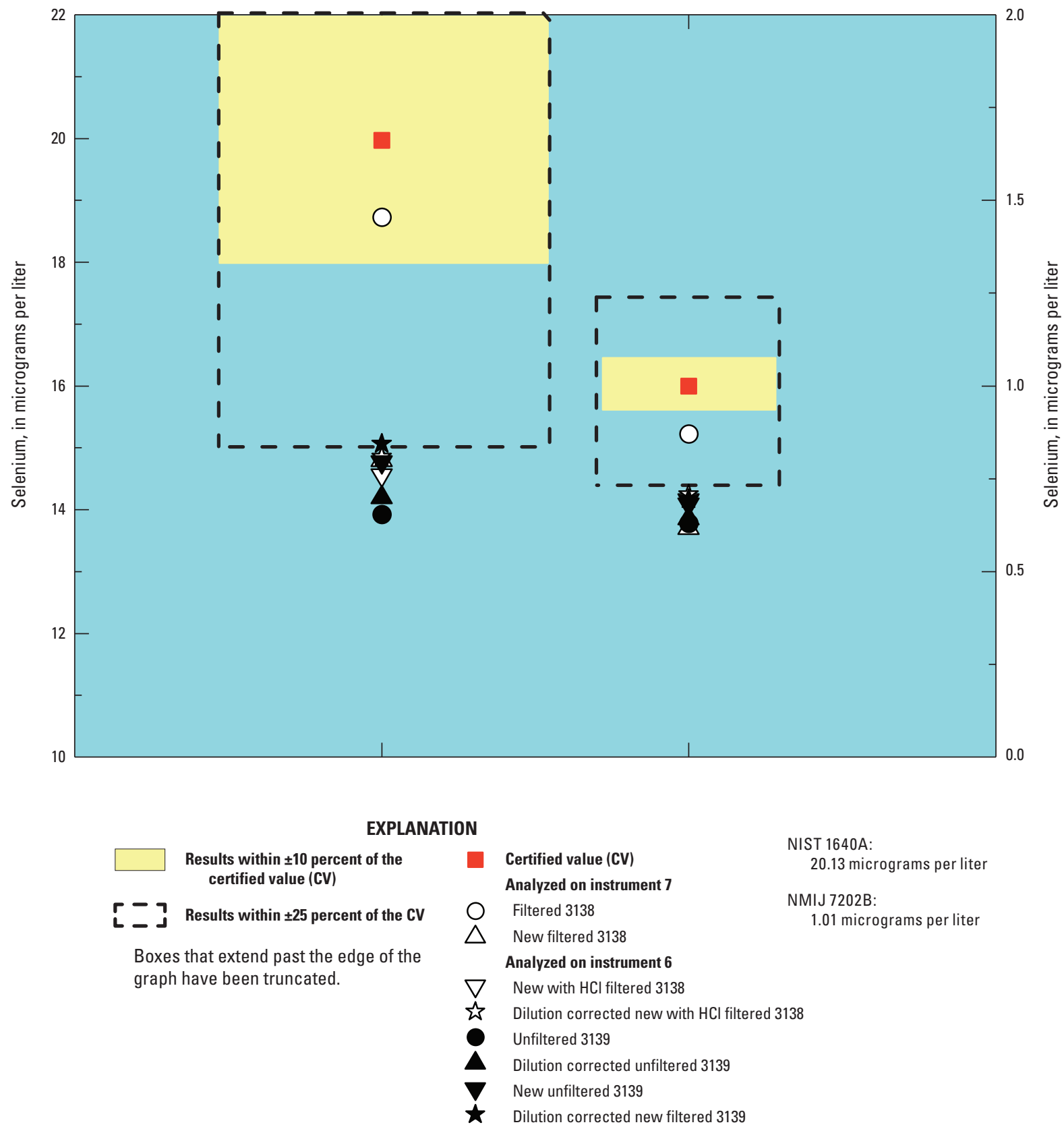

Figure D6. Selenium concentrations in standard reference materials (SRMs) analyzed on instruments 6 and 7. 


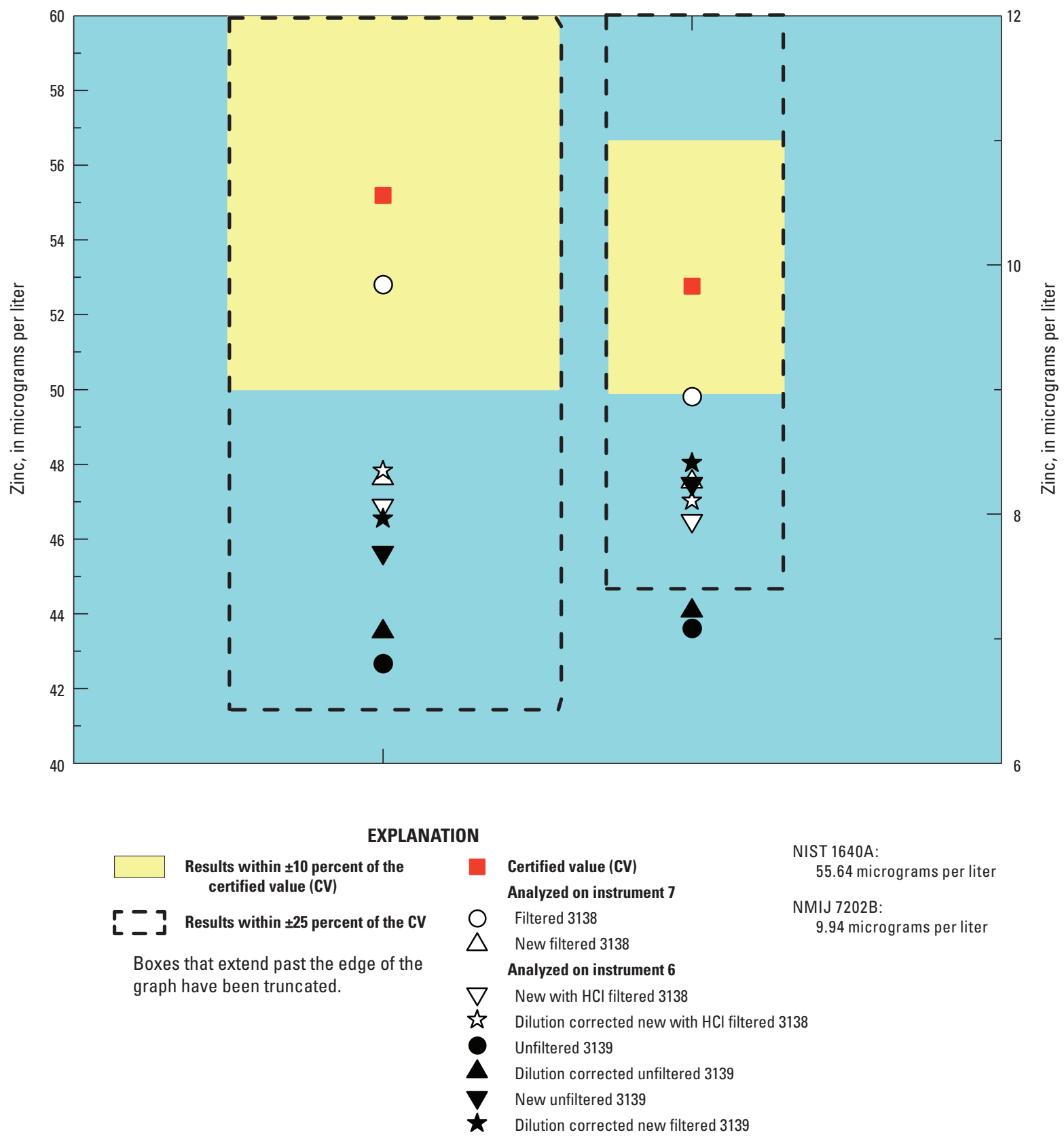

Figure D7. Zinc concentrations in standard reference materials (SRMs) analyzed on instruments 6 and 7 . 


\section{Supplemental Information E. Results for Standard Reference Material (SRM) and Trace Element Spike Recoveries in Filtered and Unfiltered Samples Analyzed on Instruments 6 and 7}

Instrument 7 is designated for the analysis of filtered samples; instrument 6 is designated for unfiltered sample analyses. SRMs are filtered materials. SRMs identified as digested, were treated with $\mathrm{HCl}$ during the in-bottle digestion procedure. Filtered and unfiltered samples were spiked with trace elements. Samples that were spiked with less than
25 percent of the ambient concentration in the sample were excluded from the data evaluations. Digested samples were adjusted for the 2 percent dilution of the sample resulting from the addition of $\mathrm{HCl}$ during the in-bottle digestion procedure. Data were evaluated for filtered trace-element concentrations in the $\mathrm{HNO}_{3}$ matrix.

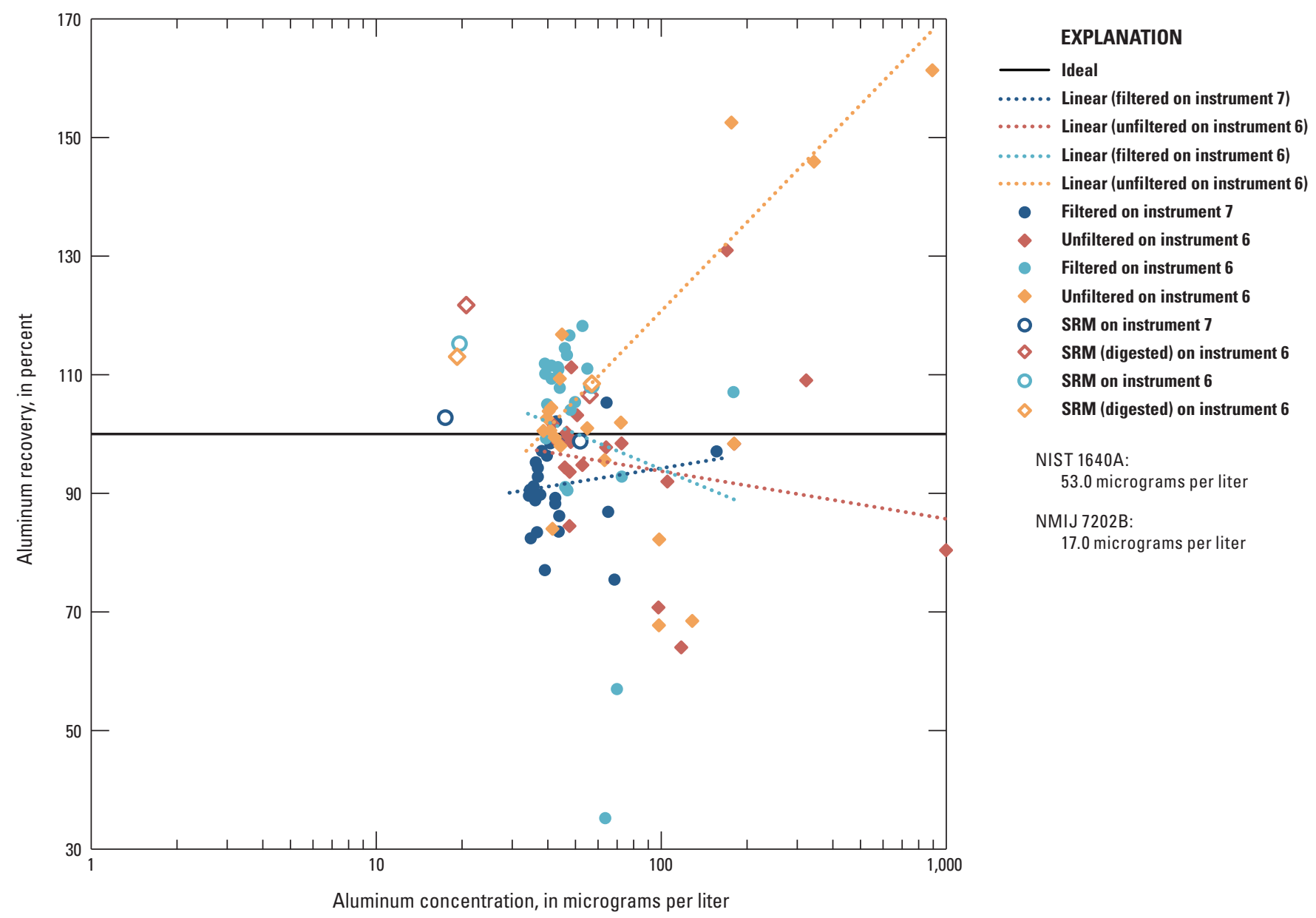

Figure E1. Spike recoveries of aluminum in filtered and unfiltered samples analyzed on instruments 6 and 7. 


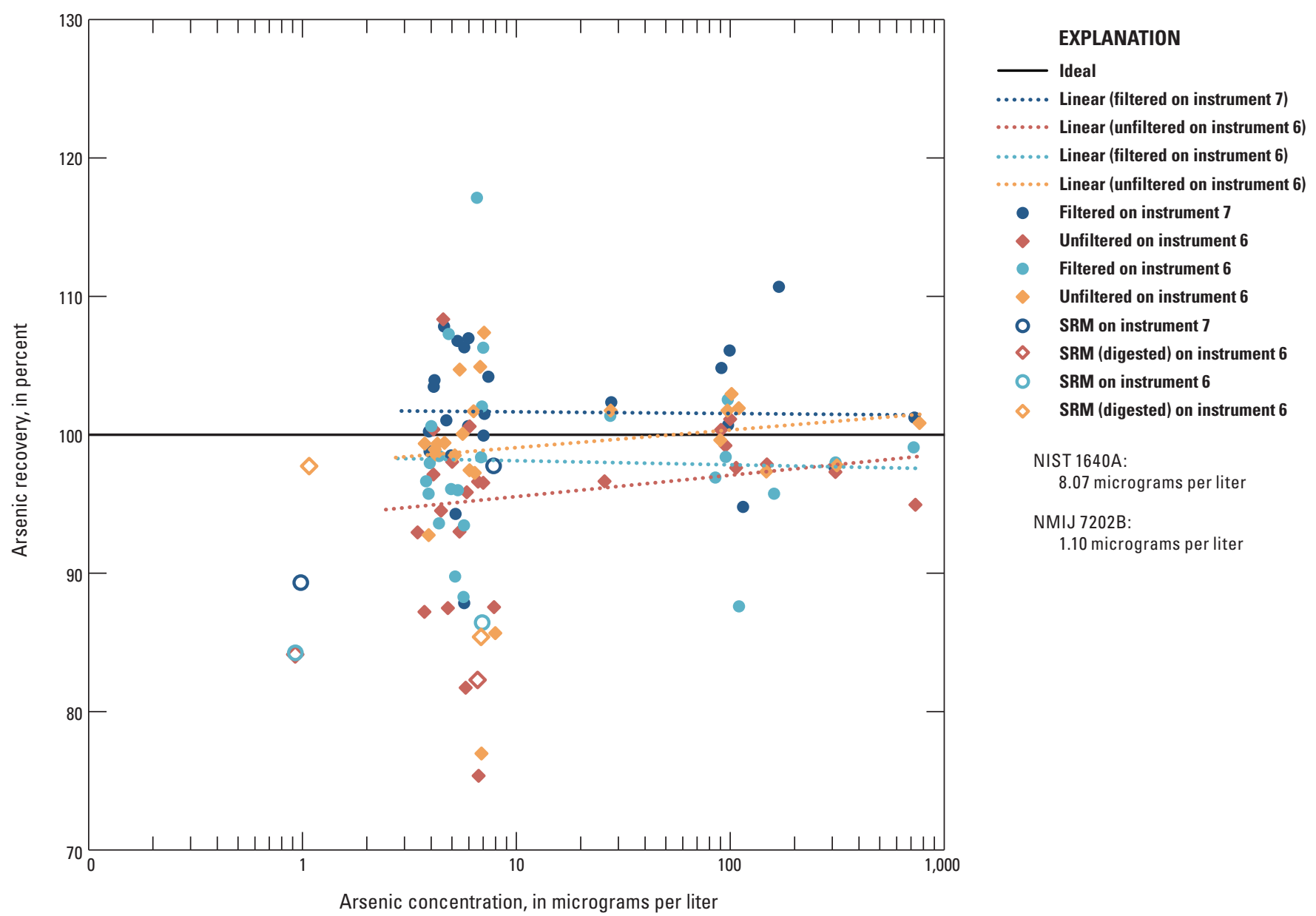

Figure E2. Spike recoveries of arsenic in filtered and unfiltered samples analyzed on instruments 6 and 7 . 


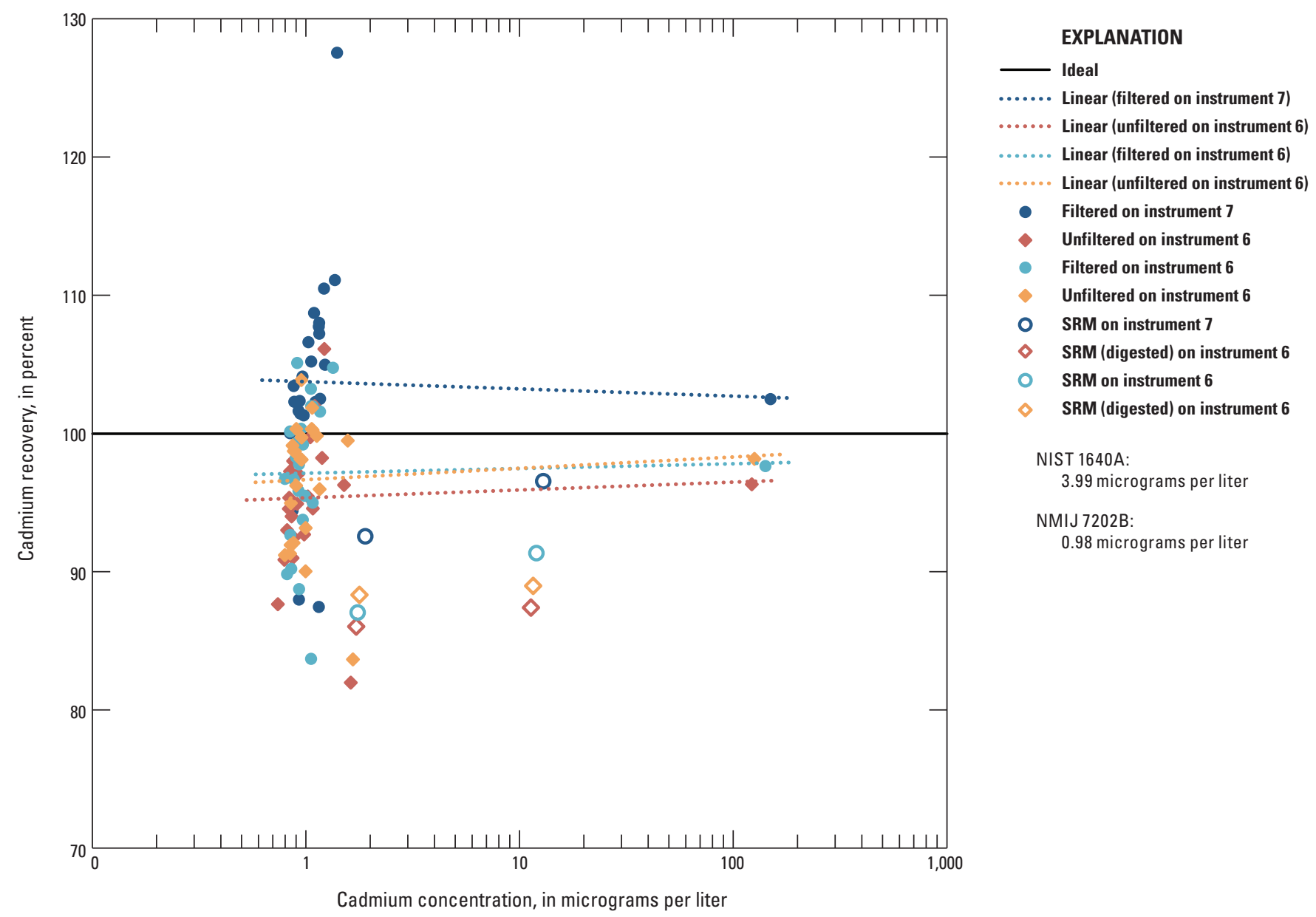

Figure E3. Spike recoveries of cadmium in filtered and unfiltered samples analyzed on instruments 6 and 7. 


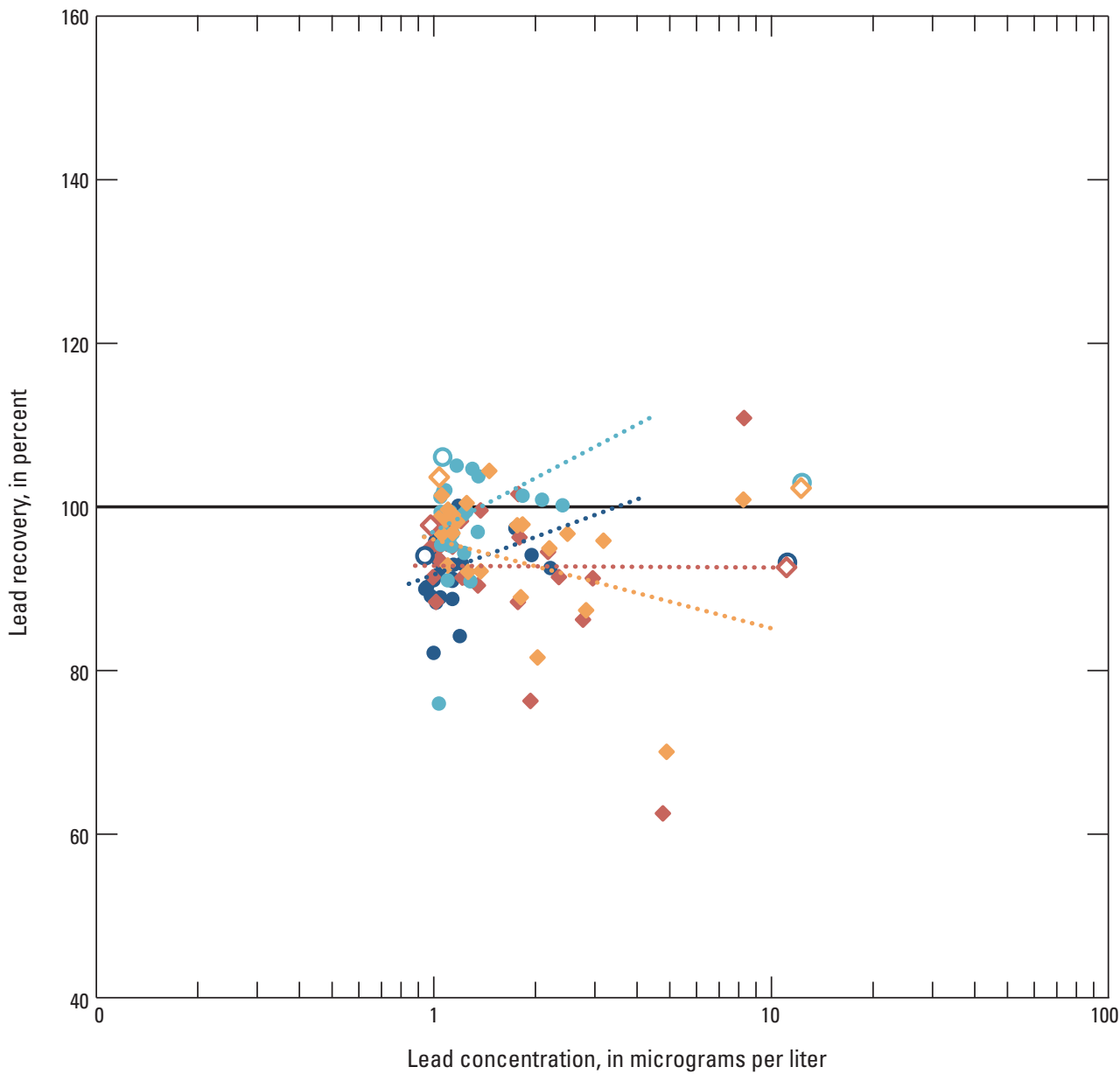

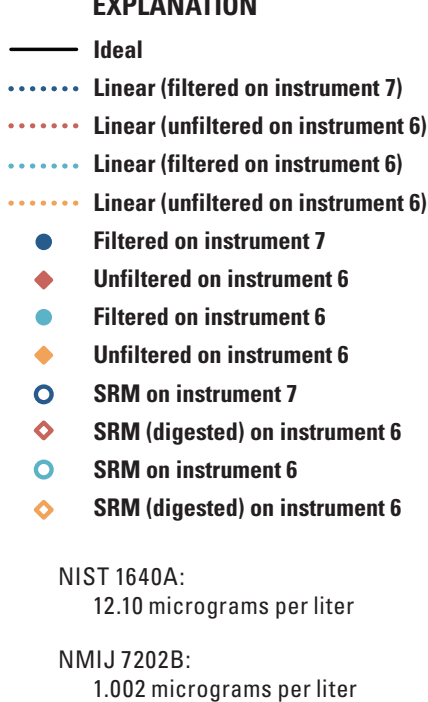

Figure E4. Spike recoveries of lead in filtered and unfiltered samples analyzed on instruments 6 and 7. 


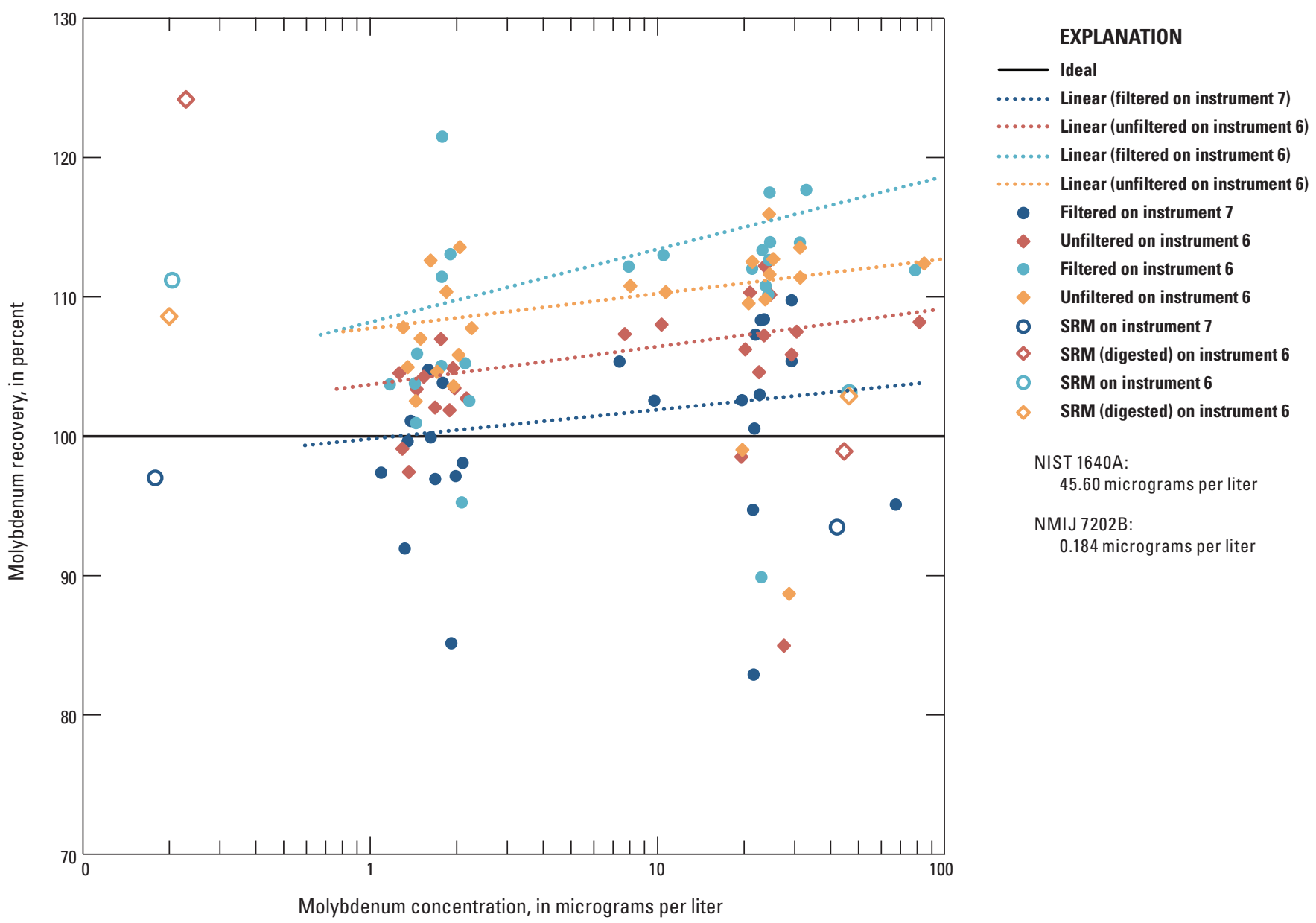

Figure E5. Spike recoveries of molybdenum in filtered and unfiltered samples analyzed on instruments 6 and 7. 


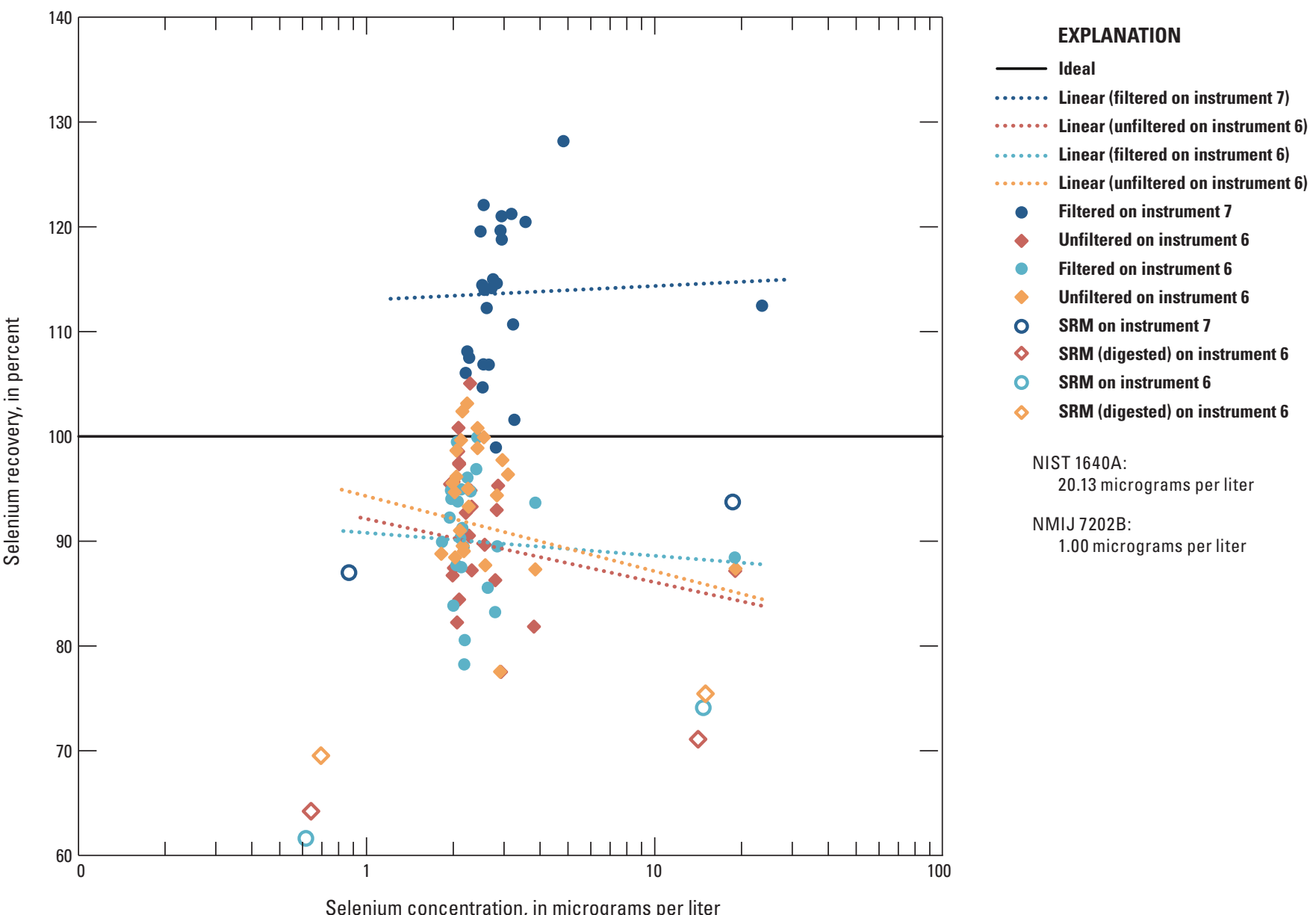

Figure E6. Spike recoveries of selenium in filtered and unfiltered samples analyzed on instruments 6 and 7 . 


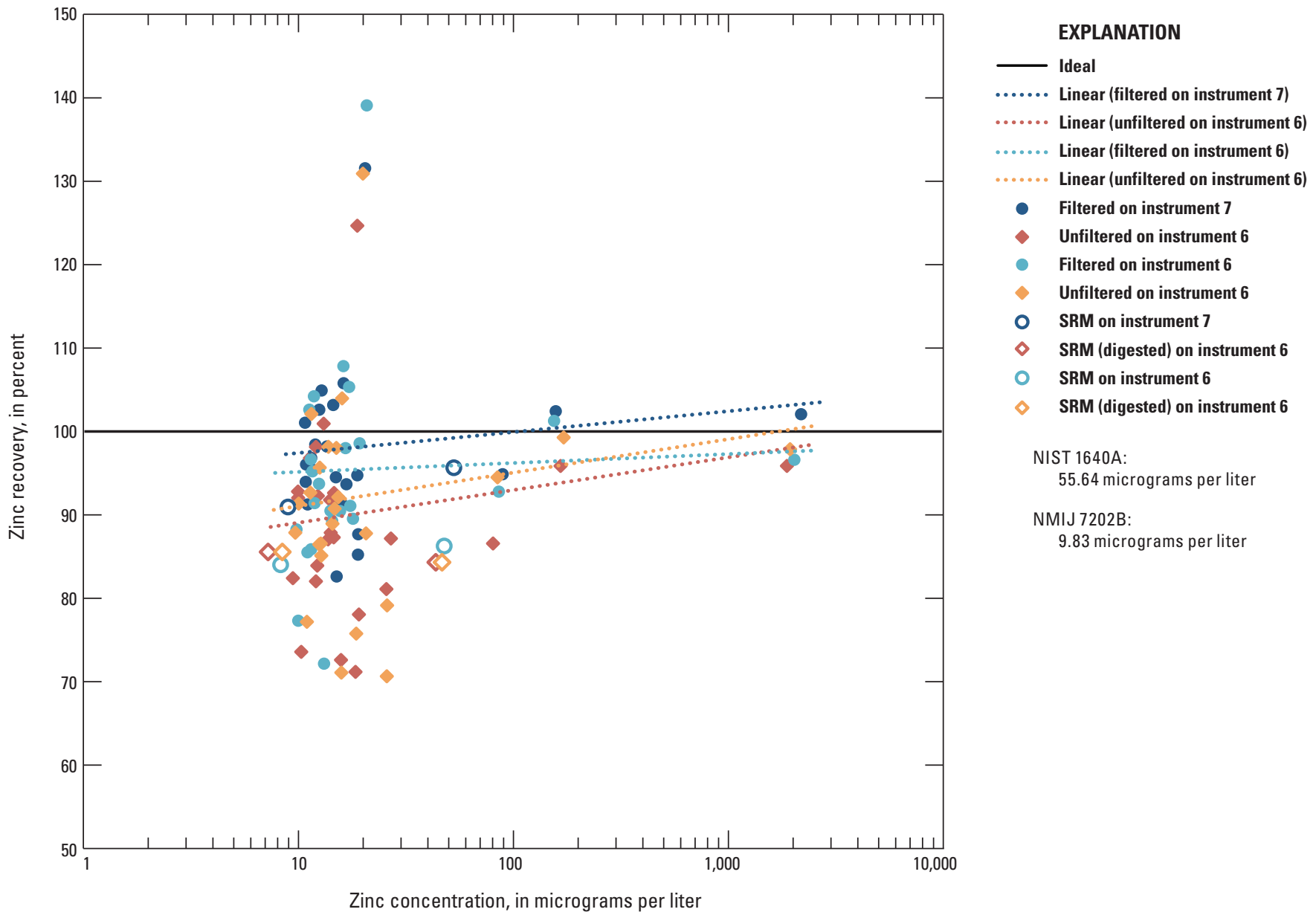

Figure E7. Spike recoveries of zinc in filtered and unfiltered samples analyzed on instruments 6 and 7 . 
Publishing support provided by the U.S. Geological Survey

Science Publishing Network, Tacoma Publishing Service Center

For more information concerning the research in this report, contact the Chief, Water Science Field Team

U.S. Geological Survey

520 North Park Avenue

Tucson, Arizona 85721

http://az.water.usgs.gov/ 
